INSTITUTO DE PESQUISAS ENERGÉTICAS E NUCLEARES

Autarquia associada à Universidade de São Paulo

ESTUDO E LEVANTAMENTOS DE PARÂMETROS PARA DOSIMETRIA DE FONTES DE IODO-125 APLICADAS EM BRAQUITERAPIA

EDUARDO SANTANA DE MOURA

Dissertação apresentada como parte dos requisitos para obtenção do Grau de Mestre em Ciências na Área de Tecnologia Nuclear Aplicações

Orientador:

Dr. Carlos Alberto Zeituni

SÃO PAULO 
INSTITUTO DE PESQUISAS ENERGÉTICAS E NUCLEARES

Autarquia associada à Universidade de São Paulo

ESTUDO E LEVANTAMENTOS DE PARÂMETROS PARA DOSIMETRIA DE FONTES DE IODO-125 APLICADAS EM BRAQUITERAPIA

EDUARDO SANTANA DE MOURA

Dissertação apresentada como parte dos requisitos para obtenção do Grau de Mestre em Ciências na Área de Tecnologia Nuclear Aplicações

Orientador:

Dr. Carlos Alberto Zeituni

SÃO PAULO 


\section{AGRADECIMENTOS}

Ao meu orientador, Dr. Carlos Alberto Zeituni, pela orientação, amizade, apoio e confiança que me acompanham desde a iniciação científica.

À Dra. Maria Elisa Chuery Martins Rostelato e coordenadora do laboratório de produção de fontes radioativas (LPFR), pela orientação inicial deste trabalho, simpatia, amizade, valiosos conselhos, tranquilidade e respeito prestados a mim.

Ao Dr. José Eduardo Manzoli pelo auxilio e acompanhamento durante todo o trabalho, amizade e por alertar-me sobre os males da "ciência contemplativa".

Ao amigo e físico Roberto Kenji Sakuraba pelo acesso aos aceleradores lineares, disponibilidade, apoio e por todas as lições sobre física médica prestadas.

Ao Dr. José Carlos Cruz por disponibilizar os excelentes recursos do setor de radioterapia do Hospital Israelita Albert Einstein.

Ao amigo João Trencher pela sua criatividade ímpar e prestatividade que auxiliou diversas etapas deste trabalho.

Ao físico médico Vinicius Demanboro Gonçalves por todas discussões proveitosas durante as etapas estafantes dos dosímetros TL.

Ao M. Sc. Márcio Müller pelo incentivo a área científica e pelo apoio e confiança no âmbito docente.

Ao Dr. Nelson Omi pelas sugestões e ensinamentos associados à tecnologia.

Aos amigos Diego Vergaças e Beatriz Nogueira pela eficiência, praticidade e por comentários brilhantes na parte operacional do laboratório.

Às biomédicas Adriana e Lidiane por toda a disponibilidade com os sistemas de planejamento, carisma e demais auxilios.

Aos Engenheiros Carlos Gaia, Samir Somessari e Elisabeth Somessari pelas irradiações com Cobalto-60.

Aos estimados companheiros do LPFR Osvaldo Costa, Anselmo Feher, Carla Daruich e João Moura.

À M. Sc. Maíra Gomes por todas as discussões versando o tratamento térmico dos dosímetros TL.

Ao grupo da oficina mecânica pela usinagem de objetos importantes para a dosimetria TL.

Ao Marcos Cardoso, Edmilson Amorim, Cláudia Nolla, Jorge Ambiel e Valdir Cosmos por todos os auxilios gentilmente prestados. 
Aos demais gerentes CTR, Dr. Wilson Aparecido Parejo Calvo, Dra. Margarida Mizue Hamada e Dr. Leonardo Gondim de Andrade e Silva pelo apoio, infraestrutura, amizade e reconhecimento acadêmico.

À Comissão Nacional de Energia Nuclear (CNEN) pela bolsa de estudos que foi fundamental para a plena realização deste trabalho.

Ao IPEN-CNEN/SP que além de um instituto pesquisa tornou-se um "lar" em muitos momentos.

A toda comissão de pós-graduação do IPEN (CPG-IPEN) pela fluidez dos trâmites burocráticos.

Ao pessoal da biblioteca Terezine Arantes Ferraz por perdoar todos os atrasos de exemplares consultados neste trabalho.

A todos aqueles que me auxiliaram de forma direta ou indireta no decorrer deste trabalho. 


\title{
ESTUDO E LEVANTAMENTOS DE PARÂMETROS PARA DOSIMETRIA DE FONTES DE IODO-125 APLICADAS EM BRAQUITERAPIA
}

\author{
EDUARDO SANTANA DE MOURA
}

\begin{abstract}
RESUMO
A utilização da técnica braquiterapia com sementes de iodo-125 para o tratamento do câncer de próstata têm sido utilizada por décadas com bons resultados clínicos. Para atender as necessidades da população brasileira, o IPEN-CNEN/SP desenvolveu o protótipo para as sementes de iodo-125 com tecnologia nacional. Os objetivos deste trabalho são o desenvolvimento e estudo dos processos dosimétricos associados à obtenção experimental dos parâmetros úteis à caracterização das sementes de iodo-125 e avaliar se os procedimentos desenvolvidos, por este trabalho, possuem as condições necessárias para a determinação das análises dosimétricas, fundamentais para o sucesso dos procedimentos clínicos. Os dosímetros escolhidos para as análises são os TLD-100 (LiF:Mg,Ti), inicialmente estes dosímetros foram submetidos por duas etapas de seleção, com o objetivo de escolher os dosímetros mais reprodutíveis para as análises dosimétricas. As duas etapas foram à seleção por medidas de massa e a reprodutibilidade após quatro séries de irradiações por um irradiador de Cobalto-60 (CTR-IPEN). Após estas etapas, os dosímetros foram irradiados em um acelerador linear com energia de $6 \mathrm{MV}$ (Serviço de Radioterapia - Hospital Israelita Albert Einstein) para gerar os fatores de calibração individuais para cada dosímetro. Posteriormente, os dosímetros foram utilizados para as irradiações com a semente de iodo-125, modelo 6711 (GE-Healthcare). As irradiações com a semente de iodo-125 e demais análises renderam os valores necessários para a determinação dos parâmetros sugeridos pela AAPM (American Association of Physicists in Medicine): constante de taxa de dose, função de geometria, função de dose radial e função de anisotropia. Os resultados obtidos mostram boa concordância com os valores publicados pela literatura, para o mesmo modelo de semente de iodo-125, ratificando que os parâmetros realizados poderão ser utilizados para a dosimetria e controle de qualidade das sementes de iodo125 que irão ser produzidas pelo IPEN-CNEN/SP.
\end{abstract}




\title{
STUDY AND PARAMETERS SURVEY FOR IODINE-125 SOURCE DOSIMETRY TO BE APPLIED IN BRACHYTHERAPY
}

\author{
EDUARDO SANTANA DE MOURA
}

\begin{abstract}
The use of brachytherapy technique with iodine-125 seeds to prostate cancer treatment has been used for decades with good clinical outcomes. To aim the Brazilian population necessities, IPEN-CNEN/SP developed the iodine-125 seed prototype with national technology. The objectives of this work are the development and the study of dosimetric procedures associates with the experimental acquisition of the useful parameters for the iodine-125 dosimetric characterization and to evaluate if the developed procedures, in this work, have the basic conditions to determinate the dosimetric analysis, that are fundamental for clinical procedures. The dosimeters selected for the analysis are the TLD-100 (LiF:Mg,Ti), initially these dosimeters were submitted for two selection steps to choose the dosimeters more reproducible for the dosimetric analysis. The two steps were the selection by the mass of the dosimeters and the reproducibility after four irradiation series in a Cobalt-60 irradiator (CTR-IPEN). Afterwards these steps, the dosimeters were irradiated in linear accelerator with $6 \mathrm{MV}$ energy (Service of Radiotherapy - Hospital Israelita Albert Einstein) to yield the individual calibration factors to each dosimeter. After, the dosimeters were used to the irradiations with iodine-125 seed, 6711 model, (GE-Healthcare). The irradiations and others analysis with iodine-125 seeds yield the useful values for the determination of the parameters suggested by the AAPM (American Association of Physicists in Medicine): constant of dose rate, geometry function, dose radial function and anisotropy function. The results showed good agreement with the values published by the literature, for the same iodine125 model, this fact confirms that the realized parameters will be able to be used for the IPEN-CNEN iodine-125 seeds dosimetry and quality control.
\end{abstract}




\section{SUMÁRIO}

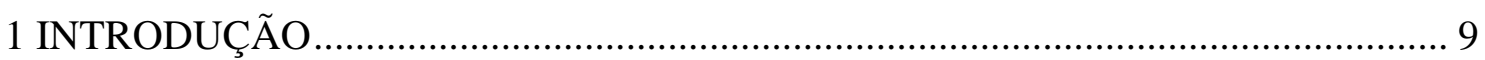

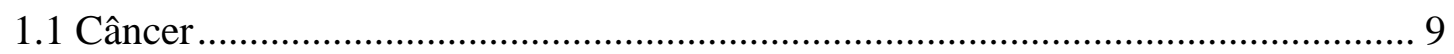

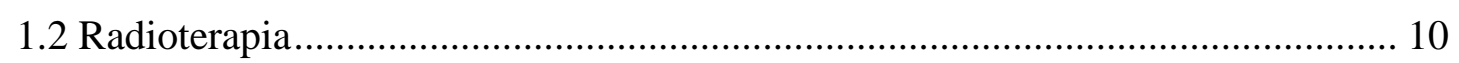

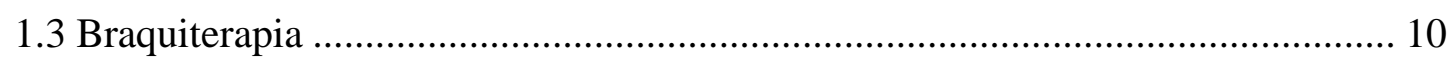

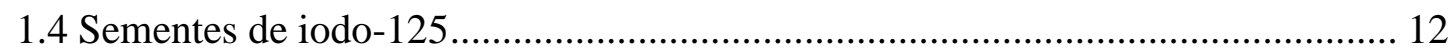

1.5 Sementes de iodo-125 - Protótipo Nacional ......................................................... 15

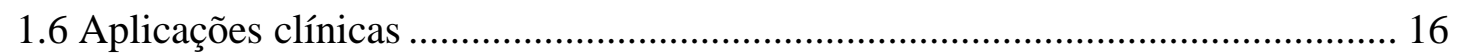

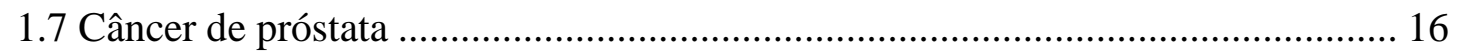

1.8 Sementes de iodo-125 para o tratamento do câncer de próstata........................... 21

1.9 Dosimetria de fontes intersticiais aplicadas em braquiterapia - Task Group N. 43

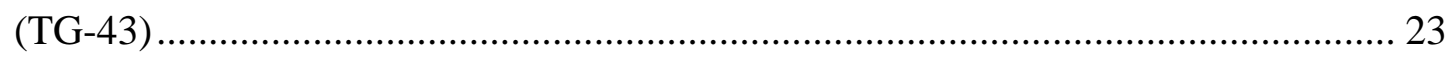

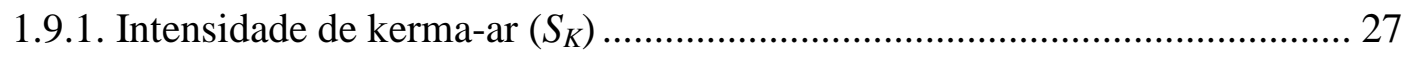

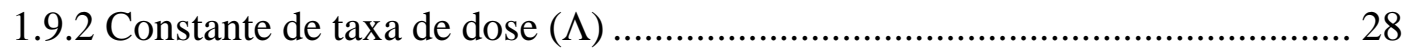

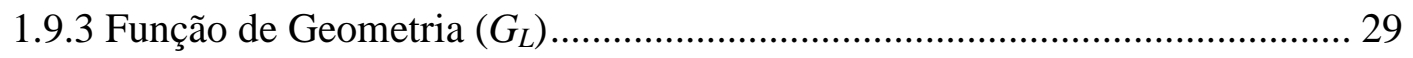

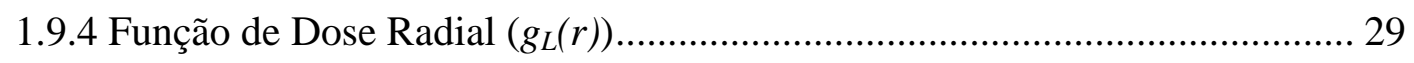

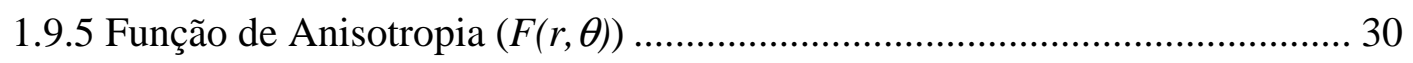

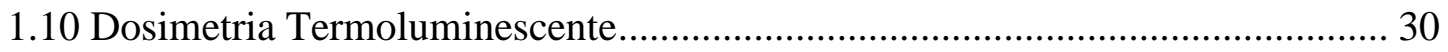

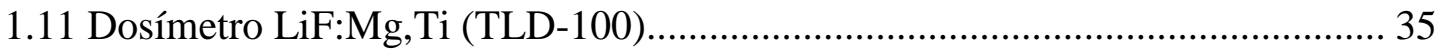

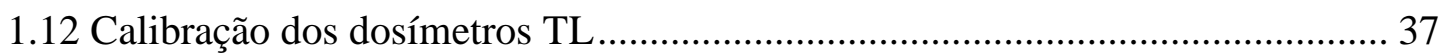

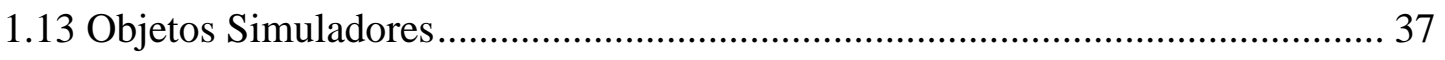

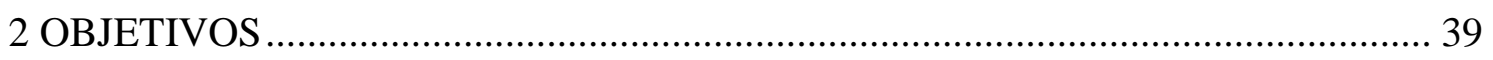

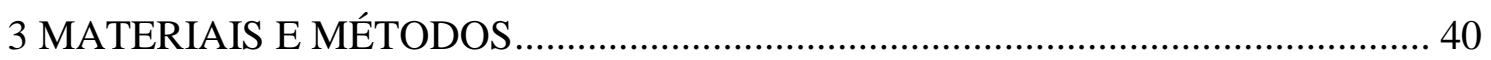

3.1 Infraestrutura - Dosimetria TL ........................................................................... 40

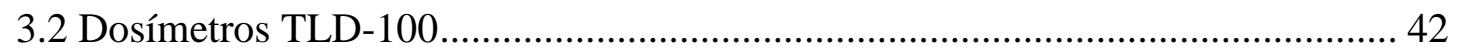

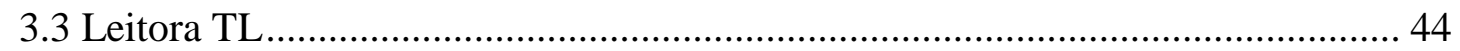

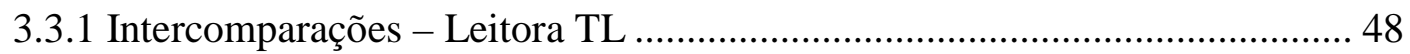

3.4 Tratamento Térmico dos Dosímetros ................................................................. 48

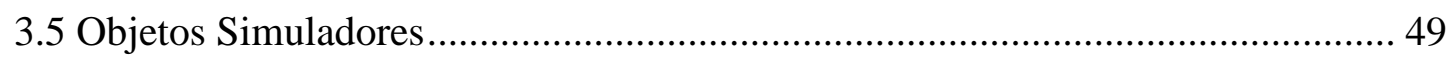

3.6 Seleção dos Dosímetros - Irradiador de Cobalto-60 …........................................ 50

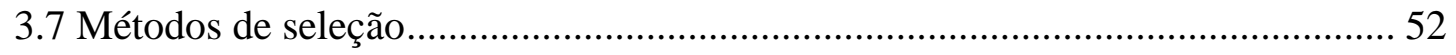

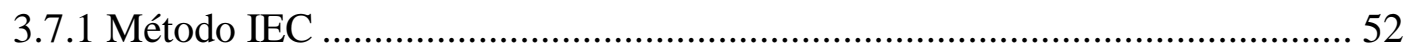

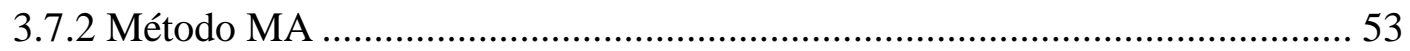




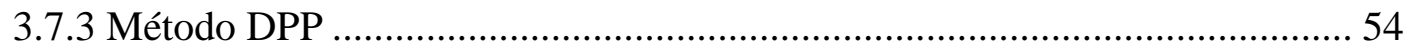

3.8 Fatores de Calibração dos Dosímetros TLD-100 ………………………………. 55

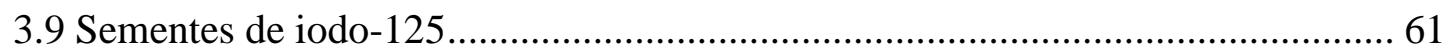

3.10 Determinação Experimental do Formalismo TG-43 ........................................... 62

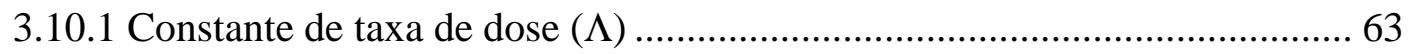

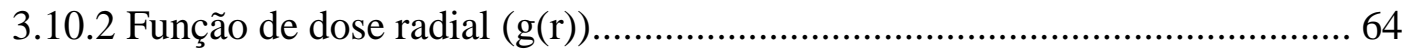

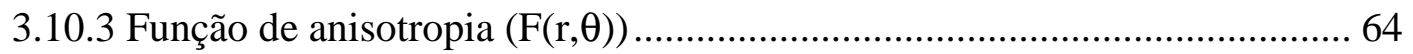

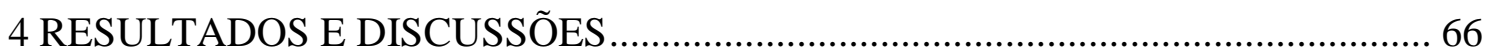

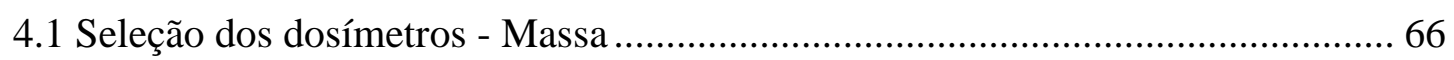

4.2 Seleção dos dosímetros - Irradiador de Cobalto 60 …………………………….... 67

4.2.1 Método IEC ……………………………………………………………. 67

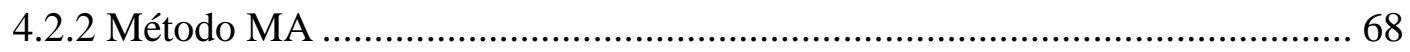

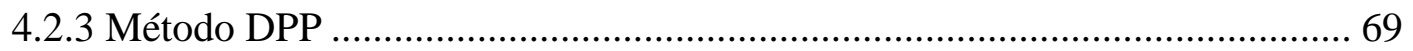

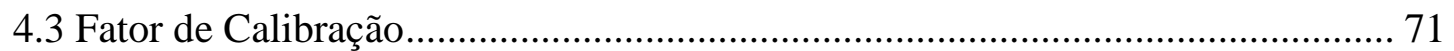

4.4 Medições das sementes de iodo-125 ……………………................................. 73

4.5 Constante de taxa de dose $(\Lambda)$......................................................................... 75

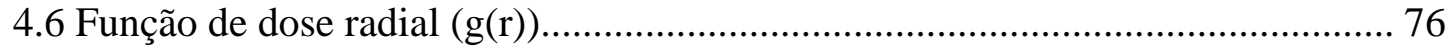

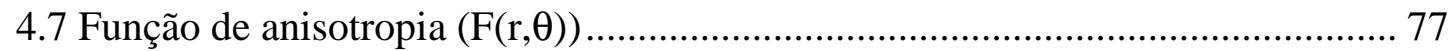

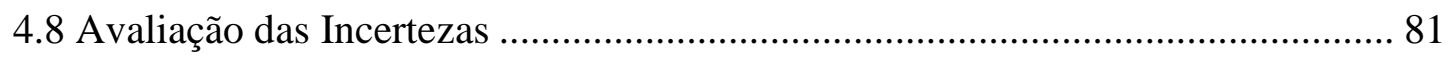

4.8.1 Incerteza na determinação da constante de taxa de dose................................ 82

4.8.2 Incerteza na determinação da função de dose radial ...................................... 82

4.8.3 Incerteza na determinação da função de anisotropia ....................................... 83

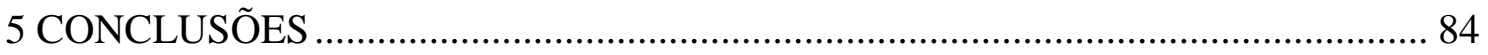

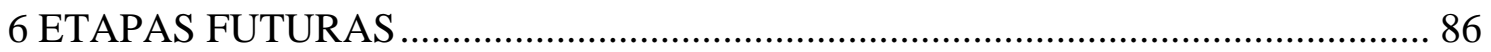

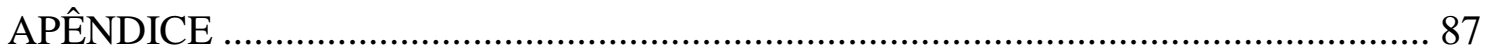

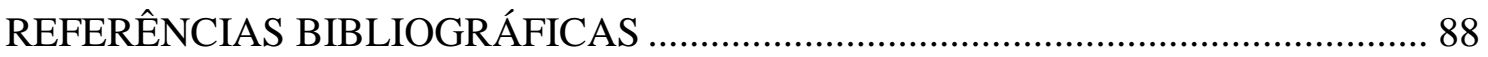




\section{INTRODUÇÃO}

\subsection{Câncer}

O câncer é um termo genérico associado a um grupo com mais de 100 doenças que se caracterizam pelo crescimento desordenado do número de células, que dependendo da severidade, podem formar tumores malignos e espalhar-se para outros sítios do corpo ${ }^{1}$. Segundo dados do World Health Organization (WHO), em 2007, o câncer levou a óbito 7,9 milhões de pessoas e para 2030 estima-se que 12 milhões de óbitos poderão ocorrer por causa do câncer, no mundo inteiro ${ }^{2}$.

Dados do Instituto Nacional do Câncer (INCA) informam que as estimativas de novos casos de câncer no Brasil, para o ano de 2010, correspondem a aproximadamente 489.270 mil casos de câncer, sendo 236.240 e 253.030 para as populações do sexo masculino e sexo feminino, respectivamente ${ }^{3}$. A TAB.1 mostra as quantidades estimadas para os casos de câncer no Brasil, estimados para o ano de 2010, divididos pelas regiões e neoplasias conforme a sua localização primária.

TABELAS 1 - Estimativas para o ano 2010 de número de casos novos por câncer, em homens e mulheres, segundo localização primária ${ }^{3}$

\begin{tabular}{|l|r|r|r|}
\hline \multirow{2}{*}{$\begin{array}{l}\text { Localização Primária } \\
\text { Neoplasia Maligna }\end{array}$} & \multicolumn{3}{|c|}{ Estimativa de Casos Novos } \\
\hline Próstata & \multicolumn{1}{|c|}{ Masculino } & \multicolumn{1}{|c|}{ Feminino } & \multicolumn{1}{c|}{ Total } \\
\hline Mama Feminina & 52.350 & - & 52.350 \\
\hline Traqueia, Brônquio e Pulmão & 17.800 & 49.240 & 49.240 \\
\hline Cólon e Reto & 13.310 & 14.830 & 27.630 \\
\hline Estômago & 13.820 & 7.680 & 28.110 \\
\hline Colo do Útero & - & 18.430 & 21.500 \\
\hline Cavidade Oral & 10.330 & 3.790 & 18.430 \\
\hline Esôfago & 7.890 & 2.740 & 14.120 \\
\hline Leucemias & 5.240 & 4.340 & 10.630 \\
\hline Pele Melanoma & 2.960 & 2.970 & 5.580 \\
\hline Outras Localizaçôes & 59.130 & 78.770 & 137.900 \\
\hline Subtotal & 182.830 & 192.590 & 375.420 \\
\hline Pele não Melanoma & 53.410 & 60.440 & 113.850 \\
\hline Todas as Neoplasias & 236.240 & 253.030 & 489.270 \\
\hline
\end{tabular}

Das diversas formas de tratamento do câncer, destacam-se algumas modalidades, tais como: cirurgia, quimioterapia e radioterapia. Conforme o caso clínico, pode-se utilizar para o tratamento do câncer uma única modalidade ou a combinação delas ${ }^{1}$. 


\subsection{Radioterapia}

Radioterapia é uma forma de tratamento que utiliza radiações ionizantes para o tratamento de diversas doenças focando uma dose precisa e acurada no volume alvo a ser tratado e minimizando os níveis de dose nos tecidos sadios ${ }^{4}$. A radioterapia é majoritariamente utilizada para o tratamento de câncer. Dentre os objetivos principais cabe destacar: o controle tumoral local, a melhoria de sintomas específicos decorrentes do tumor, a melhora da qualidade de vida dos pacientes e o aumento da probabilidade de cura da doença ${ }^{5}$.

A radioterapia pode ser subdividida em duas técnicas, que se distinguem pela aproximação da fonte radioativa ou pelo dispositivo eletrônico que emana radiação ionizante, ambos em relação ao volume alvo. Se a fonte radioativa fica próxima ou dentro do volume alvo, esta técnica é denominada braquiterapia. Para fontes (ou aparelhos) que emanam radiação ionizante, situadas a que distam de alguns centímetros ou até alguns metros do volume alvo, a técnica é denominada teleterapia ${ }^{6,7}$.

\subsection{Braquiterapia}

Com o descobrimento dos raios X por Roentgen, em 1895, e a descoberta da radioatividade natural por Becquerel, 1896, além do isolamento do elemento rádio por Marie e Pierre Curie em 1898, aventou-se a possibilidade de que estas descobertas poderiam ser utilizadas para diversos fins, dentre eles, o tratamento de doenças cancerígenas. As primeiras fontes radioativas utilizadas em braquiterapia, por volta de 1903, eram constituídas por agulhas de platina, contendo sulfato de rádio com cerca de $1 \mathrm{mg}$ do isótopo rádio- $226^{8,9}$.

Atualmente, há muitas fontes radioativas para aplicação em braquiterapia que utilizam variados isótopos, dos quais podem se destacar: isótopos emissores de raios $\mathrm{X}$ ou raios $\gamma$ (iodo-125, irídio-192, paládio-196, césio-131, césio-137 e cobalto-60), partículas $\beta$ (estrôncio/ítrio-90, fósforo-32, xenônio-133, tungstênio/rênio-188 e rutênio/ródio-106) e nêutrons (Cf-252) ${ }^{10,11}$. As fontes de braquiterapia podem ser eletrônicas, e não somente constituídas por elementos radioativos. Recentemente pequenos tubos de raios $-\mathrm{X}$ (com comprimento inferior a $15 \mathrm{~mm}$ e diâmetro próximo a $5,3 \mathrm{~mm}$ ) estão sendo aplicados. Estas fontes podem funcionar sob diferentes faixas de voltagens, proporcionando uma variedade de taxas de dose e diferentes penetrações no volume alvo ${ }^{12,13,14}$. 
Os procedimentos em braquiterapia são classificados por meio de diversas características de tratamento e também das fontes radioativas aplicadas, dentre as classificações destacam-se ${ }^{6}$ :

a) Tipos de Implantes: intersticiais, intracavitários, intraoperatórias e aplicações com placas;

b) Duração do tratamento: temporários e permanentes;

c) Carregamento (loading) da fonte radioativa: pré-carregamento (preloading) e Pós-carregamento (afterloading);

d) Taxa de dose: baixa, média e alta taxa de dose.

Nos implantes intersticiais são inseridas fontes radioativas dentro do volume alvo, através de aplicadores específicos ou com aplicação direta das fontes radioativas no volume alvo. Implantes intracavitários caracterizam-se por aplicações de fontes radioativas em cavidades do corpo, utilizada principalmente em tumores ginecológicos. Quando a fonte é aplicada cirurgicamente dentro ou próximo ao tumor, para procedimentos temporários, denomina-se implante intraoperatório. Nas aplicações de fontes radioativas em forma de placas, estas são alocadas diretamente no tecido ou na superfície a serem tratados. Tais placas têm a vantagem de moldarem-se ao órgão onde se encontra a lesão, podendo ficar em contato direto com o órgão ou volume alvo.

Com relação ao tempo em que a fonte radioativa fica em contato com o volume a ser tratado, pode-se classificar a braquiterapia em duas categorias: Os implantes braquiterápicos podem ser temporários, com a aplicação da fonte durante intervalos de minutos ou horas, retirando a fonte radioativa após a aplicação. Ou implantes permanentes são realizados posicionando fontes radioativas dentro do volume alvo e mesmo após um decaimento considerado da fonte radioativa, elas não são retiradas do paciente.

Para o pré-carregamento (preloading), as fontes radioativas estão localizadas nos próprios aplicadores durante o implante. No pós-carregamento (afterloading) são posicionados os aplicadores (manualmente ou por meio de aparelhos) e após esta aplicação, as fontes são postas em contato com o volume alvo (carregadas).

As fontes radioativas são classificadas quanto à faixa de dose em baixa, média e alta taxa de dose para intervalos de: 0,4 a $2 \mathrm{~Gy} / \mathrm{h} ; 2$ a $12 \mathrm{~Gy} / \mathrm{h}$ e > $12 \mathrm{~Gy} / \mathrm{h}$, respectivamente ${ }^{6}$. 
A braquiterapia possibilita uma dose localizada no volume alvo, apresentando assim uma excelente adequação em relação à teleterapia. $\mathrm{O}$ rápido decréscimo da dose absorvida fora do volume alvo preserva os tecidos sadios, próximos a região de tratamento, evitando irradiações desnecessárias além do volume alvo.

\subsection{Sementes de iodo-125}

As primeiras fontes radioativas contendo o isótopo iodo-125 foram investigadas inicialmente na década de 60 por Lawrence et al. e estudadas clinicamente por Hillaris et. al. com implantes em vários sítios, inclusive em cânceres pulmonares, implantes de próstata e linfadenectomia pélvica ${ }^{15,16,17}$.

O isótopo iodo-125 é produzido em reator nuclear a partir do gás xenônio-124 $\left({ }^{124} \mathrm{Xe}\right)$ que constitui apenas $0,1 \%$ do xenônio natural. A reação nuclear ocorre por meio de captura radiativa ${ }^{124} \mathrm{Xe}(\mathrm{n}, \gamma)^{125(\mathrm{~m}+\mathrm{g})} \mathrm{Xe}$, cuja seção de choque para nêutrons térmicos $(0,0253 \mathrm{eV})$ perfaz $\sigma=(165 \pm 20)$ barns $^{18}$. O núcleo-produto Xenônio-125m decai através de transição isomérica (100\%) com meia-vida de 57 segundos para Xe-125 o qual, por sua vez, decai por captura eletrônica $(99,3 \%)$ e emissão de pósitron $(0,7 \%)$, com meia-vida de 16,9 horas, gerando o iodo- $125^{19}$. O iodo-125 decai por captura eletrônica (100\%) para o Telúrio-125 ${ }^{19}$, conforme ilustrado na FIG. $1^{20}$.

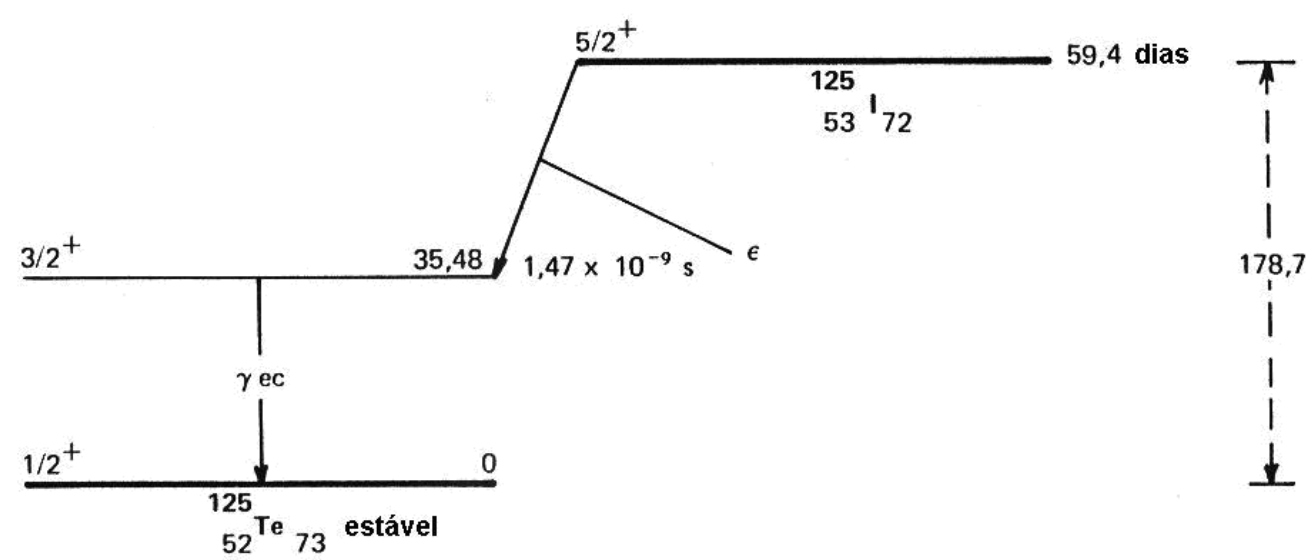

Figura 1 - Diagrama esquemático do decaimento do isótopo iodo-125 ${ }^{21}$

A TAB.2 mostra o espectro de emissão radioativa típica do isótopo iodo-125, nas sementes de iodo-125, os elétrons decorrentes da captura eletrônica ficam dentro do invólucro de titânio, responsável pelo encapsulamento da semente de iodo- $125^{22}$. 
TABELA 2 - Elétrons e fótons emitidos durante o decaimento do isótopo iodo-125. Os símbolos $\varepsilon$, x e $\gamma$ denotam elétrons, raios $-\mathrm{X}$ e raios gama, respectivamente ${ }^{22}$

\begin{tabular}{ccc}
\hline Energia $(\mathrm{keV})$ & Tipo & Intensidade $(\%)$ \\
\hline 3,19 & $\varepsilon$ & 158,4 \\
3,68 & $\varepsilon$ & 80,2 \\
22,70 & $\varepsilon$ & 20,0 \\
30,55 & $\varepsilon$ & 10,7 \\
34,49 & $\varepsilon$ & 2,15 \\
3,77 & $\mathrm{x}$ & 14,9 \\
27,20 & $\mathrm{x}$ & 40,1 \\
27,47 & $\mathrm{x}$ & 74,0 \\
30,94 & $\mathrm{x}$ & 6,83 \\
30,99 & $\mathrm{x}$ & 13,2 \\
31,70 & $\mathrm{x}$ & 3,8 \\
35,49 & $\gamma$ & 6,7 \\
\hline
\end{tabular}

A constituição interna da semente de iodo-125 é fundamental para os planejamentos dosimétricos. Pois as emissões energéticas podem sofrer alterações, conforme o material (matriz) interno da semente é alterado. Por exemplo, para sementes de iodo-125 que possuem o elemento prata no interior do seu invólucro, há geralmente três fótons adicionais devido à interação de das radiações ionizantes emitidas pelo iodo125 com a prata, de energias $22,1 \mathrm{keV} ; 24,9 \mathrm{keV}$ e $25,2 \mathrm{keV}{ }^{23,24}$. Estes fótons adicionais devem ser levados em conta nos sistemas de planejamento e simulações computacionais.

Além do isótopo iodo-125, dentro do invólucro de qualquer semente de iodo-125 (bem como de outros isótopos utilizados) há algum material com alto número atômico, este material tem a função de aumentar o grau de visualização em imagens de raios $-\mathrm{X}$, pois o invólucro de titânio possui espessuras micrométricas (aproximadamente $5 \mu \mathrm{m}$ ). Estes materiais são denominados marcadores e o tipo de material a ser utilizado depende de cada semente de iodo-125. A FIG. 2 ilustra alguns exemplos de sementes de iodo-125 com a representação interna do invólucro de titânio. Os modelos de sementes utilizados na FIG. 2 foram: 

a) OncoSeed ${ }^{125}$ I modelo $6711^{24}$;
b) ThinSeed ${ }^{125}$ I modelo $9011^{25}$;
c) IsoSeed ${ }^{125}$ I modelo I25.S06 ${ }^{26}$;
d) International Brachytherapy Intersource - $125^{27}$;
e) ${ }^{125}$ I Model I125-SL ${ }^{28}$;
f) NASI model MED3631-A/M.

a)

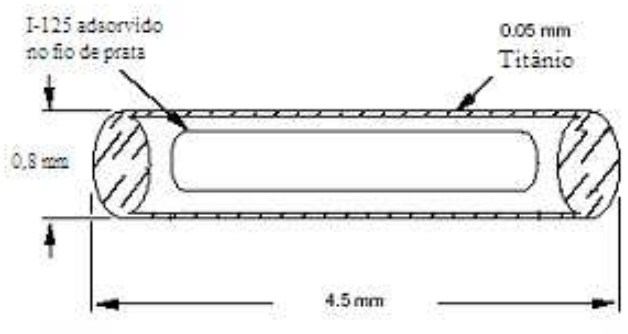

b)

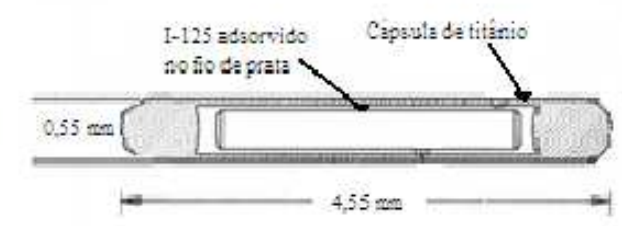

c)

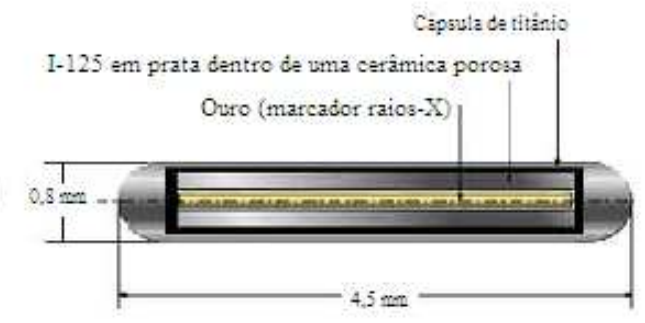

d)

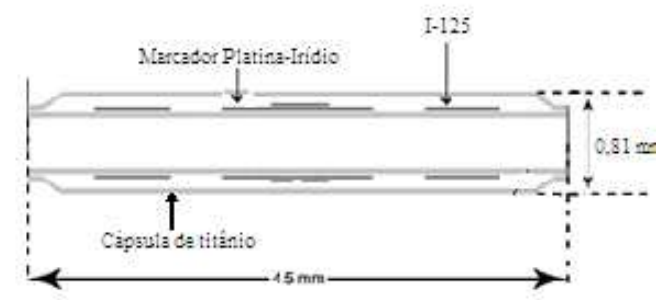

e)

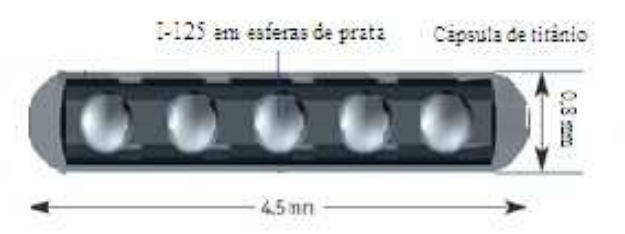

f)

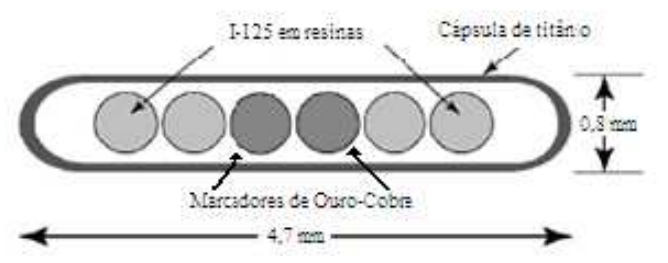

Figura 2 - Ilustração adaptada de algumas sementes de iodo-125 mostrando a parte interna do invólucro de titânio. O modelo de cada semente é descrito no texto

Observando a FIG. 2, nota-se que algumas sementes de iodo-125 podem apresentar marcadores de elementos com prata, ouro, platina-irídio, cobre e entre outras. Os estudos dos parâmetros dosimétricos devem considerar as possíveis interações do isótopo iodo-125 com os marcadores, pois tais interações podem acarretar em diferenças na distribuição de dose ${ }^{29}$.

Dos modelos de sementes de iodo-125 descritos anteriormente, este trabalho utilizou o modelo 6711 (OncoSeed, Oncura GE HealthCare) para as análises dosimétricas. A escolha justifica-se, pois este modelo de semente de iodo-125 possui características similares ao modelo de semente de iodo-125, que será produzido pelo Instituto de Pesquisas Energéticas e Nucleares (IPEN/CNEN-SP). 


\subsection{Sementes de iodo-125 - Protótipo Nacional}

No Brasil, para os procedimentos de braquiterapia com sementes de iodo-125 faz-se necessário a importação destas fontes radioativas, isto acarreta em custos elevados para o implante privando uma boa parcela da população brasileira deste procedimento devido ao custo.

Observando este fato, a classe médica transmitiu ao IPEN-CNEN/SP a necessidade de uma produção de sementes de iodo-125 nacional. Esta semente de iodo125 terá custo menor que as demais e servirá como uma alternativa de tratamento, principalmente para a população de baixa renda. Para atender os objetivos de uma produção de sementes de iodo-125, com tecnologia nacional, o IPEN-CNEN/SP iniciou o projeto de desenvolvimento de uma semente de iodo-125. Após este desenvolvimento o laboratório de produção de fontes para radioterapia (LPFR) iniciou um projeto para a produção de sementes de iodo-125 em larga escala, atendendo as demandas nacionais ${ }^{30}$.

A FIG. 3 ilustra o protótipo da semente de iodo-125 desenvolvida pelo IPENCNEN/SP. A semente é constituída de uma cápsula de titânio de $0,8 \mathrm{~mm}$ de diâmetro externo, 0,05 $\mathrm{mm}$ de espessura e 4,5 $\mathrm{mm}$ de comprimento. A parte interna é composta por um fio de prata com $0,5 \mathrm{~mm}$ de diâmetro e $3 \mathrm{~mm}$ de comprimento, material no qual o iodo-125 está adsorvido ${ }^{20,30}$.

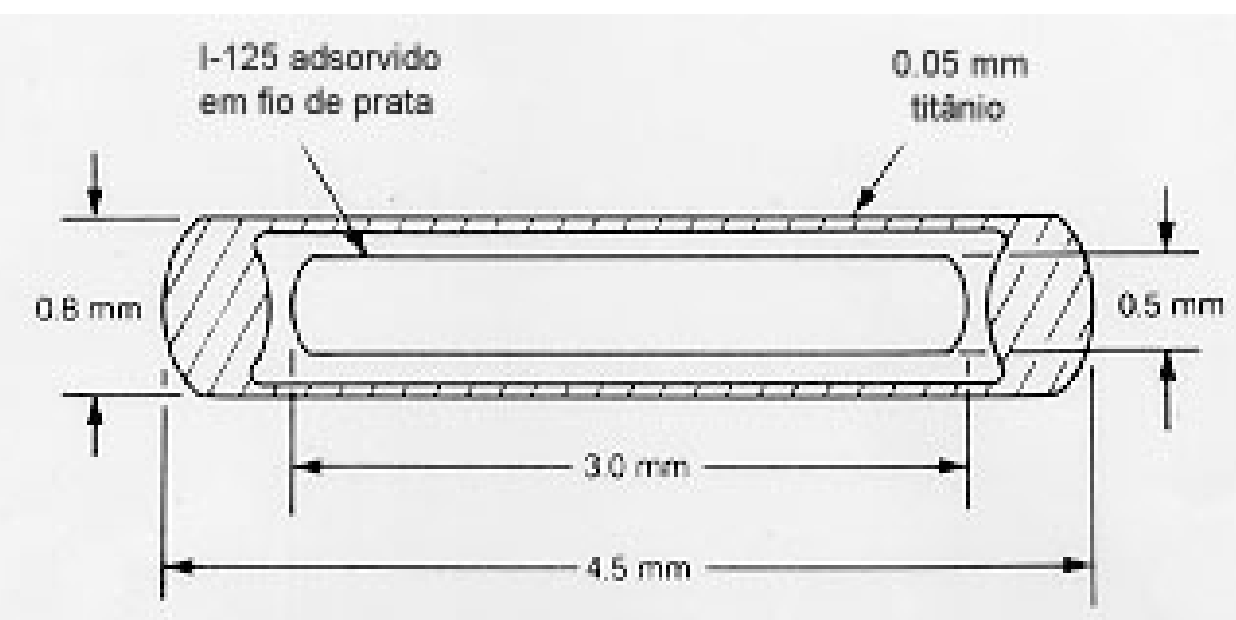

Figura 3 - Protótipo nacional da semente de iodo-125 produzido pelo IPEN-CNEN/SP

O invólucro de titânio é um material biocompatível, essencial para procedimentos intersticiais, além de ser leve e ter elevada resistência a corrosão. Nas extremidades da semente de iodo-125, o tubo de titânio é submetido ao processo de solda que tem a finalidade de garantir a estanquiedade do material radioativo ${ }^{31,32}$. As 
sementes de iodo-125 são classificadas como fontes radioativas seladas conforme a norma International Standard Organization. Radiation Protection - Sealed Radioactive Sources - General Requirements and Classification ISO-2919 ${ }^{33}$.

\subsection{Aplicações clínicas}

As sementes de iodo-125 podem ser utilizadas para implantes temporários ou permanentes com aplicações intersticiais ou por meio de aplicadores de superfícies. Pode ser utilizada como terapia primária, terapia adjunta e para tratamento de recidiva de tumores. Informações encontradas na literatura descrevem diversas aplicações das sementes de iodo-125 no tratamento de diversos tumores, tais como: tumores cerebrais ${ }^{34,35}$, câncer de fígado ${ }^{36}$, carcinomas pancreáticos ${ }^{37}$, neoplasias oculares ${ }^{38,39}$ e o mais utilizado, câncer de próstata ${ }^{40,41,42,43,44,45}$.

As sementes de iodo-125 a serem produzidas pelo IPEN-CNEN/SP terão como foco o tratamento do câncer de próstata, que após o câncer de pele não-melanoma, é o segundo câncer que mais atinge os homens no Brasil ${ }^{3}$. Estima-se que a demanda nacional, para o tratamento do câncer de próstata com sementes de iodo-125, chegue próximo a 8000 sementes/mês ${ }^{30,32}$.

\subsection{Câncer de próstata}

A próstata é uma glândula com comprimento próximo a 4,6 cm e espessura de 3 cm e é encontrada abaixo da bexiga, circundando uma porção do canal uretral. A próstata produz uma secreção que auxilia a mobilidade dos espermatozóides e com a sua alcalinidade facilita a passagem do esperma dentro do canal vaginal ${ }^{46}$.

Após os 40 anos de idade, cerca de $80 \%$ a $90 \%$ dos homens apresentam um crescimento benigno da glândula, este crescimento causa uma compressão no canal uretral criando graus variados de dificuldade para expelir a urina ${ }^{47}$.

O câncer da próstata atinge principalmente indivíduos com mais de 50 anos e a sua frequência cresce com a idade. Com o aumento da longevidade do homem, mais casos são gerados na população atingindo quase $50 \%$ dos indivíduos com 80 anos. A FIG.4 ilustra a porcentagem do crescimento benigno da próstata e a incidência do câncer em função da idade ${ }^{20}$. 


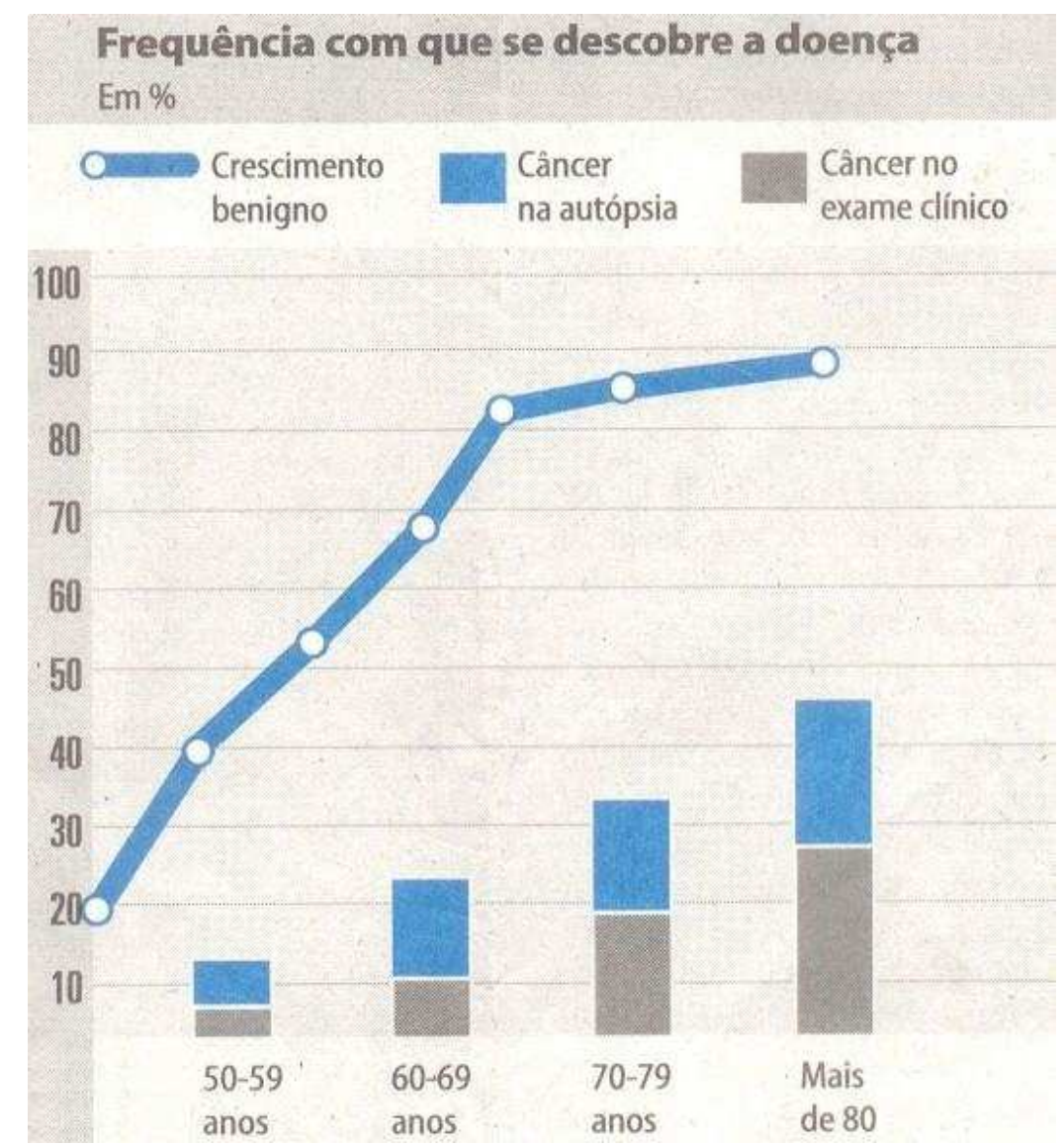

Figura 4 - Histograma de diagnóstico do crescimento beningo da prostáta e a incidência do câncer de acordo com a idade ${ }^{20}$

No Brasil, foram estimados para 2010, 53.350 novos casos para o câncer de próstata e que em 2008, 11.995 óbtidos foram registrados tendo como causa principal o câncer de próstata ${ }^{3}$.

A detecção do câncer de próstata pode ocorrer por meio de uma substância eliminada somente pela glândula prostática, esta substância é denominada antígeno prostático específico, ou PSA (Prostate-Specific Antigen). O valor do PSA é diretamente proporcional com a quantidade de tecido prostático, isto é, quanto maior a próstata, maior é o PSA. A célula cancerosa produz mais PSA do que uma célula prostática normal. A identificação do câncer pode ser feita com precisão pelo especialista, por meio do toque da próstata e das dosagens no sangue do PSA. Esses dois exames devem ser realizados conjuntamente, já que se registram falhas na identificação pelo toque em $30 \%$ a $40 \%$ dos casos e, pelo PSA, em $20 \%{ }^{20}$. A FIG.6 mostra o estágio de desenvolvimento do câncer de próstata. O estágio relaciona-se com o tamanho do túmor, profundidade e se já houve invasões a outros orgãos. 
Como ilustrado na FIG.5, os estágios do câncer de próstata podem ser caracterizados pelos seguintes aspectos:

- Estágio I: Tumor situado somente dentro da próstata, não detectável pelo toque da próstata bem como por imagens. Referências sobre o tumor pode ser somente indicado pelo aumento do PSA;

- Estágio II: Mais evoluído do que o estágio I, mas sem o espalhamento externo ao volume da próstata. Geralmente pode ser identificado por imagens e pelo toque da próstata, porém neste estágio não há sintomas para o paciente;

- Estágio III: O tumor espalha-se para órgãos próximos a próstata (como a vesícula seminal e o canal uretral). O sintoma mais frequente é a dificuldade ao urinar;

- Estágio IV: O tumor começa a atingir outros órgãos mais afastados da glândula prostática, tais como, o sistema linfático e ossos gerando metástases. 

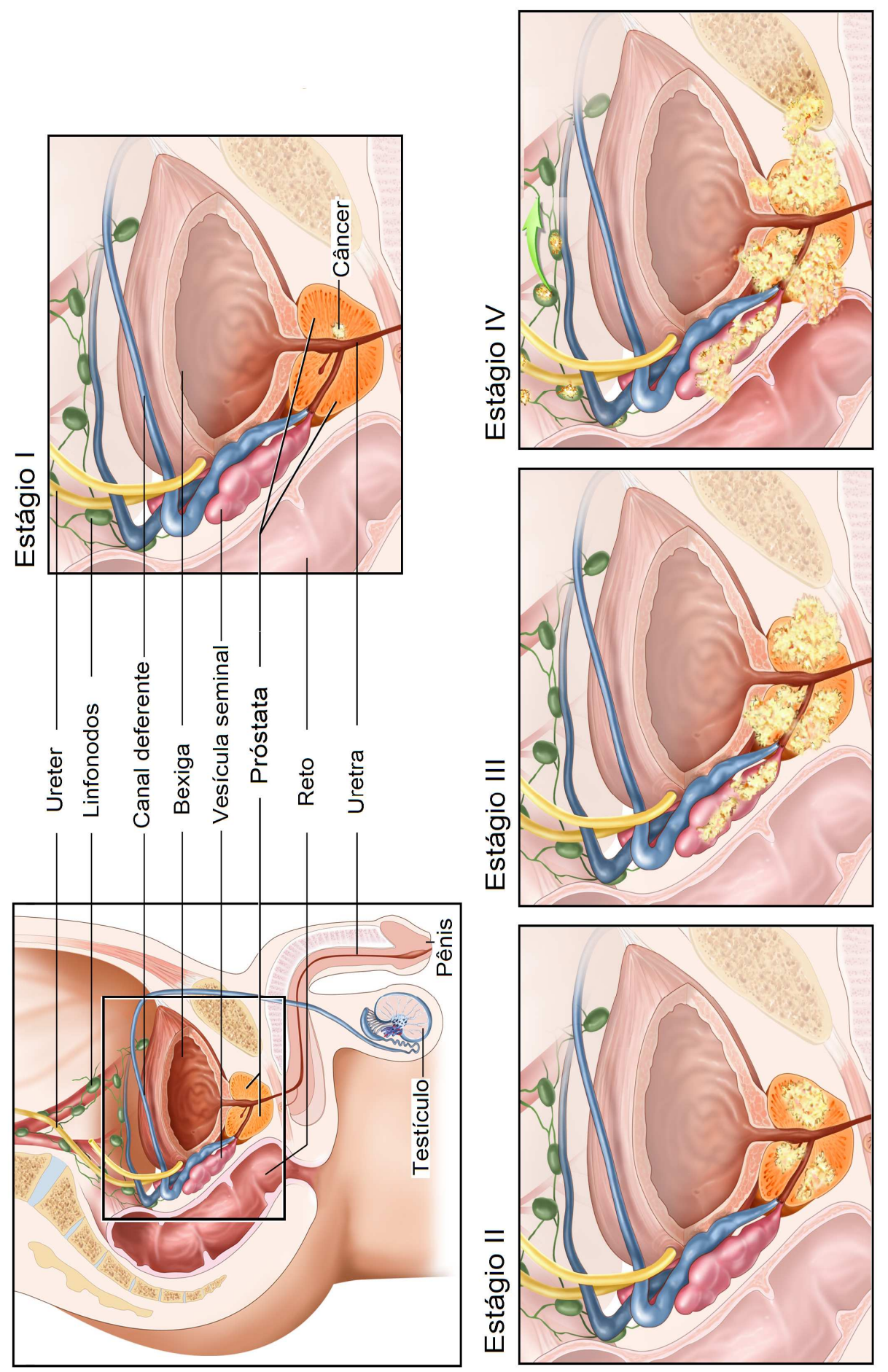

Figura 5 - Ilustração adaptada sobre o desenvolvimento do câncer de próstata ${ }^{48}$

Há instrumentos denominados nomogramas que permitem saber como deve ser o tratamento. O mais utilizado, conhecido como nomograma de Partin, relaciona as taxas de PSA no sangue, a extensão da doença no organismo e o aspecto do tumor na biópsia (escala de Gleason) ${ }^{49}$. 
O relatório da biópsia anátomo-patológica deve fornecer a graduação histológica do sistema de Gleason, cujo objetivo é informar sobre a provável taxa de crescimento do tumor e sua tendência à disseminação, além de ajudar na determinação do melhor tratamento para o paciente. $\mathrm{Na}$ graduação histológica, as células do câncer são comparadas às células prostáticas normais. Quanto mais diferentes das células normais forem as células do câncer, mais agressivo será o tumor e mais rápida será sua disseminação ${ }^{49}$.

A classificação de Gleason varia de 2 a 10. Quanto mais baixo o escore de Gleason, melhor será o prognóstico do paciente:

- Gleason de 2 a 4 - existe cerca de $25 \%$ de chance de o câncer disseminar-se para órgãos externos a próstata em 10 anos;

- Gleason de 5 a 7 - existe cerca de $50 \%$ de chance de o câncer disseminar-se para órgãos externos a próstata em 10 anos;

- Gleason de 8 a 10 - existe cerca de $75 \%$ de chance de o câncer disseminar-se para órgãos externos a próstata em 10 anos.

Em todas as classificações de Gleason, podem ocorrem sérios danos aos outros órgãos, afetando diretamente a sobrevida dos pacientes.

Para o PSA aceitam-se como valores limites normais até $4 \mathrm{ng} / \mathrm{ml}$; porém podem existir tumores com PSA abaixo deste valor. Quando o PSA estiver acima de $10 \mathrm{ng} / \mathrm{ml}$ há indicação formal para biópsia. Para valores entre $4 \mathrm{ng} / \mathrm{ml}$ a $10 \mathrm{ng} / \mathrm{ml}$ deve-se também levar em consideração a velocidade do PSA e a relação PSA livre/total. A TAB. 3 mostra os valores do níveis de PSA no sangue associado ao risco de câncer de próstata 20,49

TABELA 3 - Risco de câncer da próstata de acordo com os níveis de PSA e com o resultado do toque da próstata ${ }^{20,49}$

\begin{tabular}{ccc}
\hline Níveis de & \multicolumn{2}{c}{ Risco de câncer } \\
PSA no sangue & Toque Normal & Toque Anormal \\
\hline Desconhecido & $10 \%$ & $40 \%$ \\
Menor que 4 & $3 \%$ & $15 \%$ \\
Entre 4 e 10 & $15 \%$ & $60 \%$ \\
Maior que 10 & $50 \%$ & $95 \%$ \\
\hline
\end{tabular}




\subsection{Sementes de iodo-125 para o tratamento do câncer de próstata}

O implante intersticial utilizando sementes de iodo-125 apresenta algumas vantagens, quando comparadas com alguns procedimentos usuais para o tratamento do câncer de próstata, tais como a prostatectomia radical (retirada da próstata por intervenções cirúrgicas) e a teleterapia. Dentre as principais vantagens do implante com sementes de iodo-125, pode-se destacar ${ }^{50,51}$ :

- Preservação dos tecidos sadios adjacentes a próstata (por exemplo, bexiga e reto);

- Baixa taxa de impotência sexual após o procedimento de braquiterapia;

- Maior cobertura de dose do volume alvo (próstata);

- Pequena incidência de incontinência urinária;

- Procedimentos de implante são de baixo impacto e não cirúrgicos.

A partir da década de 80 , os implantes das sementes de iodo-125 tornaram-se mais acurados e menos invasivos, devido ao avanço das técnicas de imagens por ultrasonografia e o auxílio de sistemas computacionais no planejamento do tratamento. O ultrassom transretal (Transrectal Ultrasound - TRUS) permite a visualização, em tempo real, do implante das sementes de iodo-125 garantindo maior confiabilidade durante o posicionamento das sementes de iodo-125 no volume alvo. Nesta técnica, uma sonda de ultrassom é posicionada no canal retal gerando imagens da próstata e órgãos vizinhos ${ }^{17,52}$.

As sementes de iodo-125 são colocadas na próstata utilizando cateteres (agulhas) inseridos através do períneo até chegar à próstata, assim as sementes de iodo-125 são posicionadas conforme a prescrição recomendada. O inicio desta técnica de implante foi em meados dos anos 80 recebendo o nome de implante guiado de próstata transperineal (template-guided transperineal prostate implant). A FIG.6 mostra os procedimentos de ultrasonografia transretal, com detalhamento de uma imagem gerado pelo aparelho de ultrassom, e implante guiado de próstata transperineal ${ }^{17,52,53}$.

As sementes de iodo-125 podem ser posicionadas dentro da próstata de forma "livres" (loose) ou envoltas de um material polimérico biocompatível, este material tem a finalidade de reduzir as migrações das sementes de iodo-125 para locais externos à próstata. Em um implante com sementes de iodo-125 na próstata, geralmente pode-se utilizar de 36 a 120 sementes de iodo-125 ${ }^{54,55,56}$. A FIG.7 mostra um modelo comercial (Rapid Strand ${ }^{\mathrm{TM}}$ ) com sementes de iodo-125, cobertas com um material biocompatível. 


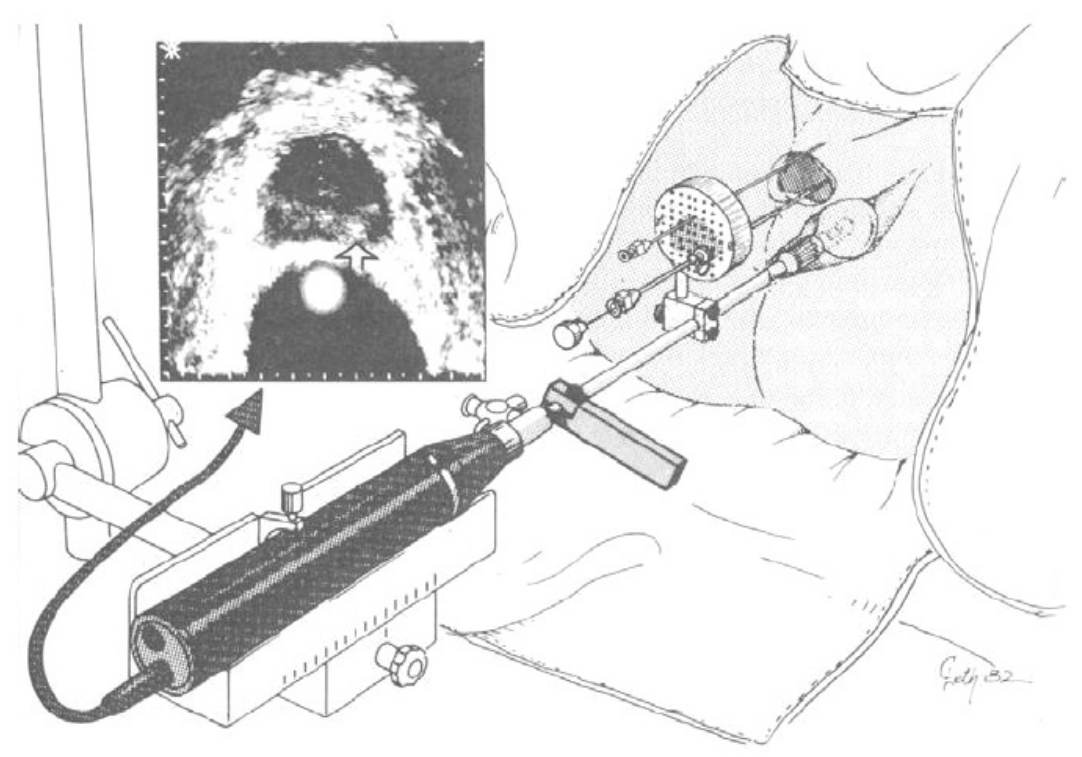

Figura 6 - Ilustração da técnica de implante das sementes de iodo-125, utilizando o TRUS e implante guiado de próstata transperineal ${ }^{17,57}$

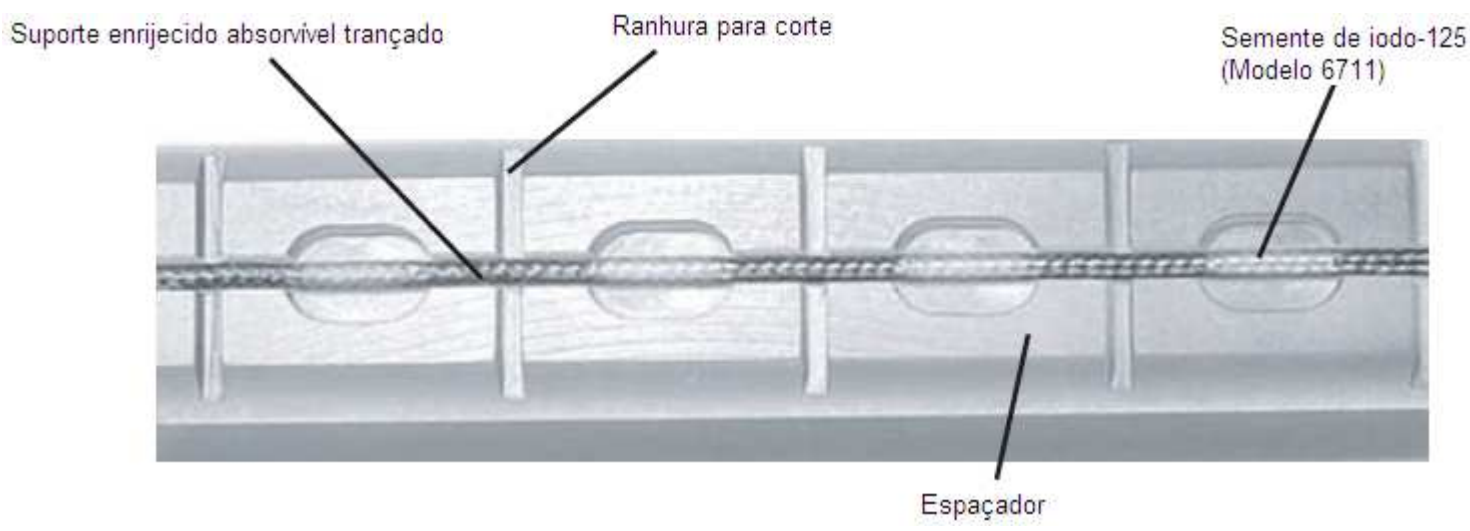

Figura 7 - Suporte com as sementes de iodo- 125 envoltas pelo material dosimétrico biocompatível ${ }^{55}$

Os planejamentos dosimétricos para o implante de sementes de iodo-125 podem ser realizados com o auxílio de softwares que possuem a capacidade de calcular a dose no volume alvo e também nos órgãos adjacentes. Desta maneira, estes dispositivos possibilitam avaliações de dose absorvida no volume a ser tratado e em regiões sadias, com as suas respectivas tolerâncias.

Estes softwares geralmente utilizam imagens obtidas por meio de tomografia computadorizada. Estas imagens permitem uma boa visualização tridimensional da região a ser tratada além dos órgãos de risco próximos ao volume alvo. Assim, os 
sistemas de planejamento, com as imagens da região a ser tratada, realiza os cálculos dosimétricos utilizando superposições de dose por meio de múltiplas fontes radioativas.

Para a plena eficácia do tratamento deve-se assegurar, por meio de controles de qualidades rotineiros, que os sistemas de planejamento realizem os cálculos de dose satisfatoriamente. Para a realização dos cálculos dosimétricos é fundamental que os sistemas de planejamento conheçam profundamente as características dosimétricas das fontes radioativas a serem utilizadas no tratamento clínico. A análise dosimétrica acurada das fontes radioativas utilizadas em braquiterapia está diretamente associada ao bom rendimento dos tratamentos que utilizam esta técnica, pois os dados relativos às características das fontes são adicionados aos sistemas de planejamento que irão realizar os cálculos com base nos parâmetros adicionados.

Estas análises dosimétricas não são triviais, pois existem diversos fatores envolvidos no tratamento clínico com implantes permanentes das sementes de iodo-125 que dificultam a realização das referidas análises, tais como: aproximação exata do meio e dimensões do volume alvo, possíveis migrações e pequenos deslocamentos das sementes de iodo-125 dentro da próstata após os implantes, descrição precisa dos elementos constituintes da semente de iodo-125, limitações experimentais para as

dimensões milimétricas envolvidas, entre outras ${ }^{58}$. Aproximações para tornar as análises dosimétricas mais próximas da realidade vêm sendo realizadas por anos, com a utilização de novos algoritmos e procedimentos experimentais diversos ${ }^{17,59}$.

\subsection{Dosimetria de fontes intersticiais aplicadas em braquiterapia - Task Group N. 43 (TG-43)}

Em 1988, um grupo formado pelo Radiation Therapy Committee da American Association of Physicists in Medicine (AAPM) compilou e revisou as publicações sobre a dosimetria de fontes intersticiais aplicadas em braquiterapia. Em 1995, uma publicação deste grupo intitulada: Dosimetry of interstitial brachytherapy sources: Recommendations of the AAPM Radiation Therapy Committee Task Group No. 43, ou simplesmente TG-43; dentre várias descrições, recomendou um novo algoritmo de cálculo da taxa de dose para as fontes de braquiterapia ${ }^{60}$. Este protocolo sofreu atualizações em 2004 e 2007 (TG-43U1), porém continua sendo referido na literatura e conhecido por membros da classe científica como TG-43 ${ }^{61,62}$. 
O objetivo principal deste protocolo foi transformar os elementos do algoritmo de cálculo da taxa de dose, em grandezas físicas mensuráveis e consequentemente quantificarem as principais diferenças dentre as diversas fontes, cada qual construída por processos diferentes de encapsulamento do material radioativo.

A equação (1) mostra os termos envolvidos no algoritmo utilizado para os cálculos da taxa de dose antes do novo formalismo proposto pelo TG-43 ${ }^{60}$ :

$$
\dot{D}(r)=A_{a p p} \cdot f_{m e d} \cdot\left(\Gamma_{\delta}\right)_{x} \cdot\left(1 / r^{2}\right) \cdot T(r) \cdot \bar{\phi}_{a n}
$$

Onde: $D(r)$ é a taxa de dose a uma distância $r$ da fonte de braquiterapia, neste algoritmo a fonte é considerada como pontual;

$A_{a p p}$ é a atividade aparente da fonte radioativa;

$f_{\text {med }}$ fator de conversão entre dose e exposição;

$\left(\Gamma_{\delta}\right)_{x}$ constante taxa de exposição do radionuclídeo inserido dentro da fonte de braquiterapia;

$T(r)$ fator de atenuação do tecido;

$\bar{\phi}_{a n}$ fator de anisotropia.

O formalismo descrito acima possui alguns problemas que podem acarretar em incertezas elevadas nos cálculos da taxa de dose em fontes para braquiterapia, dentre os quais se destacam ${ }^{60}$ :

- Não considerada as diferenças de constituição interna, invólucro e dimensões das fontes existentes;

- Baseia-se em modelos semi-analíticos que consideram somente as características do radionuclídeo utilizado;

- As quantidades e os fatores utilizados são baseados na fluência de fótons em espaço livre e não em um meio espalhador;

- Os cálculos dosimétricos são baseados somente em uma dimensão, não permitindo comparações em duas dimensões (aproximações 2 D).

Os termos da equação foram substituídos pelas seguintes constantes e funções, para uma aproximação 2D: 
$A_{a p p}$ (atividade aparente) $-S_{K}$ (Intensidade kerma-ar)

$\left(\Gamma_{\delta}\right)_{x}$ (constante de taxa de exposição) $-\Lambda$ (Constante de taxa de dose)

$\left(1 / r^{2}\right)$ (inverso do quadrado da distância) - $G(r, \theta)$ (Função de Geometria)

$T(r)$ (fator de atenuação do tecido) - $g(r)$ (Função de dose radial)

$\bar{\phi}_{a n}$ (fator de anisotropia) $-F(r, \theta)$ (Função de anisotropia)

A adição de $\theta$ (ângulo relativo ao centro ativo da fonte de braquiterapia) cria a possibilidade de calcular em duas dimensões tornando o formalismo mais realístico. As quantidades relativas (função de dose radial e função de anisotropia) inseridas para o novo formalismo permitem a redução das incertezas em suas determinações e facilita as intercomparações com outros valores fornecidos pela literatura ${ }^{60,61}$.

A FIG.8 ilustra uma fonte de braquiterapia simetricamente cilíndrica, na qual os pontos a ser analisados podem ser descritos por meio de coordenadas polares $(r, \theta)$. O ponto de referência para o cálculo da taxa de dose $\mathrm{P}\left(r_{0}, \theta_{0}\right)$ determinado por este algoritmo localiza-se no plano bissetor da fonte a uma distância de $1 \mathrm{~cm}$ do seu centro, isto é, $r_{0}=1 \mathrm{~cm}$ e $\theta_{0}=\pi / 2$ radianos ou $90^{\circ}$.

O ângulo de referência $\left(\theta_{0}\right)$ define o plano transversal da fonte, perpendicular ao eixo longitudinal (eixo Z). Na FIG.8, $\mathrm{P}\left(r_{0}, \theta_{0}\right)$ é o ponto de referência para os cálculos, $\mathrm{P}(\mathrm{r}, \theta)$ é o ponto de interesse para medida dosimétrica, L é o comprimento ativo da fonte, t é a distância da fonte "ativa" ao encapsulamento, $\mathrm{Z}$ é o eixo longitudinal, $\beta$ é a diferença entre o ângulo $\theta_{2}$ e $\theta_{1}$ relativo as extremidades da fonte e $r$ é a distância do centro ativo da fonte (centro geométrico) até o ponto de interesse $\mathrm{P}(\mathrm{r}, \theta)$. 


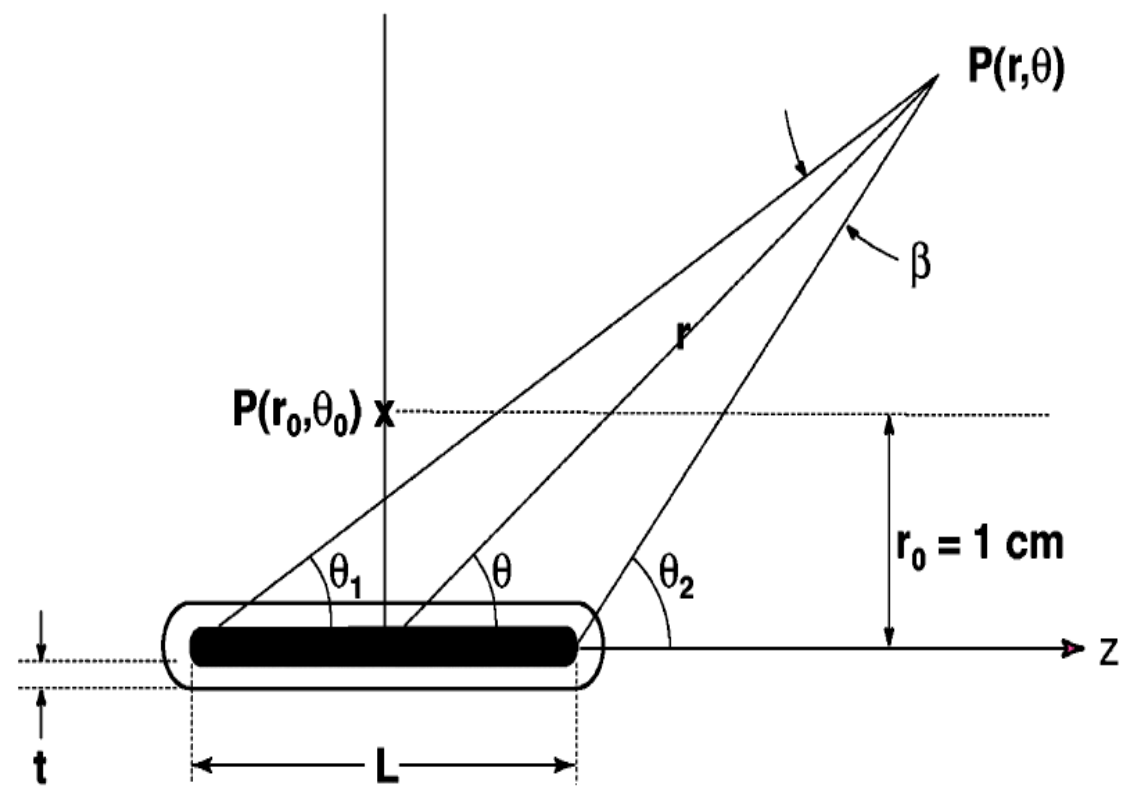

Figura 8 - Sistema de coordenadas utilizado para o cálculo de taxa de dose sugerido pelo TG-43 ${ }^{60}$

O algoritmo de cálculo da taxa de dose, sugerido pelo TG-43, pode ser escrito conforme mostra a equação (2):

$$
\dot{D}(r, \theta)=S_{K} \cdot \Lambda \cdot \frac{G_{L}(r, \theta)}{G_{L}\left(r_{0}, \theta_{0}\right)} \cdot g_{L}(r) \cdot F(r, \theta)
$$

Assim:

- $D(r, \theta)$ é a taxa de dose no ponto de interesse, $\left(c G y \cdot h^{-1}\right)$;

- $S_{K}$ é a intensidade de kerma-ar $\left(c G y \cdot \mathrm{cm}^{2} \cdot h^{-1}\right.$ ou U );

- $\Lambda$ constante de taxa de dose $\left(c G y \cdot h^{-1} \cdot U^{-1} \mathrm{ou} \mathrm{cm}^{-2}\right)$;

- $G_{L}(r, \theta)$ é a função de geometria $\left(\mathrm{cm}^{-2}\right)$;

- $G_{L}\left(r_{0}, \theta_{0}\right)$ é a função de geometria no ponto de referência $\left(\mathrm{cm}^{-2}\right)$;

- $g_{L}(r)$ é a função de dose radial (adimensional) e

- $F(r, \theta)$ é a função de anisotropia (adimensional).

O subscrito L inserido na função de geometria e função de dose radial denota a aproximação linear (2D) de uma fonte cilíndrica e nota-se que os três últimos termos da equação 2 renderá valores adimensionais. Verifica-se que o símbolo U também equivale em outras unidades a $1 \mu G y \cdot m^{2} \cdot h^{-1},{ }^{61}$. As principais características dos termos expressos pela equação (2) serão apresentadas nos itens subseqüentes. 


\subsubsection{Intensidade de kerma-ar $\left(S_{K}\right)$}

A intensidade de kerma-ar mensura a intensidade de uma fonte aplicada em braquiterapia. Esta grandeza é designada através do produto da taxa de kerma-ar, com energia de fótons maiores do que o limiar $\delta$ (energia de corte), no vácuo, $K_{\delta}(d)$, pela distância ao quadrado, $d^{2}$, da fonte até o centro geométrico do volume sensível do sistema de medida, como mostra a equação (3) ${ }^{61}$ :

$$
S_{K}=\dot{K}_{\delta}(d) \cdot d^{2}
$$

A distância $d$ é calculada a partir do centro da fonte radioativa até ao ponto de medida, está distância situa-se no plano transverso da fonte e pode assumir qualquer valor, porém este valor deve ser elevado o suficiente se comparado com as dimensões da fonte radioativa (alguns milímetros), tornando $S_{K}$ independente da distância $d$. Tipicamente a distância adotada é equivalente a 1 metro; o termo vácuo refere-se às correções de atenuação e espalhamento no ar entre a fonte e o detector.

A energia de corte é aplicada para excluir os fótons de baixas energias que aumentam o valor da taxa de kerma-ar, porém sem contribuir significantemente na dose absorvida, em distâncias maiores do que $0,1 \mathrm{~cm}$ de tecido. A ordem do valor da energia de corte é equivalente a $5 \mathrm{keV}^{61}$.

A determinação da intensidade de kerma-ar demanda condições experimentais especiais, atingida somente por laboratórios metrológicos de padronização e calibração primários ou secundários. Desde a década de 80, pesquisadores do antigo National Bureau of Standards (NBS) desenvolveram uma câmara de ar-livre para a padronização de diferentes modelos de sementes de iodo- $125^{63}$. Por causa de problemas encontrados nas mensurações realizadas e a necessidade da padronização de novas fontes de braquiterapia, o atual National Institute of Standards and Technology (NIST) foi levado a desenvolver um novo detector para a determinação da intensidade de kerma-ar ${ }^{64}$.

Esta nova câmara é conhecida pelo termo WAFAC (Wide-Angle Free-Air Chamber) e é utilizada para mensurar fontes de braquiterapia com energias de até 40 $\mathrm{keV}^{65}$. A FIG.9 mostra o desenho esquemático da WAFAC utilizada pelo NIST, a fonte de braquiterapia é posicionada em um rotor que gira regularmente, o filtro de aluminío é utilizado para eliminar as energias abaixo ou igual a energia de corte. $\mathrm{O}$ desenho inferior contido na FIG.9 ilustra como as interferências das janelas (Mylar-alumínizado) dos eletrodos coletores são contabilizadas ${ }^{65}$. 


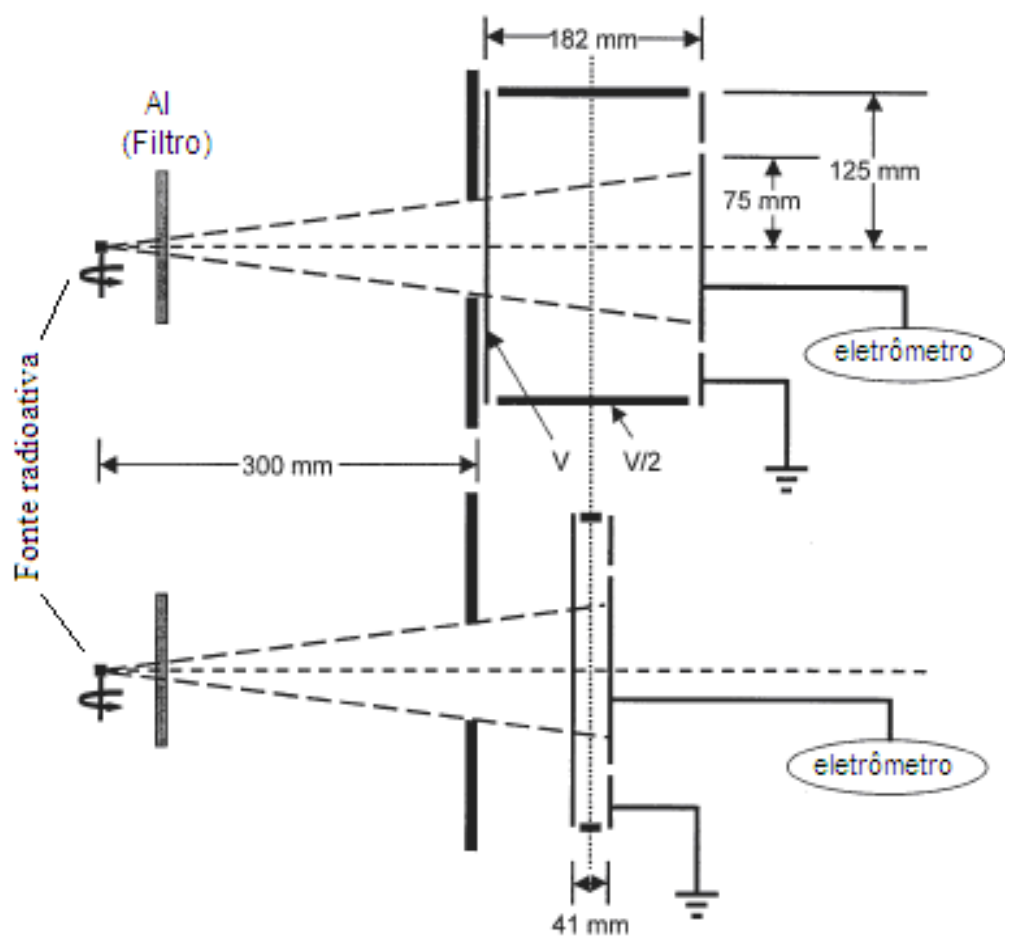

Figura 9 - Desenho esquemático da WAFAC (figura superior) com o sistema de subtração das interferências ocasionadas pela janela dos eletrodos (figura inferior) ${ }^{65}$

\subsubsection{Constante de taxa de dose $(\Lambda)$}

A constante de taxa de dose é uma grandeza absoluta sendo definida, em água ou em um objeto simulador equivalente, como a razão da taxa de dose no ponto de referência $\left(\mathrm{P}\left(r_{0}, \theta_{0}\right)\right)$ pela intensidade kerma-ar, como representado pela equação 4 :

$$
\Lambda=\frac{\dot{D}\left(r_{0}, \theta_{0}\right)}{S_{K}}
$$

Por meio da equação (4) infere-se que cada modelo de fonte terá a sua constante de taxa de dose. Os efeitos da geometria da fonte, a distribuição espacial do radionuclídeo dentro da fonte, encapsulamento, auto-filtração e espalhamento no meio são os fatores levados em conta pela constante de taxa de dose ${ }^{60}$. A unidade da constante de dose por ser expressa por $c G y \cdot h^{-1} \cdot U^{-1}$ ou simplesmente $\mathrm{cm}^{-2}$.

Qualquer mudança no valor da intensidade de kerma-ar irá alterar o valor da constante de taxa de dose. Por isto, é comum denotar a constante de taxa de dose com as referências ao laboratório onde a intensidade kerma-ar foi obtida juntamente com o ano da calibração, pois os padrões de intensidade de kerma-ar podem ser alterados, 
revisados ou modificados. Por exemplo, $\Lambda_{97 D, N 99 S}$ denota que a constante de taxa de dose foi obtida por medidas dosimétricas publicadas em 1997 (97D) e normalizada para um padrão de intensidade de kerma-ar com o padrão do NIST em $1999(N 99 S){ }^{61}$.

\subsubsection{Função de Geometria $\left(G_{L}\right)$}

A função de geometria explica a variação de dose relativa devido somente às características internas da fonte, rendendo uma correção efetiva para a lei do inverso quadrado da distância, de acordo com a distribuição espacial do material radioativo dentro da fonte. Esta função ignora a absorção e o espalhamento dos fótons na estrutura da fonte e é utilizada para propiciar uma acurácia nos valores de taxa de dose, que podem ser interpolados em determinados pontos de medida, por meio de aproximações realísticas, úteis principalmente para o planejamento do tratamento ${ }^{60,61}$.

Utilizando um aproximação de fonte linear (2D), a função de geometria pode ser expressa por meio da equação $5^{61}$ :

$$
G_{L}=\left\{\begin{array}{l}
\frac{\beta}{L \cdot r \cdot \operatorname{sen} \theta} \Rightarrow \theta \neq 0^{\circ} \\
\frac{1}{\frac{r-L / 2}{r+L / 2}} \frac{1}{L} \Rightarrow \theta=0^{\circ}
\end{array}\right.
$$

na equação $5, L$ é o comprimento ativo da fonte; $\beta$ é o ângulo sub-entendido pela fonte ativa com relação ao ponto $(r, \theta)$, como ilustrado na FIG.8; $r$ é a distância do ponto $(r, \theta)$ ao centro do comprimento ativo da fonte. Para os valores de $\beta$, utilizando conceitos de geometria plana, este trabalho utilizou a expressão descrita pela equação $6^{66}$ :

$$
\beta=\theta_{2}-\theta_{1}=\frac{\tan ^{-1}\left(\frac{r \cos \theta+L / 2}{r \operatorname{sen} \theta}\right)-\tan ^{-1}\left(\frac{r \cos \theta-L / 2}{r \operatorname{sen} \theta}\right)}{\operatorname{Lrsen} \theta}
$$

\subsubsection{Função de Dose Radial $\left(g_{L}(r)\right)$}

A função de dose radial basicamente quantifica os efeitos de absorção e espalhamento ao longo do eixo transversal da fonte radioativa, esta função também pode ser influenciada pela filtração dos fótons devido ao encapsulamento e materiais 
constituintes da fonte radioativa. A equação 7 mostra como a função de dose radial pode ser obtida:

$$
g_{L}(r)=\frac{\dot{D}\left(r, \theta_{0}\right)}{\dot{D}\left(r_{0}, \theta_{0}\right)} \cdot \frac{G_{L}\left(r_{0}, \theta_{0}\right)}{G_{L}\left(r, \theta_{0}\right)}
$$

Comumente, a função de dose radial pode ser obtida utilizando modelos matemáticos, o modelo mais comum é representado funções polinomiais de quinta ordem, como mostrado pela equação 8:

$$
g_{L}(r)=a_{0}+a_{1} r+a_{2} r^{2}+a_{3} r^{3}+a_{4} r^{4}+a_{5} r^{5}
$$

os coeficientes da equação são determinados por meio dos resultados experimentais de cada fonte e devem estar dentro de $\pm 2 \%{ }^{61}$.

\subsubsection{Função de Anisotropia $(F(r, \theta))$}

A função de anisotropia representa a anisotropia ao redor da fonte radioativa, incluindo os efeitos de absorção e espalhamento do meio, onde esta função é mensurada 60. Esta função é fortemente influenciada pelo encapsulamento da fonte radioativa e energia dos fótons. A equação 9 mostra como a função de anisotropia é obtida:

$$
F(r, \theta)=\frac{\dot{D}(r, \theta)}{\dot{D}\left(r, \theta_{0}\right)} \cdot \frac{G_{L}\left(r, \theta_{0}\right)}{G_{L}(r, \theta)}
$$

Devido à dificuldade experimental de mensurar alguns pontos experimentais, por exemplo, distâncias menores do que $0,5 \mathrm{~cm}$ ou maiores do que $10 \mathrm{~cm}$, devido aos elevados gradientes de dose nestas regiões, alguns valores da função de anisotropia podem ser obtidos por meio de interpolações ou extrapolações.

\subsection{Dosimetria Termoluminescente}

A termoluminescência ou a luminescência termicamente estimulada é um fenômeno que ocorre em sólidos isolantes ou semicondutores e está associada à emissão de luz durante o aquecimento do material previamente excitado ${ }^{67}$. De forma simplificada, o processo termoluminescente pode ser explicado pela alteração dos estados eletrônicos dentro do sólido, através da interação das irradiações ionizantes, tais como, raios-X, raios gama, feixe de elétrons, nêutrons, partículas carregadas e íons pesados ${ }^{68}$. As excitações são os estados metaestáveis dentro do material, com o 
aquecimento, estes estados metaestáveis liberam fótons de luz (relaxação) e consequentemente retornam ao estado estável ${ }^{69}$.

A criação de estados metaestáveis está associada à existência de impurezas ou defeitos na rede cristalina. Os estados destes defeitos ou impurezas localizam-se entre as bandas de valência e condução do cristal ${ }^{68}$.

Estes defeitos geram alterações nos estados eletrônicos, que dentro da rede cristalina criam "armadilhas" energéticas. Quando o material é irradiado, estas armadilhas armazenam os elétrons e buracos nos estados metaestáveis do cristal e quando aquecidos até as temperaturas específicas retornam ao estado estável, ocasionando em boa parte a emissão de luz (recombinação radiativa) ${ }^{69}$. A FIG.10 mostra um desenho esquemático do ciclo existente no processo de termoluminescência. A circunferência vermelha preenchida e a vazia denotam os elétrons e os buracos da rede cristalina, respectivamente ${ }^{70}$. Diversos tipos de interações e recombinações podem ocorrer nos materiais termoluminescentes (TL), para tanto existe alguns modelos que tentam explicar tais eventos, porém não é o objetivo deste trabalho explicá-los, contudo podem ser encontrados nas referências previamente citadas.

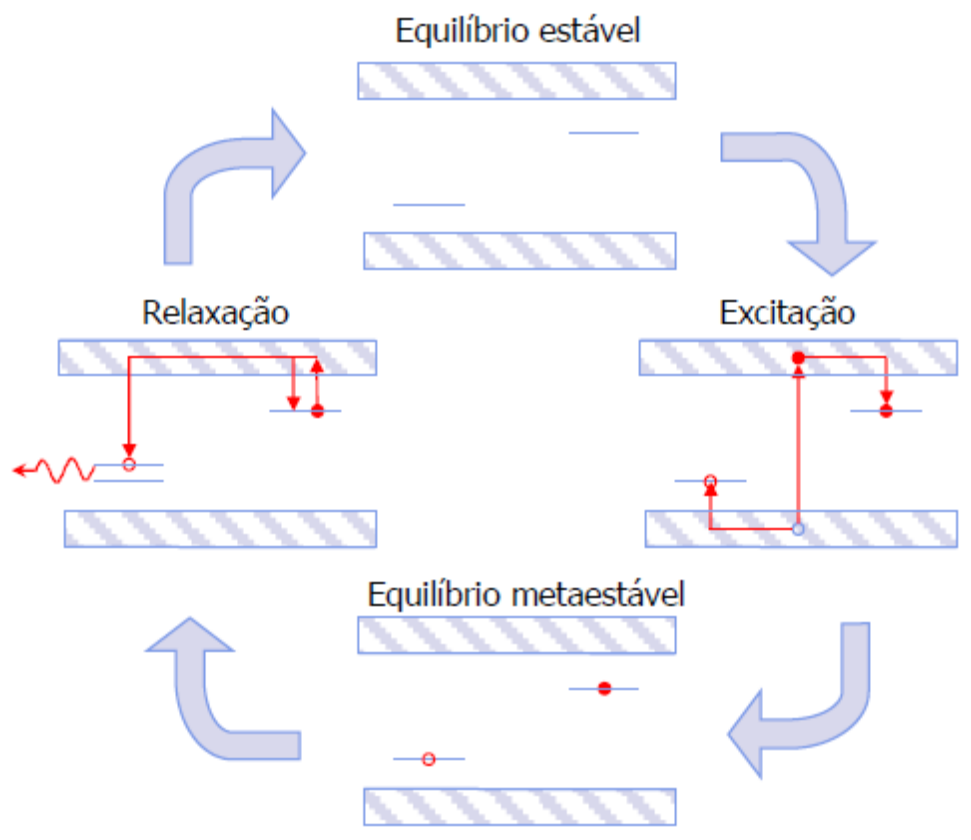

Figura 10 - Desenho simplificado representando um ciclo com os estágios do processo de termoluminescência ${ }^{70}$

Uma das primeiras aplicações da técnica TL foi a detecção e medida da radiação absorvida e consequentemente a dosimetria das radiações ionizantes (direta e indiretamente ionizantes) ${ }^{67,68,71}$. Basicamente, a utilização da técnica TL para a 
dosimetria de radiações ionizantes justifica-se, pois a intensidade do sinal TL liberado pelo material exposto é diretamente proporcional à energia por ele absorvida. As respostas, em termos de dose para uma exposição desconhecida podem ser encontradas mediante a comparação do sinal TL mensurado com o sinal TL obtido pela exposição do material a um feixe calibrado ${ }^{72}$.

Há diversos materiais termoluminescentes. A TAB. 4 mostra os principais dosímetros utilizados para a técnica TL. A TAB. 4 denota a formulação química dos materiais, o nome comercial (muito utilizado na literatura para a representação dos dosímetros), o número atômico efetivo $\left(\mathrm{Z}_{\mathrm{eff}}\right)$, região de resposta linear do dosímetro, saturação da resposta e a resposta energética gerada a partir da razão de irradiação com fótons de $30 \mathrm{keV}$ e Cobalto-60 - ${ }^{60} \mathrm{Co}$ ( média de $1250 \mathrm{keV}$ ) ${ }^{72}$. As características dos materiais TL são de grande importância, considerando as aplicações a quais estes materiais serão submetidos ${ }^{70}$. Deste modo, a seleção do material TL deve ser realizada cuidadosamente observando as características básicas do dosímetro, por exemplo, número atômico efetivo, região linear, saturação, formas físicas e sensibilidade.

TABELA 4 - Principais materiais TL e algumas propriedades (adaptado ${ }^{72}$ ). ${ }^{(1)}$ Nome popular, como designado pelos fabricantes. ${ }^{(2)}$ Há também as versões enriquecidas com ${ }^{6} \mathrm{Li} \mathrm{e}{ }^{7} \mathrm{Li}$

\begin{tabular}{|c|c|c|c|c|c|}
\hline Material TL & $\begin{array}{c}\text { Nome } \\
\text { Comercial }^{(1)}\end{array}$ & $\mathrm{Z}_{\mathrm{eff}}$ & $\begin{array}{l}\text { Região linear } \\
\text { de dose (Gy) }\end{array}$ & $\begin{array}{c}\text { Saturação } \\
\text { (Gy) }\end{array}$ & $\begin{array}{l}\text { Resposta energética } \\
\qquad\left(30 \mathrm{keV} /{ }^{60} \mathrm{Co}\right)\end{array}$ \\
\hline $\mathrm{LiF}: \mathrm{Mg}, \mathrm{Ti}^{(2)}$ & TLD-100 & 8,2 & $5.10^{-6}-1$ & $\sim 10^{5}$ & 1,3 \\
\hline $\mathrm{LiF}: \mathrm{Mg}, \mathrm{Cu}, \mathrm{P}^{(2)}$ & GR-200 & 8,2 & $3.10^{-6}-10$ & $\sim 10$ & anômalo \\
\hline $\mathrm{CaF}_{2}: \mathrm{Mn}$ & TLD-400 & 16,3 & $10^{-5}-10$ & $\sim 2.10^{2}$ & $\sim 13$ \\
\hline $\mathrm{CaF}_{2}: \mathrm{Dy}$ & TLD-200 & 16,3 & $10^{-5}-10$ & $\sim 5.10^{2}$ & $\sim 13$ \\
\hline $\mathrm{CaF}_{2}: \mathrm{Tm}$ & TLD-300 & 16,3 & $1-10$ & $\sim 10$ & $\sim 13$ \\
\hline $\mathrm{Al}_{2} \mathrm{O}_{3}: \mathrm{C}$ & TLD-500 & 10,2 & $10^{-6}-10^{2}$ & $\sim 50$ & $\sim 2,8$ \\
\hline $\mathrm{Al}_{2} \mathrm{O}_{3}: \mathrm{Mg}, \mathrm{Y}$ & D-2/D-3 & 10,2 & $10^{-3}-10^{4}$ & $\sim 10^{4}$ & $\sim 2,8$ \\
\hline $\mathrm{CaSO}_{4}: \mathrm{Dy}$ & TLD-900 & 15,5 & $10^{-6}-10$ & $\sim 10^{5}$ & $10-12$ \\
\hline $\mathrm{CaSO}_{4}: \mathrm{Tm}$ & - & 15,5 & $10^{-6}-30$ & $\sim 10^{2}$ & $10-12$ \\
\hline $\mathrm{Li}_{2} \mathrm{~B}_{4} \mathrm{O}_{7}: \mathrm{Mn}$ & TLD-800 & 7,4 & $10^{-4}-3$ & $\sim 10^{4}$ & $\sim 0,9$ \\
\hline $\mathrm{Li}_{2} \mathrm{~B}_{4} \mathrm{O}_{7}: \mathrm{Cu}^{(2)}$ & - & 7,4 & $10^{-4}-3$ & $\sim 10^{3}$ & $\sim 0,8$ \\
\hline $\mathrm{MgB}_{4} \mathrm{O}_{7}: \mathrm{Dy}$ & - & 8,4 & $10^{-5}-1$ & $\sim 10$ & $\sim 1.5$ \\
\hline $\mathrm{BeO}$ & - & 7,1 & $10^{-4}-0,5$ & $\sim 10^{2}$ & $\sim 1,4$ \\
\hline $\mathrm{MgO}$ & - & 10,0 & $10^{-4}-10^{4}$ & $\sim 10^{4}$ & - \\
\hline
\end{tabular}


O sinal TL é mensurado por equipamentos específicos comumente denominados como leitoras TL. Há diversos modelos, porém o funcionamento de todos os leitores TL segue basicamente as seguintes condições:

1. Aquecimento do material dosimétrico até a temperatura selecionada, com uma taxa de aquecimento apropriada;

2. Durante o aquecimento, o material TL irá liberar fótons de luz, que com certa eficiência serão coletados pelo tubo fotomultiplicador ou fotodiodo;

3. O tubo fotomultiplicador irá converter, proporcionalmente, a luminescência captada em unidades de carga elétrica (Coulomb);

4. Esta carga é enviada ao sistema eletrônico da leitora TL, controlada ou não por um microcomputador, onde as respostas são armazenadas ou mostradas.

Essas cargas ou os sinais TL, que são mostrados geralmente como a resposta TL do dosímetro em função da temperatura do material, é uma "curva" (glow curve), onde cada material TL possui o formato de curva TL diferente uns aos outros ${ }^{67,70}$. Essas curvas são espectros compostos por "picos" sobrepostos, onde estes picos estão associados, em princípio, a uma ou várias armadilhas $\mathrm{TL}^{68}$.

A FIG. 11 mostra um exemplo de um sinal TL do LiF:Mg,Ti (TLD-100) irradiado com $45 \mathrm{mGy}$ de Cobalto-60, a temperatura ambiente ${ }^{73}$. As linhas sólidas representam os valores calculados para cada pico TL e os pontos representam os valores mensurados pelo material TL. Nesta figura é possível observar quatro picos TL, estes quatros picos correspondem aos picos 2, 3, 4 e 5, respectivamente do TLD-100, o pico 1 não é encontrado, pois já teve sua luminescência liberada espontaneamente ( 5 minutos de meia-vida pós irradiação) a temperatura ambiente, este processo é denominado como fading ${ }^{74}$.

Para propósitos dosimétricos, comumente utiliza-se a área sob a curva TL ou a altura dos picos TL para a obtenção dos sinais TL ${ }^{70,72}$. A área sob a curva TL é calculada somando as respostas TL obtidas em cada canal e a altura do pico é avaliada mensurando a resposta TL no pico correspondente. Assim a dose absorvida pelo dosímetro é associada a quantidade de luminescência registrada pelo sistema de leitura $\mathrm{TL}^{73}$. 


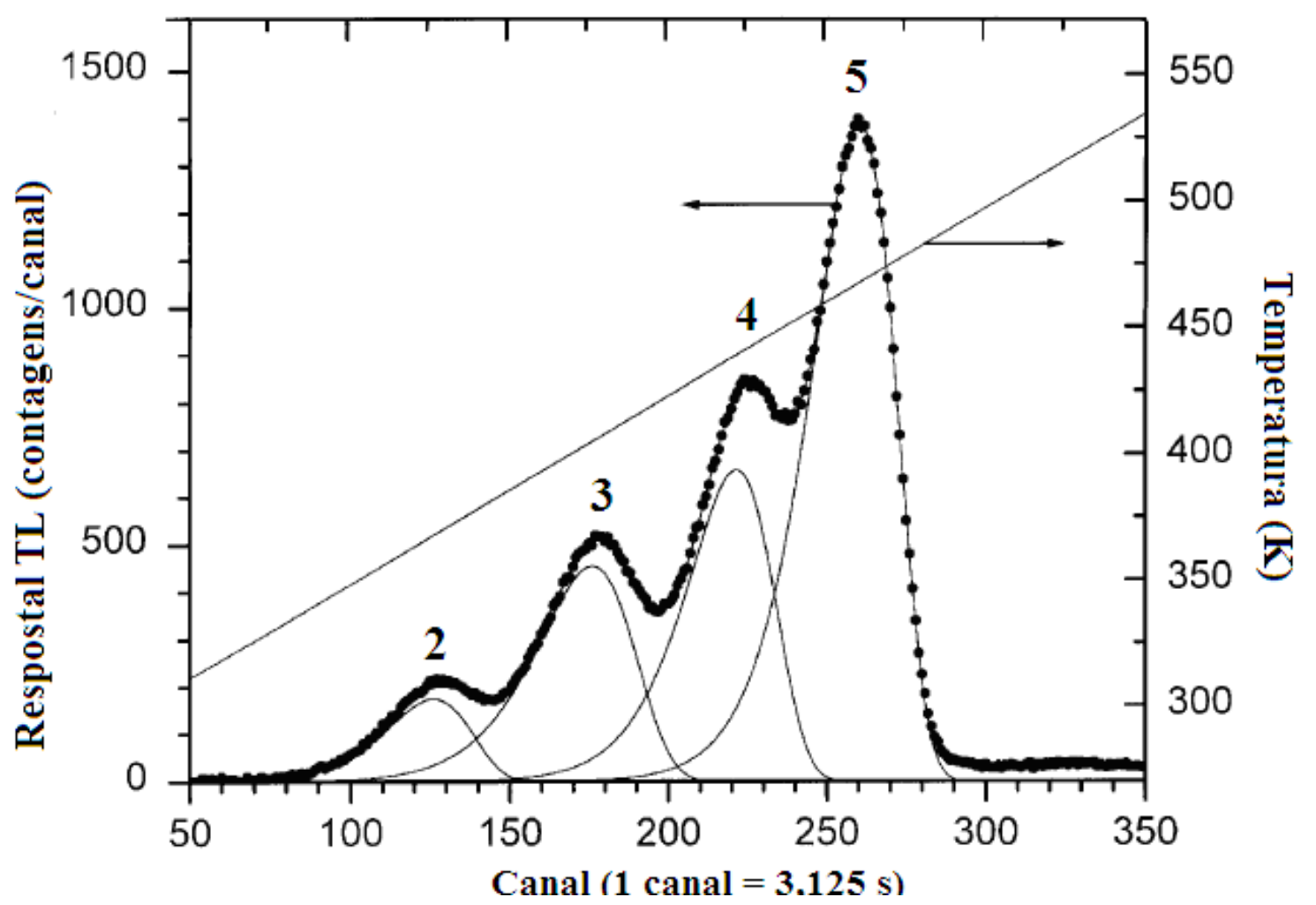

Figura 11 - Curva TL do LiF:Mg,Ti obtida após irradiação com 45 mGy de Cobalto-60, a linha representa a taxa de aquecimento $-0,24 \mathrm{~K} / \mathrm{s}$ (adaptado ${ }^{69}$ )

Experimentalmente, o ciclo TL consiste principalmente de três etapas: irradiação, leitura e tratamento térmico pós irradiação ${ }^{68,69,74}$. Também é possível realizar o tratamento pré leitura do dosímetro, para minimizar a influência dos picos de baixa temperatura, que podem ocasionar um aumento nas incertezas durante a aquisição dos sinais TL. Ou aguardar um tempo até realizar a leitura dos dosímetros, com isto, os picos mais instáveis tendem a evanescer. Qualquer que seja a escolha das etapas que serão utilizados no ciclo TL, a característica fundamental que deve ser seguida é a reprodutibilidade de todos os ciclos TL, pois as respostas dos dosímetros podem ser muito sensíveis a alterações dos parâmetros acima descritos ${ }^{70}$.

Antes de qualquer utilização dos dosímetros TL é conveniente selecioná-los dentro de lote específico. As seleções mais utilizadas são quanto a sensibilidade (sinal $\mathrm{TL} /($ dose.massa) e quanto a reprodutibilidade do lote de dosímetros. Estas seleções visam escolher os dosímetros mais aptos para as diversas tarefas que envolvam a dosimetria TL causando a redução das incertezas nas respostas TL. 


\subsection{Dosímetro LiF:Mg,Ti (TLD-100)}

O Fluoreto de Lítio dopado com Magnésio e Titânio, ou simplesmente TLD-100 é utilizado a décadas para diversas investigações dosimétricas, sendo o dosímetro TL mais utilizado para tais fins ${ }^{69}$. Estes dosímetros estão disponíveis comercialmente em alguns formatos e dimensões. São produzidos utilizando técnicas de crescimento de cristais e para a maior sensibilidade possível, estes dosímetros são dopados com cerca de 180 ppm e 10 ppm de $\mathrm{Mg}^{2+}{\text { e } \mathrm{Ti}^{4++} \text {, respectivamente }}^{68,69}$.

O número atômico efetivo deste dosímetro, $(8,2)$, é próximo do tecido biológico com valor próximo a $(7,4){ }^{75}$. Possui um comportamento linear até $1 \mathrm{~Gy}$, tornando-se supralinear (resposta TL maior que a variação da dose, não proporcional) até $10^{3} \mathrm{~Gy}$ e apresentando um comportamento sublinear (resposta TL menor que a variação da dose, não proporcional) acima deste valor de dose absorvida ${ }^{69}$. Apresenta sensibilidade de dose em torno de $5 \mu \mathrm{Gy}$ para aproximadamente $50 \mathrm{mg}$ de amostra do dosímetro ${ }^{69}$.

Este dosímetro é sensível a diferentes tratamentos térmicos ao qual ele é submetido. Alguns autores recomendam o seguinte procedimento ${ }^{67,68,69}$ :

1. Tratamento térmico à alta temperatura: Utilizado para no re-uso dos dosímetros e possui duas funções: a) minimizar os sinais TL residuais "esvaziando" os picos que são ativados por temperaturas altas (picos 6 - 10); b) restaurar a sensibilidade original e as estruturas da curva TL. A temperatura recomendada para este nível de temperatura é $400{ }^{\circ} \mathrm{C}$ por 1 hora ${ }^{69,76}$.

2. Tratamento térmico à baixa temperatura: Realizado após o tratamento térmico à alta temperatura, este tratamento tem como objetivo reduzir o fading e também com isto minimizar a contribuição dos picos de baixa temperatura $(1-3)$. A temperatura padrão para o tratamento térmico a baixa temperatura é $80{ }^{\circ} \mathrm{C}$ por 24 horas, porém o tratamento a $100{ }^{\circ} \mathrm{C}$ por 2 horas mostra-se mais prática e apresenta resultados similares ao tratamento térmico de $80{ }^{\circ} \mathrm{C}$ por 24 horas.

O formato da curva TL do TLD-100 pode ser visualizado na FIG. 11. Para propósitos dosimétricos, os picos mais adequados são os picos 4 e 5 , pois possuem as respostas mais estáveis (a temperatura ambiente, a meia-vida são iguais a 7 e 80 anos, respectivamente ${ }^{74}$ ) e mais intensas em sinal TL. Os formatos destes picos estão associados diretamente a vários fatores, dentre os principais, pode-se citar: tratamento térmico, energia e tipo das radiações incidentes, dose absorvida, taxa de aquecimento e 
tempo de fading ${ }^{72,73,77}$. A obtenção dos dados dosimétricos experimentais possuem grandes variações de um grupo de pesquisa a outro, por isto é recomendável que os pesquisadores coloquem as condições experimentais utilizadas tidas como essenciais ${ }^{78}$.

A dependência energética para fótons, dos TLD-100, não é tão acentuada se comparada com outros dosímetros. A FIG. 12 mostra a razão dos coeficientes de massa do tecido (com número atômico efetivo próximo a 7,35) pelo coeficiente de massa dos dosímetros em função de diferentes energias de fótons, sob condições idênticas de fluência de fótons ${ }^{73}$. O aumento na razão até aproximadamente $200 \mathrm{keV}$ deve-se ao predomínio do efeito fotoelétrico, que possui uma forte dependência com o número atômico efetivo $\left(\sim Z^{3,5}\right)^{79}$.

$\mathrm{Na}$ prática, costuma-se referenciar a dependência energética para fótons por meio da razão da reposta TL de fótons de baixa energia $(30 \mathrm{keV})$ pela de fótons com alta energia, como do Cobalto-60 (1250 keV), como denotado na TAB. $4 .{ }^{73}$.

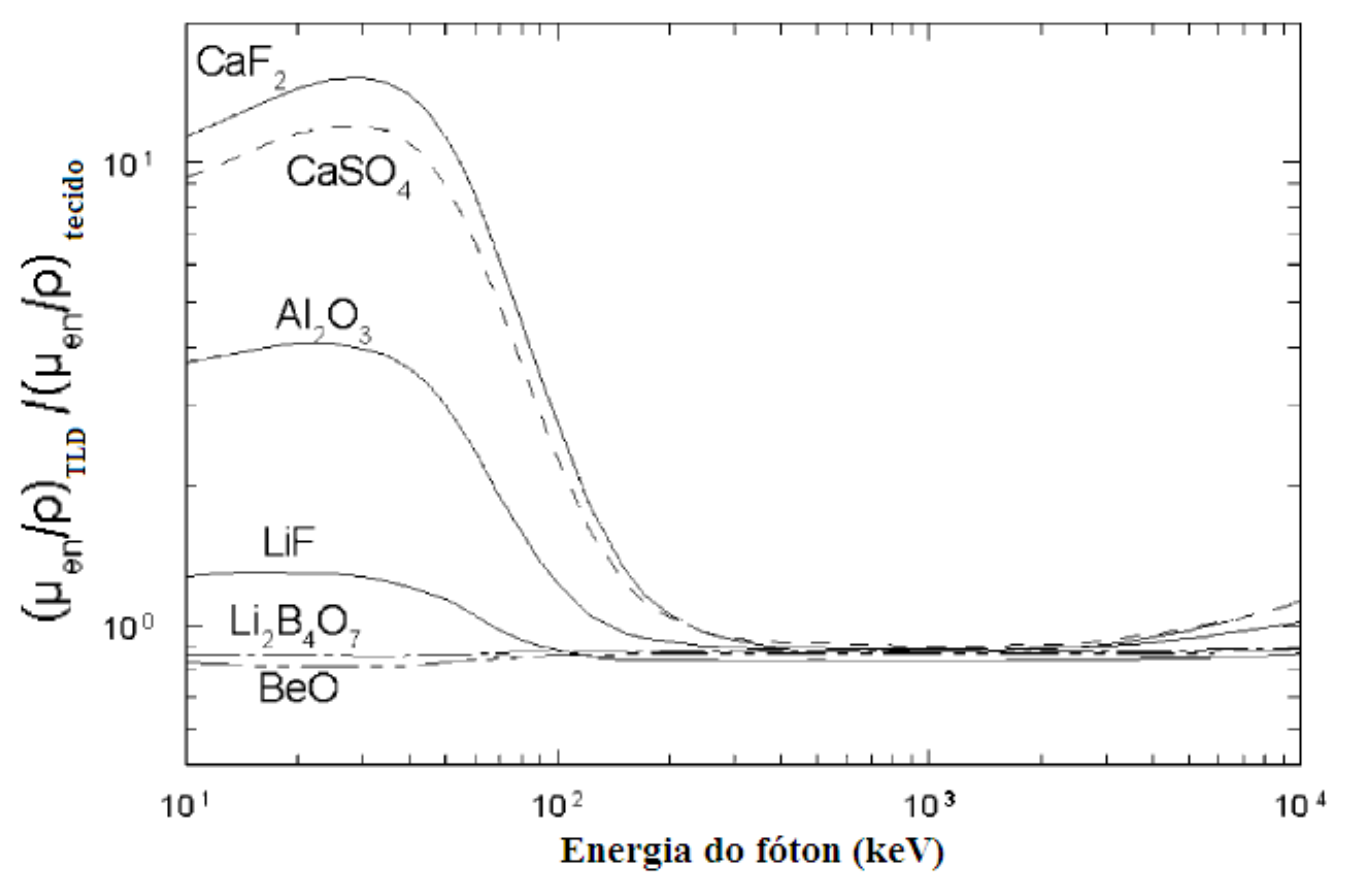

Figura 12 - Dependência energética de alguns dosímetros TL ${ }^{73}$. O material de referência é o tecido com número atômico efetivo de 7,35 


\subsection{Calibração dos dosímetros TL}

Os dosímetros TL são classificados como dosímetros relativos, pois para gerar as respostas em unidades de dose absorvida são necessárias calibrações com valores de dose absorvidas conhecidas. Se o tipo de dosímetro tiver um comportamento linear de resposta na faixa de dose absorvida utilizada, torna-se possível construir uma reta que estabelece a relação da dose absorvida por meio da resposta do dosímetro TL ${ }^{75}$. Deste modo, obtém-se um fator multiplicativo que converte a resposta do dosímetro em unidades de dose absorvida.

Para gerar este fator multiplicativo, ou fator de calibração, é comum irradiar estes dosímetros sob diferentes faixas de dose "conhecidas" ou rastreáveis com padrões metrológicos ${ }^{80}$. A calibração de dosímetros TL pode ser realizada por meio de fontes de Cobalto-60 ${ }^{81}$, Césio-137 ${ }^{82}$, aparelhos de raios-X ${ }^{20}$ e aceleradores lineares de mega voltagem $83,84,85$. Porém, fatores de correção devem ser utilizados caso haja a dependência energética entre o feixe calibração e o feixe a qual o dosímetro será submetido para a investigação dosimétrica. Campos mistos de radiações ionizantes requerem outras técnicas dosimétricas, neste trabalho os campos utilizados são compostos somente por fótons.

\subsection{Objetos Simuladores}

Os objetos simuladores são materiais constituídos com número atômico efetivo próximo ao da água e, consequentemente, do tecido humano. Para feixes de fótons ou de elétrons, em radioterapia, a água é recomendada como o meio de referência. Porém, para certos requisitos, alguns materiais, majoritariamente plásticos podem ser utilizados como substitutos da água, se as incertezas da dose absorvida entre o material e a água não ultrapassar a $1 \%{ }^{86,87}$.

Para a dosimetria de algumas fontes intersticiais de braquiterapia (principalmente aquelas com dimensões milimétricas), a dosimetria em meio com água torna-se complexa, pois o posicionamento dos dosímetros e da fonte em um meio aquoso gera elevadas incertezas no posicionamento destes elementos. Objetos simuladores sólidos contornam este tipo de inconveniente, oferecendo acurácia no posicionamento dos dosímetros e da fonte analisada.

A TAB. 5 mostra a composição atômica (percentual), a densidade ( $\rho$ ) e o número atômico médio $(\bar{Z})$ de alguns objetos simuladores. As siglas $S W, P W, V W$ e 
PMMA denotam Solid Water ${ }^{T M}$, Plastic Water $^{T M}$, Virtual Water $^{T M}$ e Polimetilmetacrilato, respectivamente ${ }^{20,88}$.

Tabela 5 - Composição atômica, densidade e número atômico médio utilizado em alguns objetos simuladores disponíveis no mercado ${ }^{88} \cdot{ }^{(1)}$ Calculado conforme as recomendações do ICRU-35 ${ }^{89}$

\begin{tabular}{c|ccccccc}
\hline Elementos & Água & $S W(\mathrm{RW} 1)$ & $S W(\mathrm{RW})$ & $P M M A$ & Poliestireno & $P W$ & $V W$ \\
\hline $\mathrm{H}$ & 0,1119 & 0,1319 & 0,0759 & 0,0805 & 0,0774 & 0,0925 & 0,0770 \\
$\mathrm{C}$ & - & 0,7941 & 0,9041 & 0,5998 & 0,9226 & 0,6282 & 0,6874 \\
$\mathrm{~N}$ & - & - & - & - & - & 0,0100 & 0,0227 \\
$\mathrm{O}$ & 0,8881 & 0,0381 & 0,0080 & 0,3196 & - & 0,1794 & 0,1886 \\
$\mathrm{Mg}$ & - & 0,0091 & - & - & - & - & - \\
$\mathrm{Cl}$ & - & - & - & - & - & 0,0096 & 0,0013 \\
$\mathrm{Ca}$ & - & 0,0268 & - & - & - & 0,0795 & 0,0231 \\
$\mathrm{Ti}$ & - & - & 0,0120 & - & - & - & - \\
$\mathrm{Br}$ & - & - & - & - & - & 0,0003 & - \\
$\rho\left(\mathrm{g} / \mathrm{cm}^{3}\right)$ & 1,000 & 0,970 & 1,050 & 1,190 & 1,060 & 1,013 & 1,030 \\
$\bar{Z}^{(1)}$ & 6,60 & 5,53 & 5,49 & 5,85 & 5,29 & 6,62 & 5,97 \\
\hline
\end{tabular}

A utilização destes objetos simuladores depende do tipo de radiação e da energia utilizada durante as irradiações. Dimensões e formatos destes objetos simuladores também dependem da aplicação, mas geralmente estes objetos simuladores apresentamse com formato quadrangular com diversas espessuras, para permitir o acoplamento de vários objetos simuladores e assim criar diversas profundidades, de acordo o arranjo experimental desejado ${ }^{90}$. 


\section{OBJETIVOS}

Estudar e pesquisar os requisitos e equipamentos básicos para a criação de um laboratório dosimétrico dedicado às análises dosimétricas e ao controle de qualidade para fontes de braquiterapia, em especial, com sementes de iodo-125.

Realizar as mensurações experimentais para os processos dosimétricos em sementes de iodo-125, seguindo as recomendações do protocolo TG-43.

Adequar e otimizar os procedimentos dosimétricos existentes e anteriormente estudados, visando a caracterização dosimétrica das sementes de iodo-125, comparando os resultados gerados com os valores contidos na literatura.

Avaliar se as etapas fundamentais do processo dosimétrico, utilizado neste trabalho, tais como: irradiação, leitura e tratamento térmico dos dosímetros; possuem as condições básicas para uso nas sementes de iodo-125.

Tornar o laboratório apto para a caracterização dosimétrica experimental e controle de qualidade, com as futuras de sementes de iodo-125 que serão produzidas pelo IPEN-CNEN/SP. 


\section{MATERIAIS E MÉTODOS}

\subsection{Infraestrutura - Dosimetria TL}

O processo TL pode ser dividido em três etapas fundamentais: irradiação, aquisição de dados e tratamento térmico dos dosímetros que serão reutilizados. Com estas premissas, o início deste trabalho foi centrado no desenvolvimento destas condições experimentais necessárias (irradiação, aquisição de dados e tratamento térmico dos dosímetros) para a realização da dosimetria TL.

Neste contexto, a irradiação dos dosímetros dependerá da sua finalidade, ou seja, poderá ser utilizada para a seleção dos dosímetros, para gerar os fatores de calibração e com as irradiações com as sementes de iodo-125 em si, para as análises dosimétricas e controle de qualidade. Assim as etapas de irradiação serão descritas conveniente dentro da sua finalidade. No entanto, para render resultados precisos e acurados, as demais etapas (aquisição de dados e tratamento térmico) deverão permanecer reprodutíveis e repetíveis durante todo o trabalho.

O Centro de Tecnologia das Radiações (CTR-IPEN-CNEN/SP) disponibilizou um espaço com área próxima a 25 metros quadrados para a implementação de um laboratório dedicado às análises dosimétricas das fontes de braquiterapia. Este espaço foi adaptado de forma a receber os equipamentos necessários para as análises dosimétrica.

A FIG. 13 mostra o espaço disponibilizado após a adaptação para um laboratório dosimétrico, com destaque para os principais dispositivos utilizados dentro do processo TL. As verificações das condições ambientais são importantes para a dosimetria TL, neste sentido, o laboratório adquiriu uma estação climática (Oregon Scientific Inc.) que avalia constantemente as condições de temperatura, pressão atmosférica e umidade relativa do ar. Durante todas as medidas dosimétricas, estes parâmetros foram registrados, se porventura surgirem discrepâncias em algumas mensurações, estes valores poderão ser consultados como possível fonte de incertezas de medição. A importância destes parâmetros climáticos concerne principalmente para a acurácia e precisão dos valores registrados na aquisição de dados TL.

Aparelhos para o controle das condições ambientais também foram utilizados. $\mathrm{O}$ controle da temperatura foi realizado por um ar condicionado e a umidade relativa do ar 
foi controlada por um desumificador, quando os níveis de umidade apresentavam índices muito elevados ( $>70 \%)$ para as medidas dosimétricas.
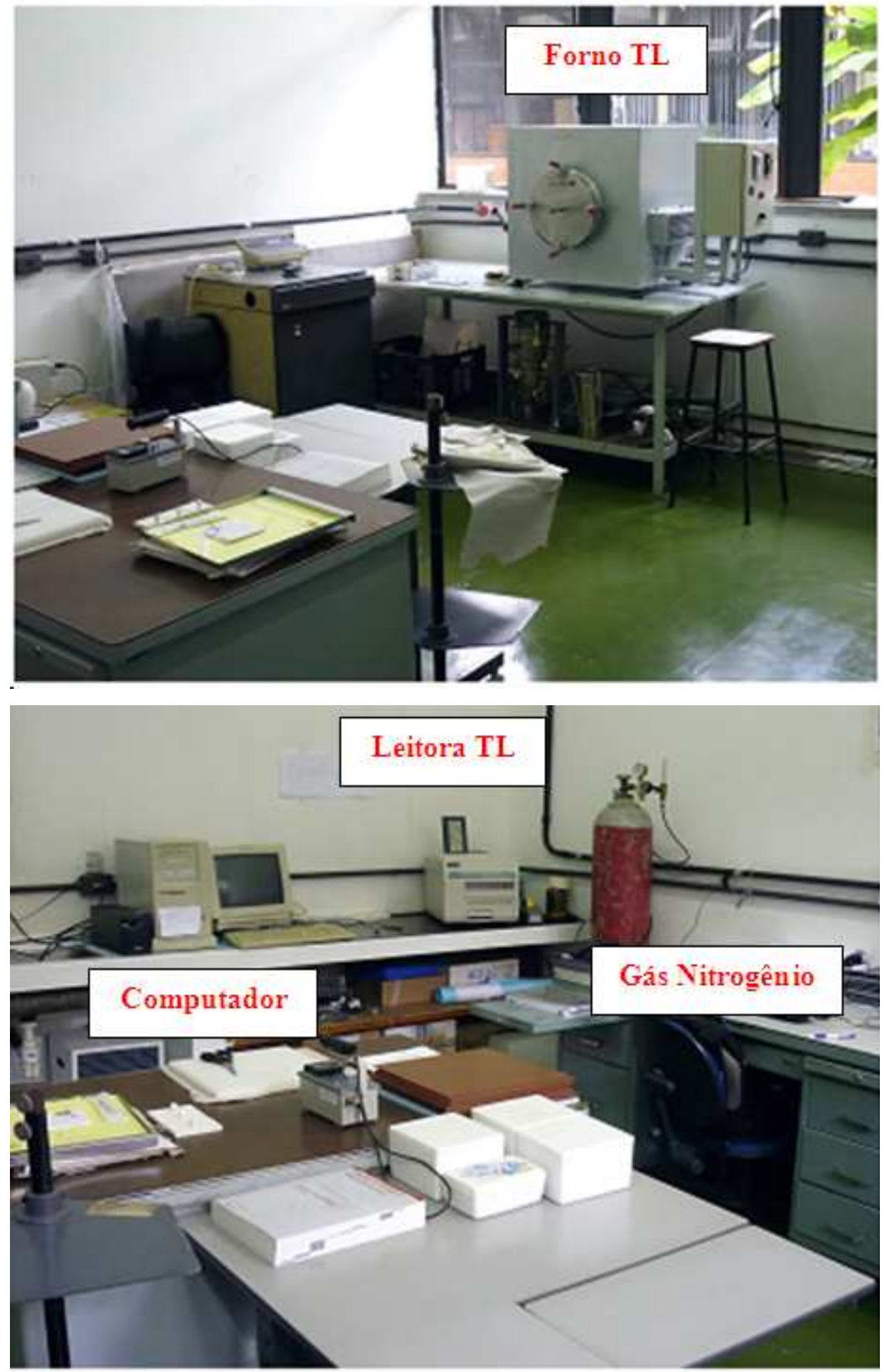

Figura 13 - Imagens do laboratório, após a adaptação para um laboratório dosimétrico, com destaque para os principais componentes para o processo TL 
Os níveis elevados de temperatura e umidade relativa do ar poderiam induzir incertezas elevadas na aquisição de dados pela leitora TL, principalmente para baixas doses registradas pelos dosímetros mensurados. Estes equipamentos para o controle das condições ambientais eram acionados mediante as indicações da estação climática.

\subsection{Dosímetros TLD-100}

Os dosímetros utilizados para as análises dosimétricas foram do tipo LiF:Mg,Ti (TLD-100), da empresa Harshaw-Bicron - Thermo Scientific, com formato cúbico de 1 milímetro de aresta. Estes dosímetros são comumente denominados como micro TLD100 ou simplesmente micro-cubes. As dimensões deste tipo dosímetro facilitam as obtenções dos parâmetros contidos no protocolo TG-43, pois estas dimensões além de produzirem baixa dependência direcional, são compatíveis com as dimensões milimétricas da fonte e evitam gradientes de dose dentro do dosímetro TL ${ }^{91}$.

A FIG. 14 mostra o dosímetro TLD-100 com dimensões de 3 x 3 x 0,89 mm e o dosímetro micro TLD-100, com uma régua graduada em centímetros para comparação. Nota-se, por meio da FIG. 14, que o dosímetro micro TLD-100 possui dimensões pequenas que tornam difícil a sua manipulação. Durante este trabalho, a manipulação destes dosímetros foi realizada somente com dois dispositivos, uma pinça a vácuo e uma pinça mecânica com pontas de politetrafluoretileno (Teflon ${ }^{\mathrm{TM}}$ ). A pinça a vácuo serve basicamente para o posicionamento dos TLD-100, nos orifícios do objeto simulador e para o transporte nos suportes de alumínio, que serão utilizados para o tratamento térmico dos dosímetros. A pinça mecânica foi utilizada durante a aquisição de dados dos dosímetros TL, com ela posicionava-se o dosímetro na "gaveta" que contém a resistência de aquecimento da leitora TL.

Apesar da manipulação cautelosa destes dosímetros, três dosímetros neste trabalho foram perdidos durante as diversas etapas realizadas. Estas perdas foram causadas por contato da pinça (a vácuo ou mecânica) com as extremidades dos objetos simuladores, sendo os dosímetros lançados fora do campo visual do manipulador. Devido às dimensões destes dosímetros, não fora possível encontrá-los posteriormente. 


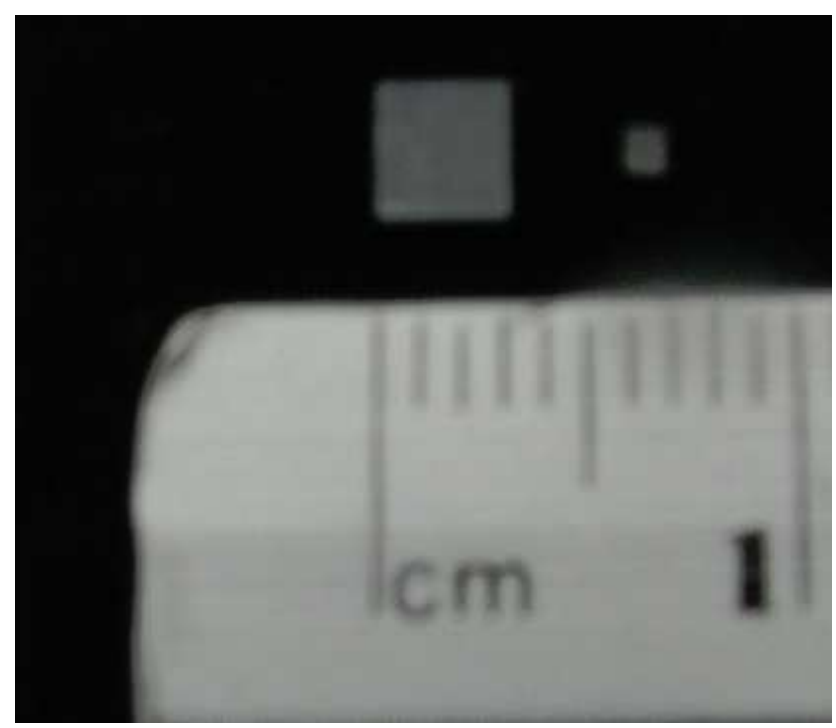

Figura 14 - Dosímetro TLD-100 (esquerda) junto com o micro TLD-100 utilizado neste trabalho

Neste trabalho, o IPEN-CNEN/SP adquiriu um lote com 204 dosímetros para as análises dosimétricas. Antes da utilização dosimétrica com sementes de iodo-125, este lote de dosímetros foi segregado para a escolha dos dosímetros com as melhores características (linearidade de massa, formato geométrico e reprodutibilidade), assim os dosímetros TLD-100 passaram pelas seguintes etapas:

1. Seleção por meio da massa dos dosímetros: Os 204 dosímetros tiveram suas massas mensuradas em uma balança analítica (Mettler Toledo modelo AB3045), com divisão 0,1 mg, situada no CTR-IPEN-CNEN/SP. Cada dosímetro teve sua massa mensurada três vezes consecutivas, a média destas respostas eram comparadas com os valores médios dos demais dosímetros. Os dosímetros que tiveram massas registradas discrepantes, comparadas com a média do lote foram retirados dos processos de analise dosimétrica posteriores.

2. Seleção pela homogeneidade do formato geométrico dos dosímetros: O formato geométrico dos dosímetros revela-se importante para critérios de manipulação e aquisição de dados dos dosímetros TL. Neste trabalho, o formato geométrico dos dosímetros foi avaliado e aqueles que tiveram as dimensões fora do padrão recomendado pelo fabricante (formato cúbico) não foram utilizados nas analises subseqüentes. 
3. Seleção por reprodutibilidade de resposta TL: Sob as mesmas condições experimentais de irradiação, os dosímetros TL devem render respostas muito próximas umas das outras, ou seja, apresentar um alto grau de reprodutibilidade. Os dosímetros selecionados nas etapas anteriores foram submetidos a séries de irradiações com uma fonte de Cobalto-60. Os dosímetros que apresentaram os maiores níveis de reprodutibilidade, sob as mesmas condições experimentais, foram os dosímetros selecionados para as futura análises dosimétricas.

Após a realização das etapas anteriores, os dosímetros selecionados estão aptos para a obtenção dos fatores de calibração e para a realização das demais análises dosimétricas.

\subsection{Leitora TL}

Para a aquisição das respostas TL dos dosímetros, o IPEN-CNEN/SP fez a aquisição de uma leitora TL Harshaw (Thermo Electron), modelo 3500. Este aparelho realiza a leitura de um dosímetro por posicionamento (operada manualmente) e possui uma interface computacional que é controlada por um software denominado WINREMS (Windows ${ }^{\circledR}$ - based Radiation Evaluation and Management System) ${ }^{92}$.

Em suma, este aparelho é composto por um suporte metálico que comporta os dosímetros (planchet), este suporte serve para aquecer os dosímetros até as temperaturas programadas; o aquecimento é realizado por meio de um contato ôhmico e pode operar sob diversas taxas de aquecimento. O tubo fotomultiplicador, ou simplesmente fotomultiplicadora, coleta a luminescência emanada transformando-a em unidades de carga elétrica, onde a resposta é transmitida ao computador que realiza os controles da leitora TL e armazena os dados das respostas TL.

A FIG. 15 mostra uma tela do software WINREMS durante a aquisição de dados de um dosímetro TL. Esta curva compreende a intensidade da resposta TL (eixo à esquerda) em função dos canais fotomultiplicadora. A curva TL, área em azul, denota o formato do espectro do dosímetro TL (neste exemplo, TLD-100); a linha vermelha representa a taxa de aquecimento realizado no dosímetro (na FIG. 15 até $260{ }^{\circ} \mathrm{C}$ ).

As informações sobre a intensidade da resposta TL são apresentadas em uma caixa de texto, a esquerda do espectro TL. Esta caixa contém o valor total de intensidade acumulada (área total) e os valores das regiões de interesse (Region Of 
Interest - ROI) que são ajustáveis pelo usuário e são úteis as verificações em certas regiões dos espectros TL. Nesta caixa também apresenta a etapa em que a leitora e a temperatura se encontram, na FIG. 15 ela encontra-se no modo de resfriamento (cooling) com $129{ }^{\circ} \mathrm{C}$; a voltagem da fotomultiplicadora - 859 volts e a corrente de fuga do sistema da fotomultiplicadora ( $8 \mathrm{pA}$ ).

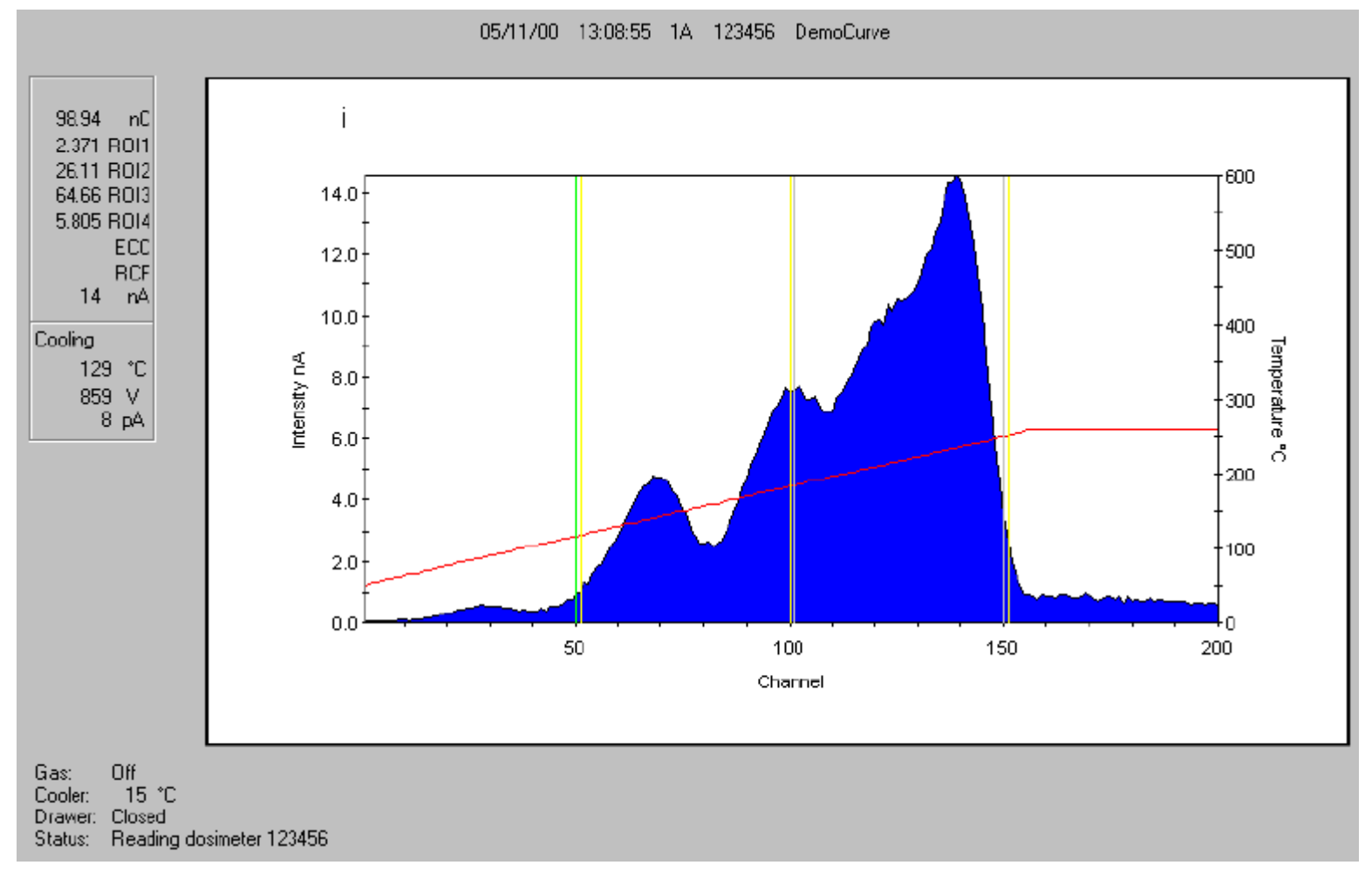

Figura 15 - Espectro TL gerado pelo software WINREMS e visualizado pelo monitor do computador, durante a utilização da leitora Harshaw 3500

Também é possível notar outras informações sobre a leitora TL (canto esquerdo inferior), uma das informações registradas é o se gás nitrogênio está acionado ou não; a temperatura do resfriador (cooler), tal resfriador possuí a função de diminuir a temperatura do contato ôhmico; o posicionamento do suporte que aloja os dosímetros (aberto, entreaberto ou fechado) e o status da leitura do dosímetro (leitura em andamento ou encerrada).

Neste trabalho, além das informações sobre o status no decorrer de cada medida, o valor da intensidade TL total, em nC, foi a informação utilizada para as respostas TL. As características e o formato do espectro não foram abordados. Os parâmetros de tratamento térmico, temperatura e taxa de aquecimento foram constantes durante todo o desenvolvimento deste trabalho. 
Durante a leitura dos dosímetros TL foi utilizado um fluxo de gás nitrogênio sobre a amostra $(99,9995 \%$ de pureza) com vazão constante de 1 litro por minuto e com controladores de pressão, conforme recomenda o manual da leitora TL. Este gás serve para minimizar a umidade formada na janela do tubo fotomultiplicador e também auxiliar no resfriamento do contato ôhmico da leitora TL, estes fenômenos são fundamentais para sinais com baixa magnitude, ou seja, para baixas doses absorvidas ${ }^{92}$.

No início das operações com a leitora TL foi notado um alto índice de sinais espúrios devido as variações da rede elétrica. Para minimizar tal efeito, o IPENCNEN/SP adquiriu um estabilizador com potência de 600 watts (SMS Net Station 600 VA), que permite uma alimentação elétrica na leitora TL mais regular e se por ventura, durante as análises dosimétricas cessarem a energia elétrica do laboratório, este estabilizador permanecerá ligado por alguns minutos. Após a aquisição deste estabilizador, os índices de corrente de fuga ficaram dentro da normalidade.

Esta leitora também possui dois modos para o controle da qualidade e acurácia da leitora, no decorrer das medidas dosimétricas, estes modos são descritos como PhotoMultiplicator Noise (PMT Noise) e Reference Light.

O PMT Noise, ou corrente escura, mensura a corrente de fuga mensurada pela fotomultiplicadora sem nenhum dosímetro, ou seja, com o contato ôhmico vazio. Além de verificar a corrente de fuga do sistema eletrônico, ela também detecta possíveis fugas de luz no interior da leitora TL. Neste trabalho utilizou-se o valor preconizado pelo fabricante para o nível médio da corrente de fuga, $400 \mathrm{pC}$, acima deste valor a leitora paralisa suas funções e questiona ao operador se deseja continuar ou refazer as medidas dosimétricas. O PMT Noise é realizado durante 10 segundos, com o suporte do contato ôhmico "quase" fechado e durante o início de cada leitura, com intervalos de 10 leituras sucessivas.

A reference light consiste de uma fonte de luz posicionada em frente à fotomultiplicadora, esta luz emite uma luminosidade constante na direção da janela da fotomultiplicadora. Serve para indicar o funcionamento do tubo fotomultiplicador e constatar possível sujeira na janela da fotomultiplicadora. A reference light também é realizada durante 10 segundos, com o suporte do contato ôhmico plenamente aberto e durante o início de cada leitura, com intervalos de 10 leituras sucessivas.

Em todas as medidas TL os valores de PMT Noise e reference light foram anotados e analisados para as analises de possíveis discrepâncias. Ressalta-se que esses 
controles de qualidade citados são optativos, pois o funcionamento das leituras TL são independentes destes testes ${ }^{92}$.

Os parâmetros de aquisição de dados, referentes aos dosímetros TL-100, utilizados neste trabalho foram escolhidos conforme a recomendação do fabricante para o tipo de dosímetro, volume e formato do dosímetro utilizado. Os valores utilizados durante todas as etapas deste trabalho estão representados na TAB. $6^{93}$.

Tabela 6 - Valores utilizados para aquisição de dados na leitora TL, utilizando o TLD100 cúbico com $1 \mathrm{~mm}^{3}$

\begin{tabular}{cc}
\hline Características de aquisição dos dados TL & Valores \\
\hline Temperatura de pré-aquecimento & $50{ }^{\circ} \mathrm{C}$ \\
Taxa de aquecimento & $10{ }^{\circ} \mathrm{C} / \mathrm{s}$ \\
Temperatura máxima de aquecimento & $260{ }^{\circ} \mathrm{C}$ \\
Tempo de aquecimento & $26 \mathrm{~s}$ \\
Tempo de pós-aquecimento & $0 \mathrm{~s}$ \\
\hline
\end{tabular}

Na TAB. 6, a temperatura de pré-aquecimento denota a temperatura até que o dosímetro será aquecido, porém sem ter o seu sinal TL registrado, esta temperatura serve para reduzir os efeitos dos picos de baixa meia vida; a taxa de aquecimento mostra a "velocidade" de aquecimento; a temperatura máxima de aquecimento mostra a temperatura máxima que o dosímetro será aquecido; tempo de aquecimento (razão da temperatura máxima de aquecimento pela taxa de aquecimento) e tempo de pósaquecimento não utilizado, pois todos os dosímetros sempre foram submetidos a tratamentos térmicos, após as leituras TL.

Contabilizando o período de posicionamento, aquecimento e resfriamento de cada dosímetro TL, o tempo gasto para realizar todo o processo leva cerca de 3 minutos, sem considerar o tempo gasto para a realização dos controles de qualidade, entre leituras. Os dados das respostas TL dos dosímetros mensurados são armazenados na leitora e também podem ser exportados, em formato ASCII (formato texto), assim os arquivos exportados podem ser convertidos no formato desejável e analisados posteriormente. 


\subsubsection{Intercomparações - Leitora TL}

Para verificar a linearidade de resposta TL foram realizadas intercomparações com a leitora Harshaw TL, modelo QS3500, do setor de radioterapia do Hospital Israelita Albert Einstein (HIAE). Estas intercomparações foram realizadas irradiando os dosímetros TLD-100 com doses conhecidas. As leituras foram realizadas tanto na leitora TL do CTR-IPEN-CNEN/SP, como na leitora do HIAE. Com estas intercomparações é possível verificar quaisquer anormalidades na resposta TL, provenientes da fotomultiplicadora, do contato ôhmico e do tratamento térmico dos dosímetros pós-irradiação.

A leitora TL do HIAE possui alguns anos de utilização (se comparada com a leitora adquirida pelo IPEN-CNEN/SP) em dosimetria in vivo e demais verificações dosimétricas; seu comportamento é conhecido e aferido por diversos controles de qualidade da instituição, tornando-se um equipamento adequado para comparações com a leitora do IPEN-CNEN/SP.

\subsection{Tratamento Térmico dos Dosímetros}

O IPEN-CNEN/SP dispõe um forno manufaturado sob recomendações especiais, para o tratamento térmico dos dosímetros TLD-100 utilizados neste trabalho. O forno manufaturado pela empresa Grion Fornos Industriais é constituído por um cilindro de aço que permite a acomodação dos suportes dos dosímetros e com resistências espiraladas externas a este cilindro para a realização do aquecimento. Este forno também possui um soprador de ar para auxiliar e homogeneizar o resfriamento do cilindro de aço, quando necessário. A FIG. 16 ilustra o forno como detalhes para o resfriador, o cilindro de aço, onde o aquecimento é realizado e o controlador eletrônico, que realiza todas as funções de aquecimento, tempo de aquecimento, resfriamento e tempo de resfriamento.

O controle da temperatura interna do cilindro de aço é realizado por um sensor de temperatura (termopar tipo $\mathrm{K}$ ) com incerteza de medição próxima a $1,7{ }^{\circ} \mathrm{C}$, calibrado por um laboratório metrológico devidamente credenciado ${ }^{94}$. Conforme a programação de aquecimento ou resfriamento, inserida pelo operador, as temperaturas e o período são realizadas automaticamente pelo controlador eletrônico do forno. A temperatura máxima que este forno pode chegar é $600{ }^{\circ} \mathrm{C}$ e, a desejo do operador, pode ter a atmosfera interna ao cilindro de aço controlada. 
O tratamento térmico adotado para os dosímetros TLD-100 é composto de duas etapas: a primeira com temperatura de $400{ }^{\circ} \mathrm{C}$ por uma hora e $100{ }^{\circ} \mathrm{C}$ por duas horas. A função básica do resfriador é acelerar o processo de resfriamento $\left(400{ }^{\circ} \mathrm{C}\right.$ para $\left.100{ }^{\circ} \mathrm{C}\right)$, torná-lo automático e consequentemente realizar o tratamento térmico de modo mais reprodutível.

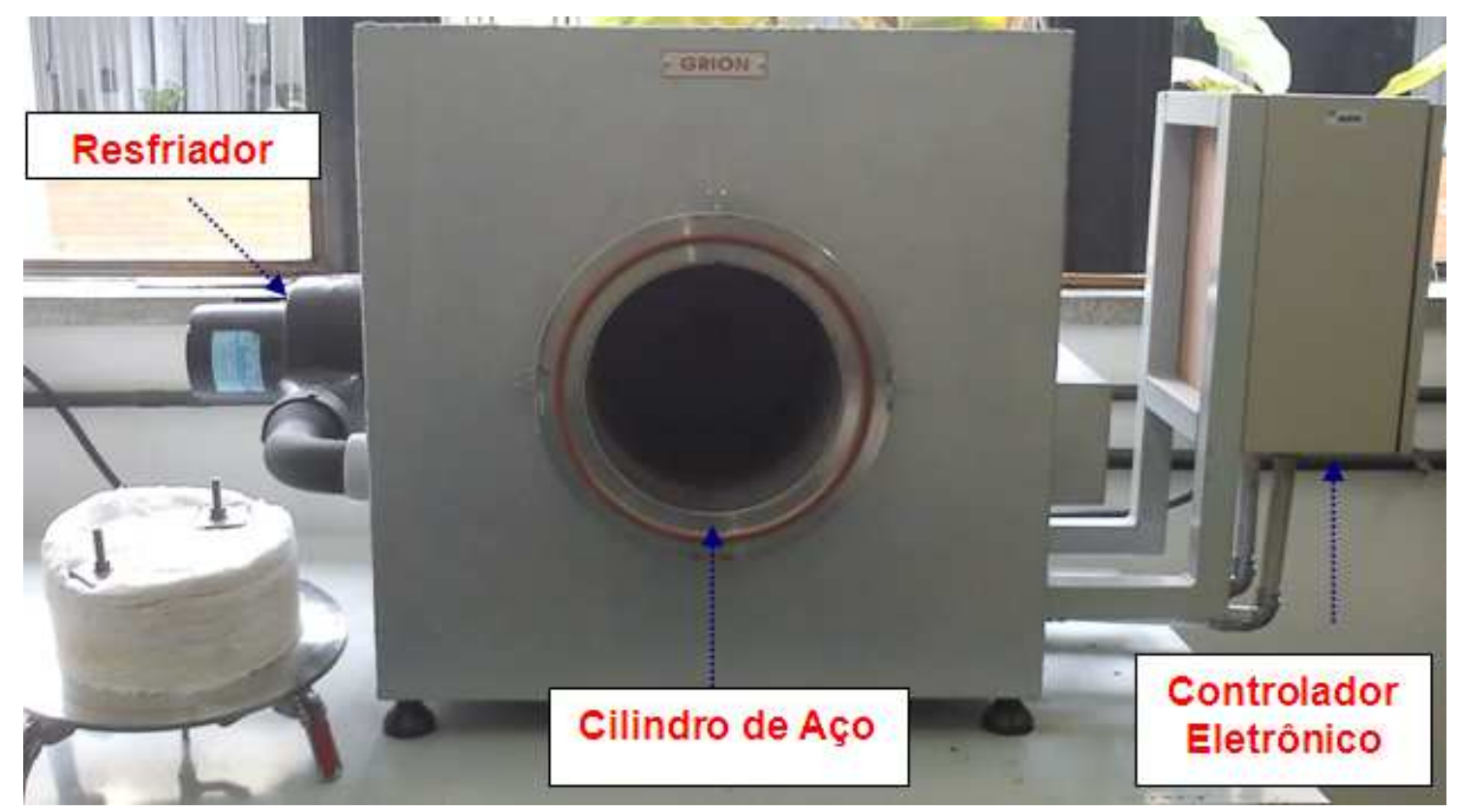

Figura 16 - Forno utilizado para o tratamento térmico dos TLD-100 com os componentes principais indicados

O tempo (gradiente) de resfriamento deste forno equivale a $3,66 \pm 0,15^{\circ} \mathrm{C} / \mathrm{min}$, este gradiente é alcançado somente com o acionamento do resfriador.

Todos os dosímetros foram tratados termicamente em suportes retangulares de alumínio puro, manufaturados pelo IPEN-CNEN/SP, com capacidade máxima de 63 dosímetros por suporte. Em todos os suportes, há perfurações individuais para cada dosímetro, evitando assim a troca de posicionamento dos dosímetros entre si.

\subsection{Objetos Simuladores}

Os objetos simuladores utilizados neste trabalho foram adquiridos pela empresa PTW-Freiburg e são denominados como Solid Water $^{T M}$ modelo RW1 (geralmente são também conhecidos como água sólida). O objeto simulador RW1 é composto por polietileno branco com óxido de magnésio e carbonato de cálcio, possui densidade e número atômico médio, próximos a 0,97 g/ $\mathrm{cm}^{3}$ e 5,53; respectivamente (ver TAB. 5). 
Este objeto simulador foi o escolhido neste trabalho pois é ideal para baixas energias $(<100 \mathrm{kV}){ }^{95}$ tornando-se o mais apto para a realização das análises dosimétricas em sementes de iodo- $125^{96}$, que possui energia média de $27,34 \mathrm{keV}^{23}$.

Para este trabalho foram disponibilizados 5 objetos simuladores em formato de placas, com $30 \mathrm{~cm}$ de comprimento, $30 \mathrm{~cm}$ de largura e $2 \mathrm{~cm}$ de espessura. Para propiciar o posicionamento preciso e acurado dos dosímetros e das sementes de iodo125, três objetos simuladores tiveram uma de suas superfícies usinadas, conforme as geometrias necessárias para a obtenção dos parâmetros dosimétricos referente às sementes de iodo-125 (ver FIG. 23 e FIG. 24). Durante as irradiações, os outros objetos simuladores, que não tinha os dosímetros posicionados, foram utilizados para propiciar as condições de espalhamento. Os objetos simuladores foram utilizados em todas as etapas de trabalho que demandavam a irradiação dos dosímetros TL e não somente para as análises dosimétricas com as sementes de iodo-125.

\subsection{Seleção dos Dosímetros - Irradiador de Cobalto-60}

Após a seleção dos dosímetros quanto a massa e à homegeneidade do formato geométrico, foi realizada a seleção sobre a homogeneidade de resposta TL. Para esta seleção foi utilizado um irradiador de Cobalto-60 tipo panorâmico, situado no CTRIPEN-CNEN/SP, da empresa Yoshizawa Kiko Company modelo FIS60-04, com atividade aparente da fonte de $15,74 \mathrm{TBq}(425,40 \mathrm{Ci})$.

Nesta seleção, todos os dosímetros foram submetidos a cinco séries de irradiações, porém a primeira série não foi utilizada para as análises estatísticas, pois esta primeira série serviu somente para ajudar alguns parâmetros experimentais de posicionamento dos objetos simuladores, procedimento de leitura dos dosímetros e permutação dos dosímetros entre as irradiações. A quantidade de séries foi escolhida para mostrar a reprodutibilidade dos dosímetros TL utilizados, nesta etapa não houve a preocupação com a sensibilidade do lote de dosímetros, pois estes dosímetros serão calibrados individualmente, rendendo assim um fator de calibração individual.

Os dosímetros utilizados nesta seleção (200 dosímetros) foram posicionados nos orifícios usinados na superfície do objeto simulador. Estes orifícios foram numerados e os dosímetros foram posicionados de modo repetível, sendo possível rastreá-los individualmente durante todo o processo de seleção e para os processos futuros. 
O objeto simulador utilizado (com a superfície usinada) para as irradiações com a fonte de Cobalto-60, possui 108 posições. Como havia 200 dosímetros a serem irradiados, primeiramente posicionavam-se os 108 dosímetros para a primeira parte da irradiação; após esta primeira parte, os dosímetros irradiados eram armazenados em suportes plásticos individuais, também numerados. Os 92 dosímetros remanescentes eram posicionados para a conclusão da segunda parte da irradiação. $O$ intervalo de tempo médio para a retirada dos 108 dosímetros do objeto simulador e o posicionamento dos 92 dosímetros para a irradiação foi de aproximadamente 35 minutos.

Todas as séries de irradiações foram realizadas para submeter os dosímetros a 60 cGy de dose absorvida. Este valor de dose foi selecionado, pois a resposta do TLD-100 encontra-se em uma região de resposta linear ${ }^{69}$, para proporcionar este valor de dose absorvida, os objetos simuladores foram posicionados a $50 \mathrm{~cm}$ do centro geométrico do irradiador panorâmico, para assegurar a repetibilidade do posicionamento dos objetos simuladores, a sua posição no local de irradiação foi demarcada com caneta marcador pincel.

Durante cada uma das cinco séries de irradiações, o tempo de exposição da fonte de Cobalto-60 era de 122 segundos e devido ao intervalo de sete dias para a realização das cinco séries de irradiações, não foram utilizados fatores de correções para o decaimento da fonte de Cobalto-60. Para gerar as condições de equilíbrio eletrônico, um objeto simulador extra, foi posicionado a frente do objeto simulador que aloja os dosímetros TL. A FIG. 17 mostra como as cinco séries de irradiações foram realizadas.

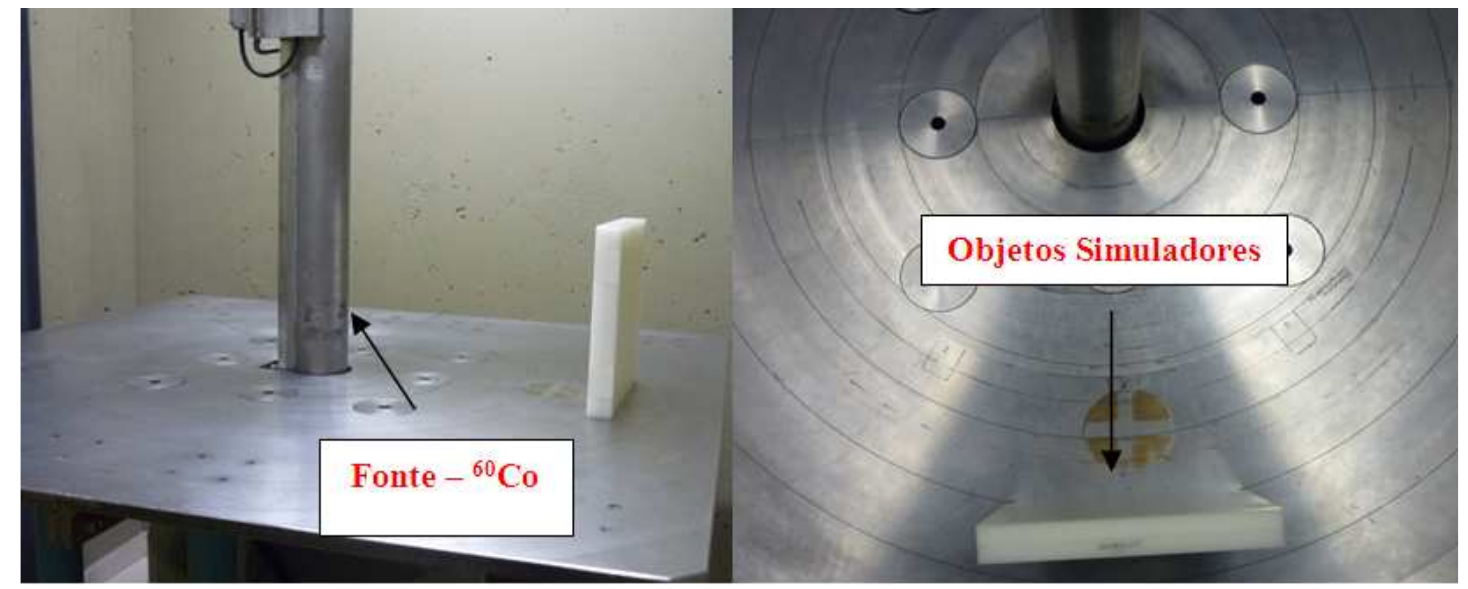

Figura 17 - Procedimento experimental para as irradiações com o irradiador Cobalto-60 


\subsection{Métodos de seleção}

Após a conclusão das séries de irradiações com o irradiador de Cobalto-60, fazse necessário estabelecer um critério para a seleção dos dosímetros com as melhores características. Há dois critérios básicos antes da seleção propriamente dita: quantos dosímetros estão disponíveis para a seleção e a quantidade de dosímetros que devem ser selecionados. A quantidade de dosímetros a serem utilizados para as etapas futuras deve considerar alguns aspectos básicos:

- Quantidade de dosímetros utilizados para as análises dosimétricas: Verificar a quantidade necessária para cada ensaio;

- Dosímetros sobressalentes: Caso os dosímetros em utilização sejam perdidos;

- Dosímetros de controle: Para medições dos níveis de background e condições de leitura;

Com a estimativa da quantidade de dosímetros necessários realizada, torna-se importante definir por qual método a sua escolha irá se basear. Neste trabalho foram analisados três métodos, para a seleção dos dosímetros. Os métodos utilizados são apresentados a seguir e explicados nas próximas seções:

1. Método recomendado pelo International Electrotechnical Comission (IEC) ${ }^{97}$;

2. Método das médias ajustadas (MA) ${ }^{20}$;

3. Método dos desvios padrões percentuais (DPP) ${ }^{97}$.

No item resultados, será discutido qual destes três métodos foram escolhidos para a seleção dos dosímetros.

\subsubsection{Método IEC}

Método utilizado em dosimetria pessoal e válido somente para dosímetros de mesmo material e sob condições idênticas de tratamento térmico. Os dosímetros devem ser irradiados com a mesma dose, utilizando uma fonte de raios gama, com o equilíbrio eletrônico apropriado. A equação 10 mostra o algoritmo de seleção deste método ${ }^{97}$. 


$$
\Delta_{\max }=\frac{(\bar{M})_{\max }-(\bar{M})_{\min }}{(\bar{M})_{\min }} \cdot 100 \leq \delta
$$

Onde: $\Delta_{\max }$ - Índice de uniformidade do lote;

$(\bar{M})_{\max }$ - Resposta líquida (subtraindo o background) máxima, ou seja, maior resposta TL dos dosímetros disponíveis no lote;

$(\bar{M})_{\min }$ - Resposta líquida (subtraindo o background) mínima, ou seja, menor resposta TL dos dosímetros disponíveis no lote;

$\delta$ - Valor atribuído ao índice de uniformidade do lote.

Com os valores da maior e menor resposta TL do lote, utiliza-se a equação 10, se o índice de uniformidade do lote $\left(\Delta_{\max }\right)$ ficar maior do que valor $\delta$, excluem-se estes dosímetros da analise. Após a exclusão destes dosímetros, escolhem-se os dosímetros com os valores de maior e menor resposta TL; utiliza-se a equação 10 e compara o valor obtido com $\delta$, se o valor ainda permanecer maior do que $\delta$, estes dosímetros são excluídos da analise e repete-se o processo até o que índice de uniformidade do lote atinja um valor menor ou igual a $\delta$.

\subsubsection{Método MA}

Este método sugere que a seleção dos dosímetros seja baseada pelo critério das médias ajustadas. O procedimento para a seleção dos dosímetros, utilizando este método é descrito a seguir ${ }^{20}$ :

Após as séries de medidas, calcula-se a média de cada seqüência de medidas, equação 11.

$$
\text { Média }_{i}=\frac{\sum \text { medidas }}{n}
$$

Onde: $\mathrm{n}$ - quantidade inicial de dosímetros a serem selecionados.

i - quantidade de irradiações (séries).

Após, divide-se cada medida dos dosímetros TL pela média calculada, isto irá gerar a média ajustada, como representada pela equação 12. 


$$
\text { Medida Ajustada }=\frac{\text { Medida }}{\text { Média }_{\mathrm{i}}}
$$

A partir das medidas ajustadas (de cada dosímetro e em cada série), calcula-se a média das quantidades de medidas séries realizadas e o desvio padrão amostral da quantidade de séries, conforme equação 13 e 14, respectivamente.

$$
\begin{gathered}
\text { Média Ajustada }=\frac{\sum \text { medida ajustada }}{\mathrm{q}} \\
\sigma=\left(\frac{\sum(x-\bar{x})^{2}}{(n-1)}\right)^{0,5}
\end{gathered}
$$

Onde: q - quantidade de séries de irradiações realizadas.

Deste modo, cada dosímetro do lote a ser selecionado terá um valor para a média ajustada, com o seu respectivo desvio padrão amostral. Este desvio padrão é normalizado com a média ajustada (coeficiente de variação), conforme a equação 15.

$$
\sigma_{\text {nor }}=\left[\frac{\sigma_{j}}{\text { médiaajustada }}\right] \cdot 100
$$

Onde: $\sigma_{n o r}$ - Desvio padrão normalizado (\%);

$\sigma_{j}$ - Desvio padrão amostral dos j dosímetros disponíveis.

O desvio padrão normalizado obtido de todos os dosímetros disponíveis para a seleção é comparado com um valor percentual, escolhido pelo operador (arbitrário), onde os dosímetros que ficarem acima deste valor arbitrário serão excluídos ${ }^{20}$.

\subsubsection{Método DPP}

Este método baseia-se simplesmente no desvio padrão normalizado das séries de medidas realizadas. O desvio padrão normalizado (coeficiente de variação), ou desvio padrão percentual (DPP) é obtido através da equação $16^{98}$.

$$
s_{j}=\frac{\sigma_{j}}{\bar{M}_{j}} \cdot 100
$$

Onde: $s_{j}$ - desvio padrão normalizado dos $j$ dosímetros disponíveis; 
$\sigma_{j}$ - desvio padrão de cada dosímetro, obtido após as séries de irradiações;

$\bar{M}_{j}$ - Média aritmética da resposta TL de cada dosímetro, após as séries de irradiações.

Os desvios padrões normalizados dos dosímetros são comparados com um valor percentual, também escolhido pelo operador (arbitrário). Os dosímetros que ficarem acima deste valor serão os dosímetros excluídos.

A quantidade selecionada de dosímetros esta diretamente associada com o número de dosímetros disponíveis para a escolha e com a quantidade de dosímetros necessária para as análises dosimétricas e demais etapas, não sendo assim uma quantidade fixa ou pré-determinada.

\subsection{Fatores de Calibração dos Dosímetros TLD-100}

As respostas fornecidas pelos dosímetros termoluminescentes são relativas, deste modo faz-se necessário irradiá-los com feixes de radiação ionizantes devidamente calibrados (com valores de dose absorvida conhecidos e rastreáveis por padrões metrológicos). Com este procedimento, as respostas relativas dos dosímetros são convertidas em grandezas físicas específicas, que são do interesse para as mensurações dosimétricas ${ }^{80,97}$.

Neste trabalho, optou-se por utilizar um equipamento, que dentre várias características, possui a capacidade de fornecer uma dose absorvida precisa, acurada e rastreável com padrão metrológico. Os aceleradores lineares, utilizados para tratamento clínico em hospitais, são os equipamentos que satisfazem as características anteriormente descritas.

Foram utilizados dois aceleradores lineares para a geração dos fatores de calibração, ambos fabricados pela empresa Varian Medical Equipaments. Os modelos utilizados foram o Clinac $6 E X$ e o Clinac 23EX, situados no setor de radioterapia do Hospital Israelita Albert Einstein (HIAE) - São Paulo. Somente fótons de 6 MV foram utilizados para a geração dos fatores de calibração dos dosímetros. A dose entregue por estes aparelhos é monitorada e aferida constantemente por diversos equipamentos e supervisionado por diversos controles de qualidade e testes de acurácia, mostrando-se 
uma boa escolha para a determinação das doses absorvidas nos dosímetros utilizados neste trabalho.

Uma câmera de ionização tipo Farmer, fabricado pela empresa IBA modelo FC65 acoplado ao um eletrômetro Max 4000 da empresa Standard Imaging, ambos rastreáveis com um laboratório secundário da Gerência de Metrologia das Radiações (GMR-IPEN) são utilizados para garantir que a dose entregue ao volume desejado possua no máximo 3,0 \% de incerteza total. A aferição de todos os parâmetros envolvidos nestes aceleradores lineares é baseada utilizando a água como meio de verificação, seguindo as recomendações contidas no protocolo TRS-398 ${ }^{86}$.

No total foram realizadas nove irradiações com os dosímetros selecionados, onde três valores de dose absorvida foram escolhidos. Cada valor de dose absorvida foi realizado três vezes, sem quaisquer alterações nas condições experimentais. Dentre as nove irradiações realizadas, somente uma delas fora realizada no acelerador linear Clinac 23EX, as demais foram feitas no aparelho Clinac 6EX. Os valores de dose absorvida escolhidos foram determinados para abranger a região linear do dosímetro e estimados conforme os níveis de dose absorvida que serão possivelmente registrados pelas sementes de iodo-125 durante as análises dosimétricas. As doses nominais escolhidas foram 105, 52 e $10 \mathrm{cGy}$.

A FIG.18 ilustra como os dosímetros foram irradiados para a geração dos fatores de calibração. Nestas irradiações foram utilizados quatro objetos simuladores Solid Water $^{T M}$, sendo um objeto simulador (usinado) utilizado para o posicionamento dos dosímetros TLD-100 selecionados; um posicionado acima do objeto simulador que comporta os dosímetros, para criar condições próximas a regiões de dose máxima $(\sim 1,5$ $\mathrm{cm}$ para fótons de $6 \mathrm{MV}$ e campos quadrados de $20 \mathrm{~cm}$ de aresta) ${ }^{6}$; e dois objetos simuladores posicionados abaixo do objeto simulador que comporta os dosímetros para propiciar condições de espalhamento.

A TAB. 7 mostra os parâmetros e os seus respectivos valores que foram utilizados para as irradiações dos dosímetros TLD-100 nas faixas de dose escolhidas neste trabalho. Estas condições foram fielmente mantidas durante todas as irradiações. O posicionamento do objeto simulador e dos dosímetros foram idênticos em todas as irradiações, para isto as cavidades que abrigam os dosímetros foram demarcadas numericamente. 


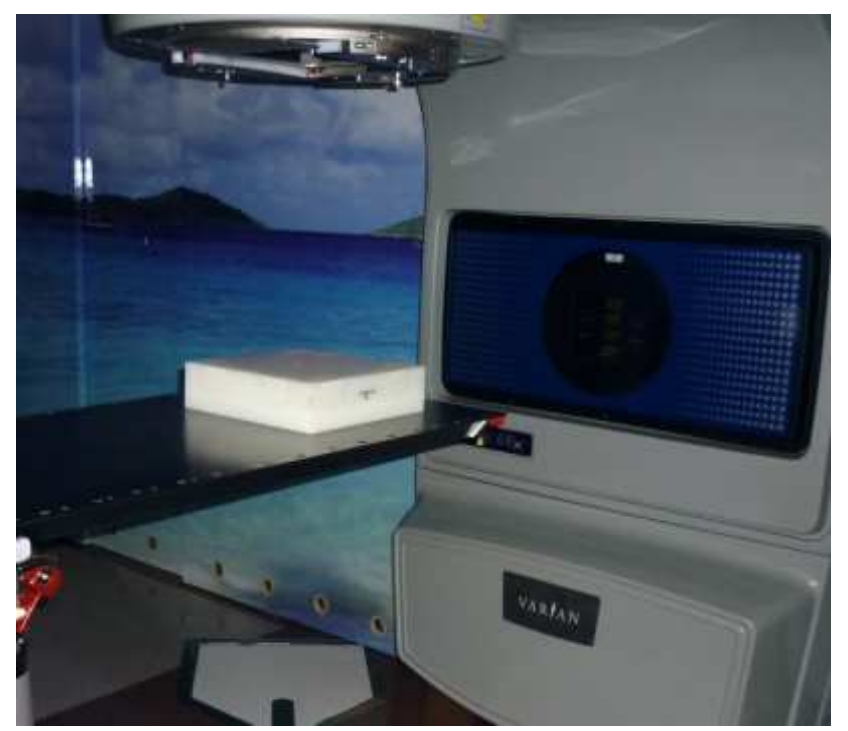

Figura 18 - Posicionamento dos objetos simuladores para as irradiações dos dosímetros TLD-100

Tabela 7 - Parâmetros utilizados durante as irradiações dos dosímetros TLD-100

\begin{tabular}{cc}
\hline Parâmetros utilizados & Valores \\
\hline Campo de Irradiação na superfície & $20 \times 20 \mathrm{~cm}$ \\
Rotação do gantry & 180,0 graus \\
Distância fonte-superfície $(S S D)$ & $100 \mathrm{~cm}$ \\
Taxa de Dose & $300 \mathrm{cGy} / \mathrm{min}$ \\
Temperatura & $21,0 \pm 0,5^{\circ} \mathrm{C}$ \\
Umidade relativa do ar & $55 \pm 1 \%$ \\
\hline
\end{tabular}

Com o objetivo de ter maior acurácia e precisão nos fatores de calibração dos dosímetros TLD-100, este trabalho comparou os valores de dose absorvida, em cada dosímetro, por meio de um sistema de planejamento utilizado para as rotinas clínicas no HIAE. Para importar os desenhos necessários para os cálculos no sistema de planejamento, os objetos simuladores utilizados nas irradiações dos aceleradores lineares foram posicionados em um tomógrafo computadorizado modelo LightSpeed RT16 da empresa GE Healthcare, no qual foram feitas imagens de todo o volume composto pelos quatro objetos simuladores utilizados nas irradiações. Foram utilizadas demarcações nos objetos simuladores, durante a tomografia, este procedimento auxiliou a identificação de cada dosímetro, evitando possíveis equívocos durante a identificação dos dosímetros no sistema de planejamento. O tomógrafo utilizado e os objetos 
simuladores, com os dosímetros em suas respectivas posições, são ilustrados na FIG. 19.

Devido às dimensões dos dosímetros utilizados neste trabalho (formato cúbico com $1 \mathrm{~mm}$ de aresta) foi escolhido o menor valor possível de espessura (slice) para as imagens tomografadas do objeto simulador para tornar possível a visualização dos dosímetros no sistema de planejamento, o valor corresponde a espessura de 0,625 $\mathrm{mm}$. As imagens obtidas no tomógrafo computacional foram transferidas para o sistema de planejamento tridimensional Eclipse ${ }^{T M}$ da empresa Varian Medical Equipaments, também situada no setor de radioterapia do HIAE.

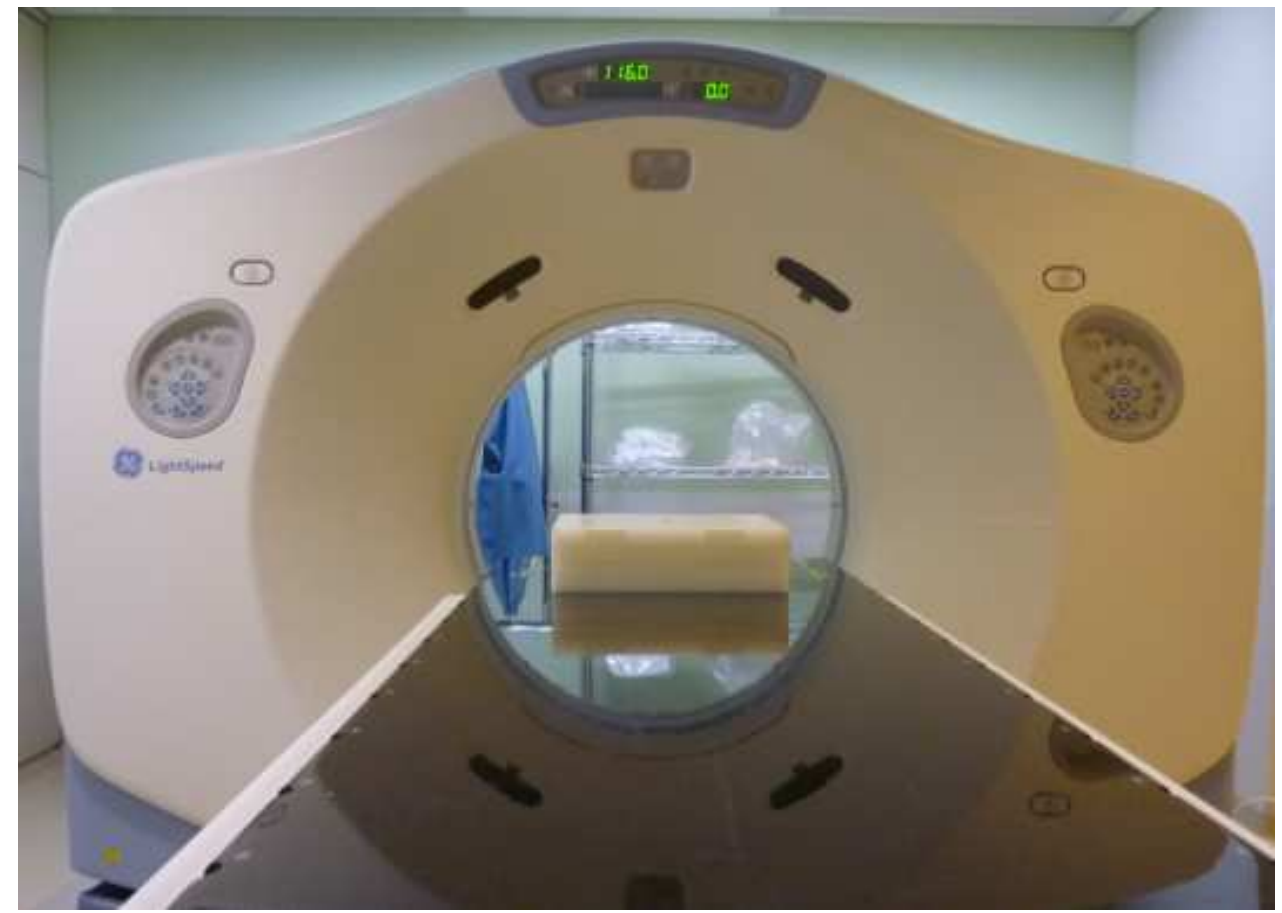

Figura 19 - Processo de tomografia dos objetos simuladores, utilizado durante as irradiações com os aceleradores lineares

Com o sistema de planejamento tridimensional é possível entrar com as características do feixe e do volume a ser irradiado, assim este sistema calcula o valor de dose absorvida na região delineada pelo operador. As características técnicas dos aceleradores lineares do HIAE já estão inseridas no sistema de planejamento, necessitando somente a inserção de parâmetros relativos à irradiação dos objetos simuladores, tais como, campo de irradiação, dose absorvida, taxa de dose e etc. Cabe ressaltar que este sistema de planejamento é constantemente aferido por diversos testes, 
que compara os valores mensurados com os valores gerados pelo sistema, analisando assim se os valores encontram-se dentro de uma margem aceitável, inferiores a $3 \%{ }^{99}$.

A FIG.20 mostra algumas imagens do objeto simulador tomografadas dentro do ambiento do sistema de planejamento, durante o cálculo de dose absorvida nos dosímetros TLD-100. O valor de dose absorvida, calculada pelo sistema de planejamento, foi registrado posicionando o cursor do software, na região onde estava cada dosímetro, assim o valor calculado fora anotado de acordo com o dosímetro correspondente. Para cada valor de dose absorvida é necessário um cálculo de dose absorvida diferente.

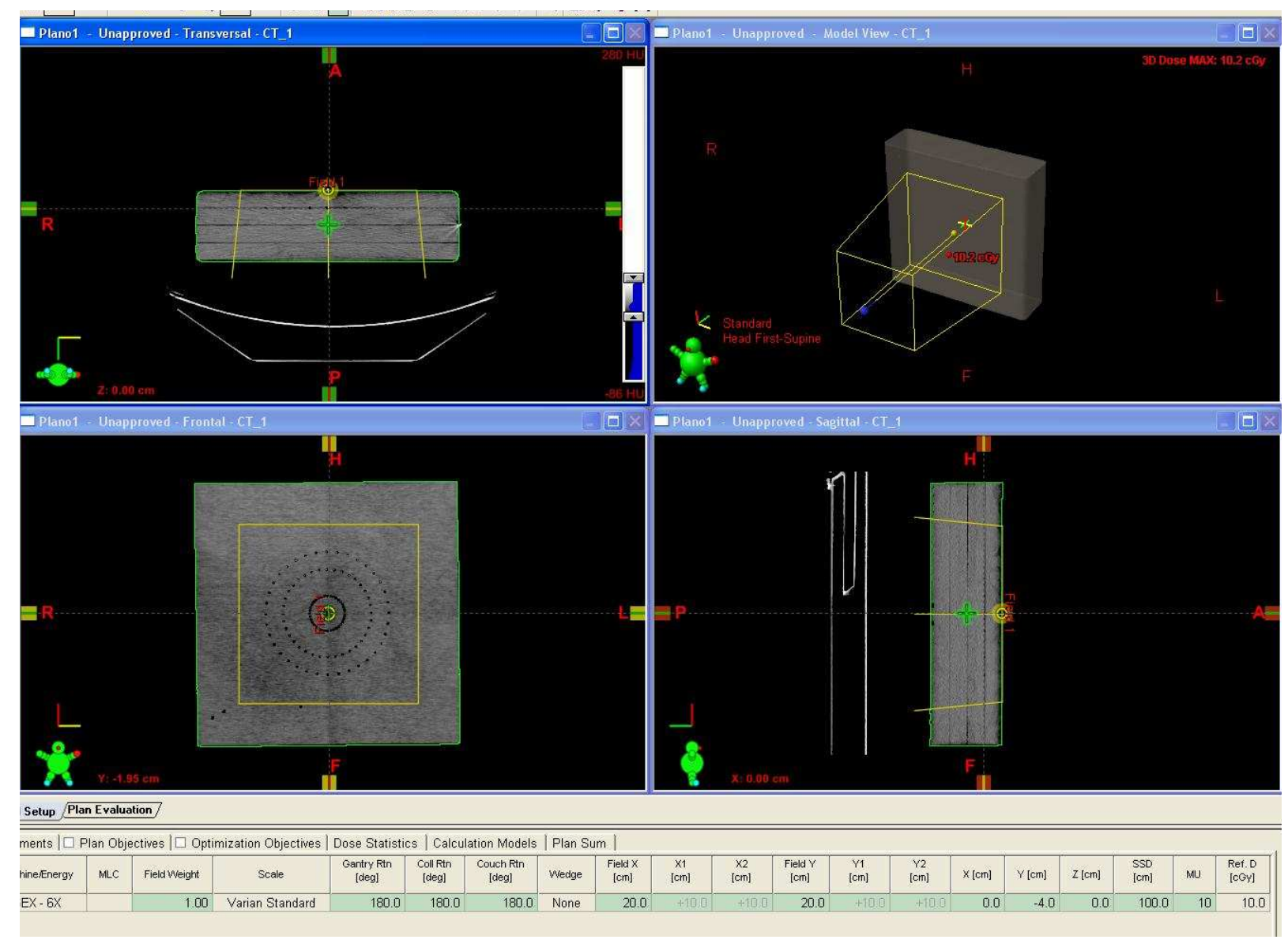

Figura 20 - Ambiente virtual do sistema de planejamento com as imagens tomografadas do objeto simulador

Os fatores de calibração dos dosímetros TLD-100 selecionados são individuais, ou seja, cada dosímetro possui o seu fator de calibração. Apesar da complexidade durante as manipulações com os dosímetros, principalmente pela possível permutação involuntária; este procedimento não necessita de fatores para a correção da sensibilidade 
nos dosímetros e evita utilizar um único fator de calibração para pequeno(s) grupo(s) ou para todo o lote de dosímetros.

Após as nove irradiações nos aceleradores lineares e o registro do valor de dose absorvida em cada dosímetro, utilizando o sistema de planejamento, torna-se possível obter os fatores de calibração do dosímetros, para cada valor de dose absorvida utilizada (10, 52, 105 cGy), conforme a equação 17.

$$
f c_{i j}=\frac{\bar{L}_{j i}}{D_{i j}}
$$

Onde: $f c_{i j}$ - Fator de calibração para o valor de dose absorvida $i$ em cada dosímetro $j(\mathrm{nC} / \mathrm{cGy})$;

$\bar{L}_{j i}$ - Valor médio das três leituras, para cada dosímetro $j$ (leitura líquida subtraindo o background de cada dosímetro), realizada em cada valor de dose absorvida $i(\mathrm{nC})$;

$D_{i j}$ - Valor de dose absorvida $i$ em cada dosímetro $j$, calculada pelo sistema de planejamento (cGy).

Na equação 17, o índice $i$ corresponde a 10, 52 e 105 cGy e o índice $j$ denota cada dosímetro TLD-100. Ressalta-se que o valor de dose absorvida, em cada dosímetro $\left(D_{i j}\right)$, necessariamente não será igual aos valores 10, 52 e 105 cGy. Como foram utilizados três valores de dose absorvida para a calibração dos dosímetros, o fator de calibração de cada dosímetro consolidado é a média dos três fatores de calibração $\left(f c_{i j}\right)$ em cada valor de dose absorvida, como mostra a equação 18 :

$$
f c a l_{j}=\frac{\left(\sum_{i=1}^{n=3} f c_{i}\right)_{j}}{3}
$$

As correções para a dependência energética entre o acelerador linear de $6 \mathrm{MV}$ e para a energia dos fótons das sementes de iodo-125 (energia média de 27,34 keV) ${ }^{23}$ serão somente utilizadas para a constante de taxa de dose, pois estas correções cancelam-se nas demais razões contidas nos parâmetros do TG-43. 


\subsection{Sementes de iodo-125}

Para as análises dosimétricas utilizaram-se as sementes de iodo-125, modelo 6711 , com 7,16 $\pm 0,25 \mathrm{U}(5,64 \pm 0,20 \mathrm{mCi})$ no início das mensurações ${ }^{24}$. A semente de iodo-125 utilizada nas análises dosimétricas foi selecionada a partir de um lote com quatro sementes de iodo-125 adquiridas pelo IPEN-CNEN/SP e disponíveis para os estudos de distribuição de dose.

Neste trabalho, somente uma semente de iodo-125 será utilizada para as análises dosimétricas, desta forma, optou-se escolher duas sementes, dentre as quatro sementes de iodo-125 disponíveis. A escolha de duas sementes foi realizada, pois uma semente fica disponível caso ocorra algum incidente com a outra semente.

A seleção das duas sementes de iodo-125 foi realizada utilizando três câmaras de ionização disponíveis para esta etapa, de modelos diferentes, CRC modelo 15-R e CRC 15 BT, ambos produzidos pela empresa Capintec e uma câmara de ionização HDR1000 Plus acoplado a um eletrômetro modelo MAX-4000, ambos fabricados pela empresa Standard Imaging. Todas as câmaras possuem os dispositivos e acessórios especiais necessários para a mensuração da semente de iodo-125. As respostas da câmara CRC 15-R são fornecidas em unidades de atividade aparente, a câmara CRC 15-BT fornece as respostas em unidade de atividade aparente e unidade de intensidade Kerma-ar (por meio de uma conversão numérica, de acordo com o modelo da semente de iodo-125). O eletrômetro MAX-400 fornece as respostas em unidade carga coletada acumulada ou corrente elétrica. Os modelos CRC 15-R e 15 BT passaram por testes de qualidades e calibrações diárias recomendadas pelos fabricantes, assim como o modelo HDR1000 passou pelos controles de qualidades especificados no manual da empresa.

Os valores fornecidos pelas câmaras de ionização foram valores relativos, pois para esta etapa do trabalho foi considerado somente a variação das medidas efetuadas em cada semente de iodo-125. Todas as sementes de iodo-125 foram submetidas a trinta mensurações, sendo dez mensurações em cada câmara, dessas dez mensurações, cinco foram realizadas rotacionando a semente em 180 graus. As duas sementes que apresentaram os menores desvios padrões das mensurações foram as sementes selecionadas para as análises dosimétricas, referentes aos parâmetros do protocolo TG43.

Imagens radiográficas da semente de iodo-125 selecionada foram realizadas. Com estas imagens é possível constatar possíveis deformidades da solda externa, bem como, localizar a posição do fio de prata, interno a cápsula de titânio. Uma imagem 
radiografada da semente de iodo-125 selecionada para as analises dosimétricas pode ser visualizada na FIG. 21, como vista na imagem, nenhuma deformidade foi encontrada.

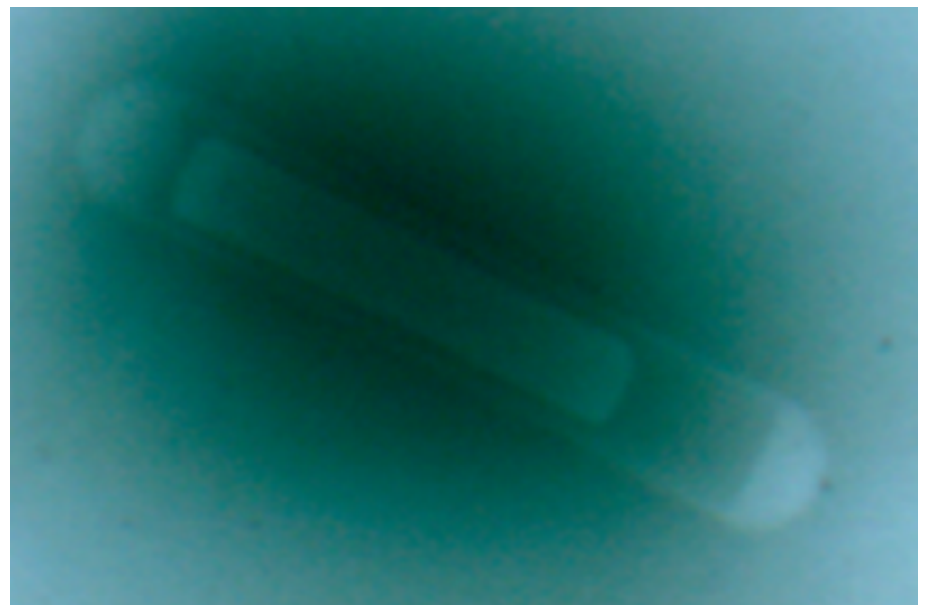

Figura 21 - Radiografia da semente de iodo-125 utilizada nas análises dosimétricas

\subsection{Determinação Experimental do Formalismo TG-43}

Para as mensurações dos parâmetros contidos no formalismo para o cálculo da taxa de dose para as sementes de iodo-125 expresso pela equação 2, utilizou-se os dosímetros selecionados e calibrados nas etapas anteriores. Os parâmetros da equação 2 que foram avaliados experimentalmente correspondem à constante de taxa de dose, função de dose radial e função de anisotropia. Os demais parâmetros são ora avaliado por laboratórios metrológicos (intensidade de Kerma-ar) ou calculados analiticamente por meio de expressões algébricas (função de geometria).

O posicionamento dos objetos simuladores, durante as irradiações dos dosímetros TLD-100 é ilustrado na FIG.22. Nesta figura, encontram-se cinco objetos simuladores; o objeto simulador usinado fica na posição intermediária e dois objetos simuladores são posicionados acima e dois são posicionados abaixo do objeto simulador onde se encontra a semente de iodo-125 e os dosímetros TLD-100, para criar as condições de meio homogêneo.

A função de geometria $(G(r, \theta))$ é obtida por cálculos analíticos somente. Os valores encontrados, utilizando as equações 5 e 6 , são encontrados no apêndice, para distâncias $(r(\mathrm{~cm}))$ de 0,5 até $10 \mathrm{~cm}$ e para ângulos de 0 até 180 graus, em intervalos de 10 graus. 


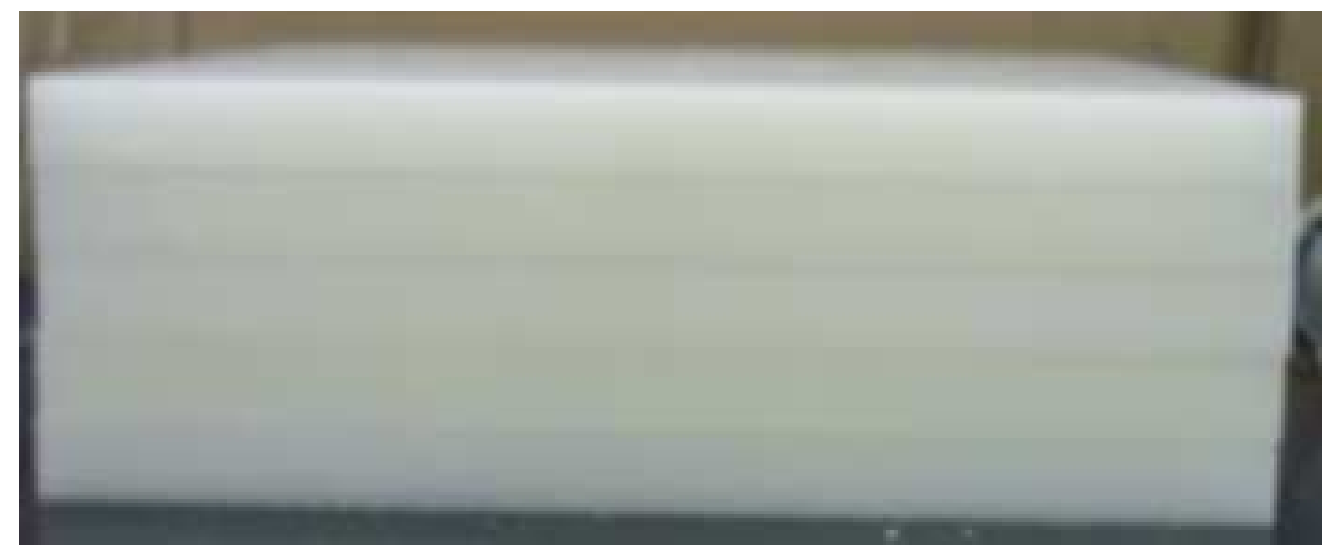

Figura 22 - Posicionamento dos objetos simuladores, durante as irradiações com a semente de iodo-125

Em todas as irradiações, os dosímetros TLD-100 eram primeiramente posicionados no objeto simulador, após o posicionamento de todos os dosímetros, em suas respectivas posições, a semente de iodo-125 era finalmente posicionada. Durante todas as analises dosimétricas com as sementes de iodo-125, os dosímetros TLD-100 foram manipulado com pinça a vácuo e com pinça mecânica com pontas de politetrafluoretileno.

\subsubsection{Constante de taxa de dose $(\Lambda)$}

Seis mensurações para a constante de taxa de dose foram realizadas. A equação 19 mostra a expressão utilizada, neste trabalho, para a determinação dos valores da constante de taxa de dose.

$$
\Lambda=\frac{T L \cdot E(r) \cdot C}{T \cdot d(T) \cdot S_{k} \cdot \varepsilon}
$$

Onde: $T L$ - Resposta relativa do dosímetro com correções para o background (nC);

$E(r)$ - Correção para a dependência energética entre o acelerador linear de 6MV e a semente de iodo-125 (adimensional) ${ }^{100}$;

$C$ - Fator de correção entre o objeto simulador (Solid Water $^{T M}$ ) e água (adimensional) ${ }^{66}$;

$T$ - Período de irradiação (h);

$d(T)$ - Correção para o decaimento da semente de iodo-125 (adimensional);

$S_{k}$ - Intensidade Kerma-ar no início das medidas ( $\mathrm{U}$ ou $c G y \cdot \mathrm{cm}^{2} \cdot \mathrm{h}^{-1}$ );

$\varepsilon$ - Fator de calibração dos dosímetros (nC/cGy). 


\subsubsection{Função de dose radial $(g(r))$}

A FIG. 23 mostra a representação do objeto simulador utilizado para a determinação da função de dose radial, o intervalo de cada dosímetro equivale a 0,5 cm, sendo o último dosímetro posicionado a $7 \mathrm{~cm}$ do centro da semente de iodo-125. $\mathrm{O}$ formato do posicionamento dos dosímetros TLD-100, neste objeto simulador foi baseado em um trabalho anterior ${ }^{66}$. Os orifícios que comportam os dosímetros TLD100 possuem formato cilíndrico com diâmetro e profundidade de 1,5 $\mathrm{mm}$.

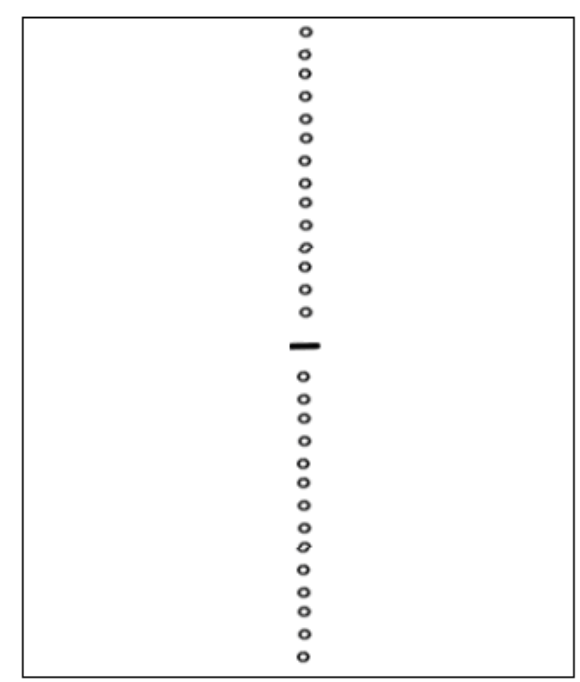

Figura 23 - Objeto simulador utilizado para a obtenção da função de dose radial

Neste trabalho foram realizadas quatro mensurações da função de dose radial. As medidas ocorreram desde $0,5 \mathrm{~cm}$ até $7 \mathrm{~cm}$, acima e abaixo do eixo transverso da semente de iodo-125 (FIG. 23), totalizando 28 dosímetros por mensuração. As funções radiais de dose foram obtidas utilizando a equação 7 .

\subsubsection{Função de anisotropia $(F(r, \theta))$}

Dois objetos simuladores com usinagens diferentes foram utilizados para a determinação da função de anisotropia. Estes objetos simuladores foram manufaturados para representar uma distribuição por toda a área circular, ao redor da semente de iodo$125^{27}$. Cada circunferência está posicionada a certa distância do centro da circunferência (este centro também coincide com o centro geométrico da semente de iodo-125) e o intervalo dos orifícios são de 10 graus entre cada um, correspondendo a 36 orifícios em cada circunferência, exceto para o raio de $0,5 \mathrm{~cm}$ que possui 12 orifícios. 
As distâncias mensuradas, considerando o centro do comprimento ativo da semente de iodo-125, utilizados nos dois objetos simuladores foram: $0,5 \mathrm{~cm}, 1 \mathrm{~cm}, 3$ $\mathrm{cm}, 4 \mathrm{~cm}, 6 \mathrm{~cm}, 8 \mathrm{~cm}$ e $10 \mathrm{~cm}$ (FIG. 24 - imagem da esquerda) e $2 \mathrm{~cm}, 5 \mathrm{~cm}, 7 \mathrm{~cm}$ (FIG. 24 - imagem da direita). As mensurações foram obtidas utilizando uma circunferência por medida e com o preenchimento de 36 dosímetros, em cada série de irradiação. As funções de anisotropia foram obtidas utilizando a equação 9.

É comum representar os valores da função de anisotropia em 90 ou 180 graus (em relação ao plano transverso da semente de iodo-125). Experimentalmente, este trabalho utilizou posições cobrindo 360 graus, porém os resultados serão apresentados apenas no intervalo de 0 a 180 graus, utilizando a média de duas posições angulares replementares ${ }^{[1]}$, em cada circunferência, assumindo que a distribuição é simétrica em relação ao plano transversal da semente de iodo- $125^{101}$.
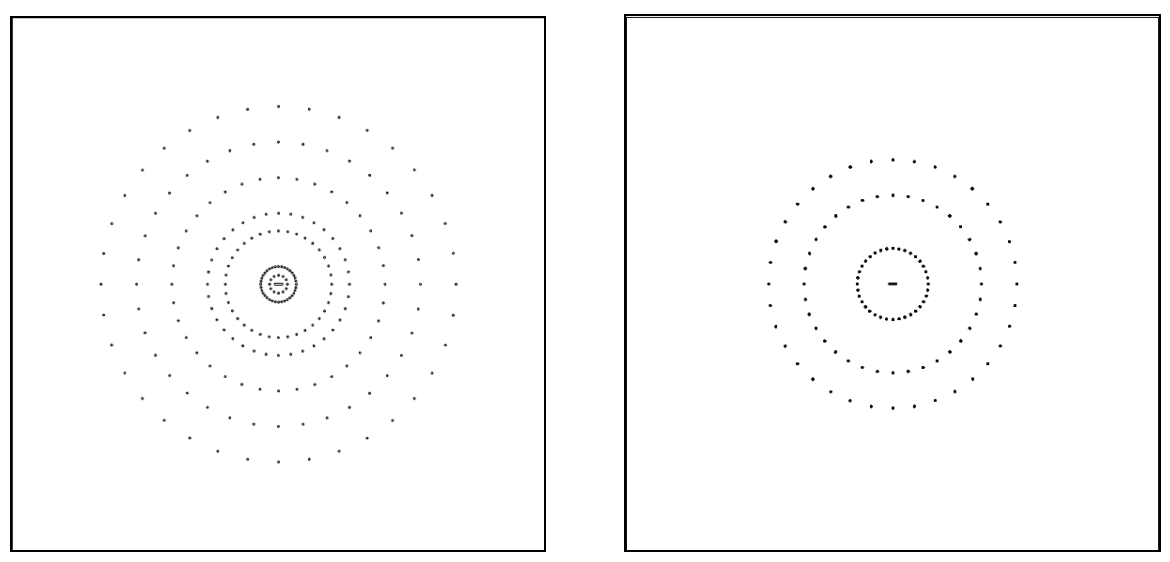

Figura 24 - Objetos simuladores utilizados para a determinação das funções de anisotropia

A baixa energia emanada pelas sementes de iodo-125 corrobora para o alto gradiente de dose, em meio simulador de água, tornando a leitura para distâncias elevadas ( $>6 \mathrm{~cm}$ no objeto simulador) complexas por estarem próximas do limiar de detecção do dosímetro TLD-100. Para minimizar tal efeito, nesta etapa, os períodos de irradiação dos dosímetros variaram de 6 horas para circunferências mais próximas da fonte até 140 horas para as mais distantes. Estes períodos elevados de irradiação são para que as respostas TL mensuradas sejam maiores do que o limiar de detecção do dosímetro TL ${ }^{102}$.

${ }^{[1]}$ Ângulos Replementares: em geometria plana, os ângulos replementares são dois ângulos, que quando somados resultam em 360 graus. 


\section{RESULTADOS E DISCUSSÕES}

\subsection{Seleção dos dosímetros - Massa}

A FIG.25 mostra a distribuição da média das massas dos 204 dosímetros avaliados, nesta seleção somente 4 dosímetros encontram-se fora da margem específicada neste ensaio, compreendendo a exclusão dos dosímetros que obtiveram massa superior a 3,1 mg e massa inferior ou igual a 2,4 mg. Os desvios padrões não foram ilustrados na FIG. 25, pois os seus valores são de tal ordem que torna complexa a visualização no gráfico. Os desvios padrões registrados possuem coeficientes de variação inferiores a $3 \%$.

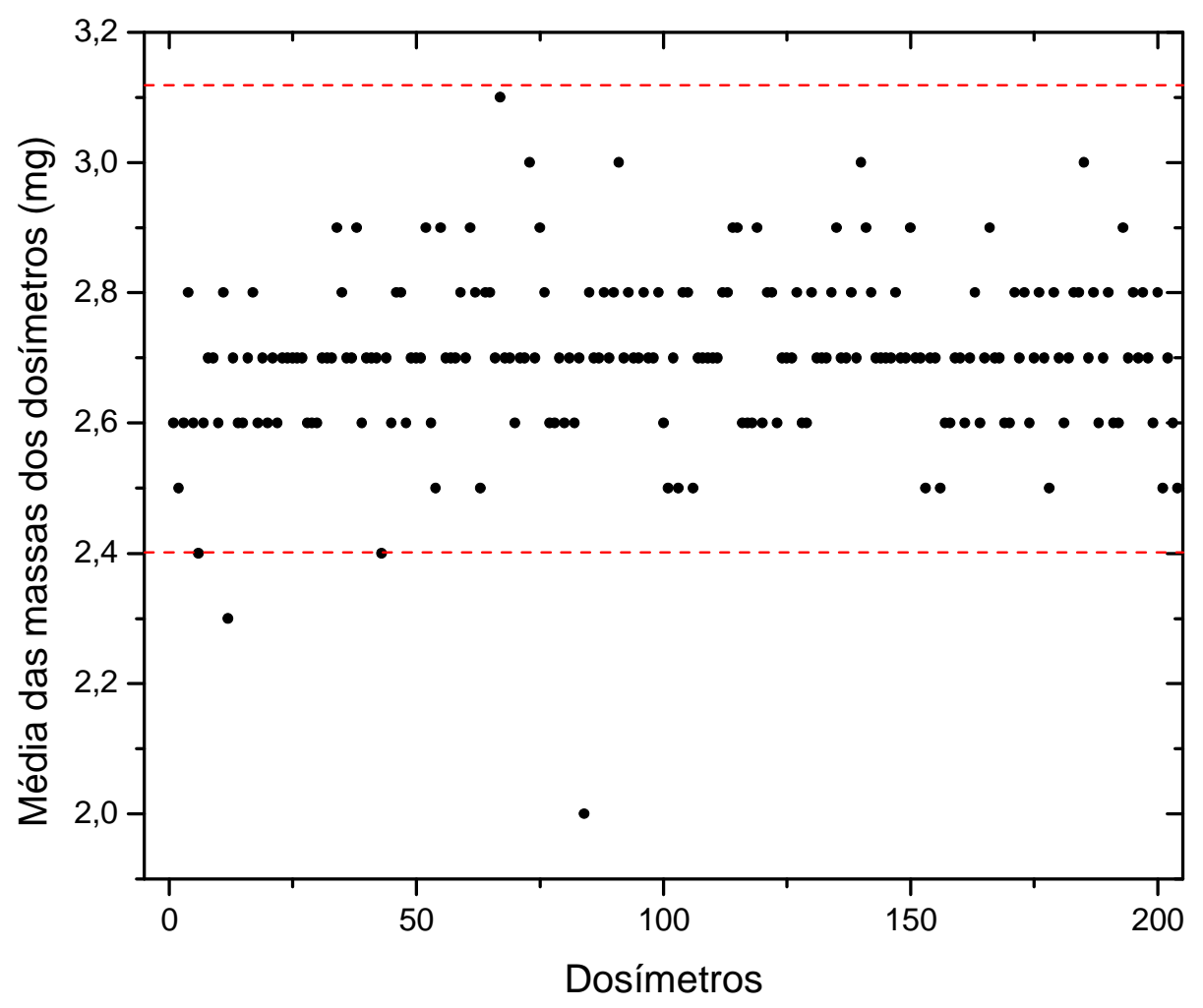

Figura 25 - Distribuição das massas dos dosímetros. Os dosímetros selecionados encontram-se dentro da região delimitada pelas retas tracejadas

Os dosímetros que foram excluídos também apresentavam formas com irregularidades acentuadas, bem diferentes do formato cúbico especificado pelo fabricante. A ausência do formato cúbico no material TL pode ser prejudicial durante as análises dosimétricas e manipulação do dosímetro. Considerando somente os dosímetros selecionados, a massa média deste lote de dosímetros TLD-100 é igual a $2,71 \pm 0,11 \mathrm{mg}$. 


\subsection{Seleção dos dosímetros - Irradiador de Cobalto 60}

Após as quatro séries de irradiações utilizando o irradiador de Cobalto-60, os 200 dosímetros disponíveis foram avaliados quanto à variação da reprodutibilidade dentro das quatro séries de irradiações. Três dosímetros tiveram que ser descartados previamente, pois em alguma das etapas de leitura, a leitora TL apresentou problemas na aquisição de dados, deste modo, optou-se por segregá-los desta seleção. Assim, nesta etapa obteve-se 197 dosímetros disponíveis para a seleção.

O objetivo principal desta etapa é selecionar os dosímetros mais reprodutíveis, dentro do lote de dosímetros disponíveis. A escolha do método a ser utilizado versará exclusivamente para as características necessárias e úteis para este trabalho, ou seja, um método escolhido neste trabalho não pode ser o mais adequado para outras seleções de dosímetros.A quantidade de dosímetros que serão selecionados deverá considerar as seguintes características:

- Ser suficiente para o preenchimento de no mínimo duas circunferências completas (72 perfurações), para ensaios acerca da função de anisotropia;

- Fazer as mensurações de background ambiental e do sistema de leitura;

- Dosímetros substitutos, caso aqueles que serão utilizados na análise dosimétrica sejam porventura perdidos.

Os resultados desta seleção serão apresentados a seguir, mostrando a quantidade de dosímetros selecionadas, de acordo com os métodos avaliados.

\subsubsection{Método IEC}

Utilizando a equação 10 e escolhendo o valor do índice de uniformidade $(\delta)$ igual a 30 , conforme a referência que descreve o método ${ }^{97}$, obteve-se 20 dosímetros excluídos. A quantidade de dosímetros selecionados esta relacionada com o valor do índice de uniformidade, ou seja, quanto menor o valor do índice de uniformidade, maior será a quantidade de dosímetro que serão excluídos.

Este método mostra-se eficiente para um lote de dosímetros que possui um fator de calibração em comum. Neste trabalho, o fator de calibração dos dosímetros será individual. Portanto, observando a equação 10, nota-se que o critério de exclusão dos dosímetros está baseado somente em suas respostas líquidas máximas e mínimas, dentro do lote avaliado, porém não diz nada sobre a reprodutibilidade das respostas fornecidas 
pelos dosímetros. Por os motivos expostos anteriormente, o método IEC não foi utilizado para a seleção dos dosímetros no irradiador de Cobalto-60.

\subsubsection{Método MA}

A TAB.8 mostra a quantidade de dosímetros que seriam utilizados, mediante a um valor percentual limiar selecionado arbitrariamente, para o desvio padrão normalizado (coeficiente de variação), utilizando o método das médias ajustadas.

Tabela 8 - Dosímetros selecionados mediante a um valor limiar arbitrário

\begin{tabular}{cc}
\hline Valor Limiar $(\%)$ & Quantidade de dosímetros selecionados \\
\hline 15 & 197 \\
10 & 197 \\
5 & 194 \\
3 & 182 \\
1,5 & 108 \\
\hline
\end{tabular}

O valor limiar de $15 \%$ (TAB.8) foi o valor limiar utilizado pela referência que utilizou o método das médias ajustadas ${ }^{20}$. Nota-se que neste trabalho, nenhum dosímetro é excluído até o valor limiar igual a $10 \%$, porém a partir de valor limiar igual a 1,5 \% são excluídos 89 dosímetros. Dos dosímetros disponíveis, aproximadamente 55 $\%$ seriam os dosímetros selecionados, se o valor limiar de $1,5 \%$ fosse escolhido. Isto mostra a boa precisão nas respostas deste lote de dosímetros, principalmente se comparados com outros dosímetros do mesmo modelo ${ }^{20}$.

A medida ajustada de cada dosímetro, gerada pela equação 12 , refere-se à média de cada série de irradiação de todos os dosímetros disponíveis. Desta forma, os valores da média ajustada de cada dosímetro possuem a dependência dos valores de todos os dosímetros dentro do lote avaliado. Experimentalmente, observou-se que a média dos coeficientes de variação, referente a quatro séries de irradiações com Cobalto-60, equivale a 8,4\%. Assim, por exemplo, um dosímetro poderia ser excluído pelo método MA por possuir uma sensibilidade elevada, comparando-o com os valores de resposta do lote de dosímetros. Porém, este dosímetro pode possuir um alto grau de reprodutibilidade e precisão, características importantes para esta etapa do trabalho. 
Apesar de o método MA possuir uma excelente eficácia, para dosímetros que possuem as respostas corrigidas através da sensibilidade do lote. O método MA não foi utilizado nesta etapa do trabalho, pois o objetivo principal é selecionar os dosímetros que possuem alto grau de reprodutibilidade, independente da sensibilidade de resposta dos dosímetros.

\subsubsection{Método DPP}

O desvio padrão percentual - DPP (coeficiente de variação) obtido após as quatro séries de irradiações dos dosímetros foi o método utilizado para a seleção dos dosímetros, devido a sua simplicidade e dentre os métodos avaliados, este avalia diretamente o grau de reprodutibilidade de cada dosímetro, após as séries de irradiações.

Os dosímetros que apresentaram os valores de desvio padrão normalizado superiores a 5,25\% foram excluídos para as futuras análises. A escolha deste valor limiar resultou na seleção de 81 dosímetros. Esta quantidade mostra-se adequada para a realização das análises dosimétrica nos objetos simuladores, pois permite o preenchimento de no mínimo duas circunferências completas (72 dosímetros), e também utilizar aproximadamente 4 dosímetros para as verificações de background (ambiental e sistema de leitura) e o restante será utilizado como dosímetros substitutos (5 dosímetros).

A TAB. 9 mostra os valores dos desvios padrões normalizados, dos 81 dosímetros selecionados para as análises dosimétricas. Nota-se que todos os dosímetros possuem desvios padrões menores do que $5,25 \%$, sendo os dosímetros selecionados para as etapas subsequentes deste trabalho.

Apesar de este método contabilizar somente a variação individual de cada dosímetro, as respostas líquidas de todos os dosímetros selecionados possuem uma variação igual $\pm 7,30 \%( \pm 1 \sigma)$. Se todos os 197 forem levados em conta, a variação é equivalente a $\pm 7,47 \%( \pm 1 \sigma)$, relativamente próxima a variação dos dosímetros selecionados. De acordo com a descrição do fabricante as respostas padrões dos dosímetros podem variar até $\pm 7,50 \%( \pm 1 \sigma)^{103}$. Porém, se considerados os 197 inicialmente disponíveis, encontre-se desvios padrões normalizados superiores a $11 \%$, mostrando um alto grau de variabilidade. 
Tabela 9 - Valores dos desvios padrões normalizados (D.P.M) para os 81 dosímetros

\begin{tabular}{|c|c|c|c|c|c|}
\hline Dos. & D.P.M (\%) & Dos. & D.P.M (\%) & Dos. & D.P.M (\%) \\
\hline 1 & 4,38 & 31 & 4,84 & 61 & 2,52 \\
\hline 2 & 4,63 & 32 & 4,54 & 62 & 4,95 \\
\hline 3 & 5,02 & 33 & 4,87 & 63 & 4,52 \\
\hline 4 & 3,60 & 34 & 5,09 & 64 & 4,16 \\
\hline 5 & 5,07 & 35 & 2,04 & 65 & 5,10 \\
\hline 6 & 5,17 & 36 & 4,07 & 66 & 5,06 \\
\hline 7 & 4,62 & 37 & 4,46 & 67 & 4,66 \\
\hline 8 & 4,39 & 38 & 4,28 & 68 & 3,19 \\
\hline 9 & 4,42 & 39 & 5,10 & 69 & 4,28 \\
\hline 10 & 4,73 & 40 & 5,09 & 70 & 4,83 \\
\hline 11 & 4,47 & 41 & 5,17 & 71 & 5,04 \\
\hline 12 & 5,24 & 42 & 4,96 & 72 & 5,10 \\
\hline 13 & 4,87 & 43 & 4,03 & 73 & 4,73 \\
\hline 14 & 4,83 & 44 & 3,22 & 74 & 4,75 \\
\hline 15 & 3,84 & 45 & 4,08 & 75 & 4,97 \\
\hline 16 & 4,77 & 46 & 5,00 & 76 & 4,83 \\
\hline 17 & 4,08 & 47 & 2,49 & 77 & 3,71 \\
\hline 18 & 4,08 & 48 & 2,45 & 78 & 4,71 \\
\hline 19 & 5,23 & 49 & 4,72 & 79 & 5,23 \\
\hline 20 & 4,60 & 50 & 4,63 & 80 & 5,09 \\
\hline 21 & 4,18 & 51 & 3,86 & 81 & 5,15 \\
\hline 22 & 3,55 & 52 & 4,30 & & \\
\hline 23 & 3,07 & 53 & 4,97 & & \\
\hline 24 & 4,83 & 54 & 5,04 & & \\
\hline 25 & 4,49 & 55 & 3,59 & & \\
\hline 26 & 5,05 & 56 & 4,75 & & \\
\hline 27 & 5,04 & 57 & 4,73 & & \\
\hline 28 & 4,55 & 58 & 2,78 & & \\
\hline 29 & 4,54 & 59 & 4,57 & & \\
\hline 30 & 4,77 & 60 & 4,49 & & \\
\hline
\end{tabular}


Discussões e estudos estatísticos, acerca dos métodos avaliados nesta etapa e análises sistemáticas nas incertezas envolvidas no processo de irradiação com o Cobalto-60 não foram realizadas. Nesta etapa o objetivo principal era reduzir a quantidade de dosímetros que terá os fatores de calibração mensurados, selecionando os dosímetros mais reprodutíveis de todo o lote.

\subsection{Fator de Calibração}

A TAB. 10 mostra os valores de dose absorvida, registrados pelo sistema de planejamento, para cada valor nominal de dose absorvida atribuída a superfície dos objetos simuladores. Conforme a TAB. 10, os valores nominais de dose absorvida podem variar até aproximadamente $2 \%$ dos valores calculados pelo sistema de planejamento. Neste trabalho, a faixa de dose absorvida para a geração dos fatores de calibração dos dosímetros será referenciada por meio do valor nominal, porém nos cálculos o valor utilizado será aquele fornecido pelo sistema de planejamento.

Tabela 10 - Valores de dose absorvida, nos objetos simuladores calculados pelo sistema de planejamento

\begin{tabular}{ccc}
\hline $\begin{array}{c}\text { Dose absorvida nominal } \\
\text { (cGy) }\end{array}$ & $\begin{array}{c}\text { Dose absorvida sistema de } \\
\text { planejamento (cGy) }\end{array}$ & Diferença (\%) \\
\hline 105 & $107,12 \pm 0,52$ & 2,02 \\
52 & $53,07 \pm 0,24$ & 2,05 \\
10 & $9,99 \pm 0,03$ & $-0,11$ \\
\hline
\end{tabular}

A FIG. 26 mostra as respostas TL líquidas obtidas $\left(\bar{L}_{j i}\right.$ - equação 17) pelos dosímetros, para 10; 52 e 105 cGy, respectivamente. As respostas TL dos dosímetros, como previsto, mostraram-se lineares, mediante a faixa de dose utilizada neste trabalho. Observando a FIG. 26, nota-se que o comportamento dos dosímetros é similar nos três valores de dose absorvida utilizados. Desta forma, modificações consideráveis na sensibilidade dos dosímetros não são observadas.

Os fatores de calibração consolidado $\left(f c a l_{j}\right)$ dos dosímetros avaliados são ilustrados pela FIG. 27. Como esperado, o comportamento do fator de calibração mostrou-se similar as respostas TL, mostrados pela FIG. 27. 

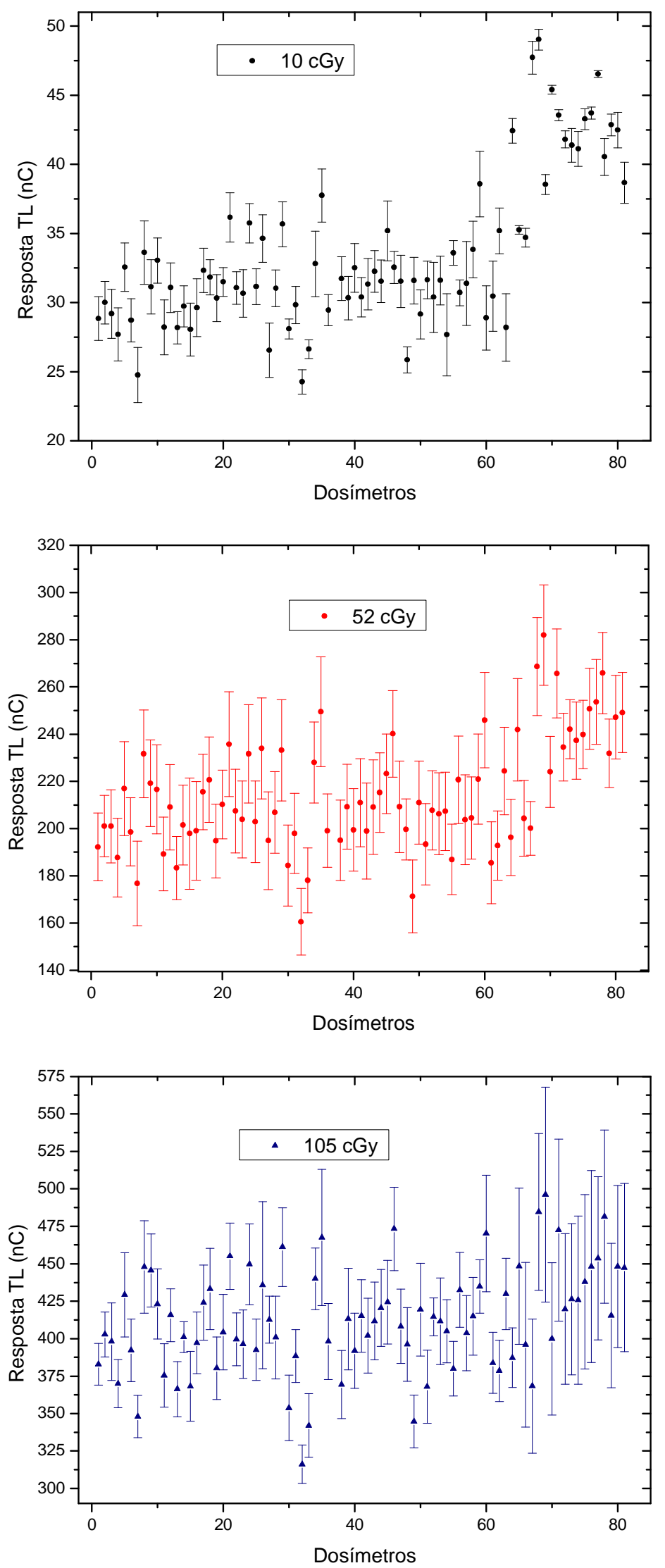

Figura 26 - Resposta TL dos dosímetros, sob as doses absorvidas nominais de 10, 52 e $105 \mathrm{cGy}$, respectivamente 


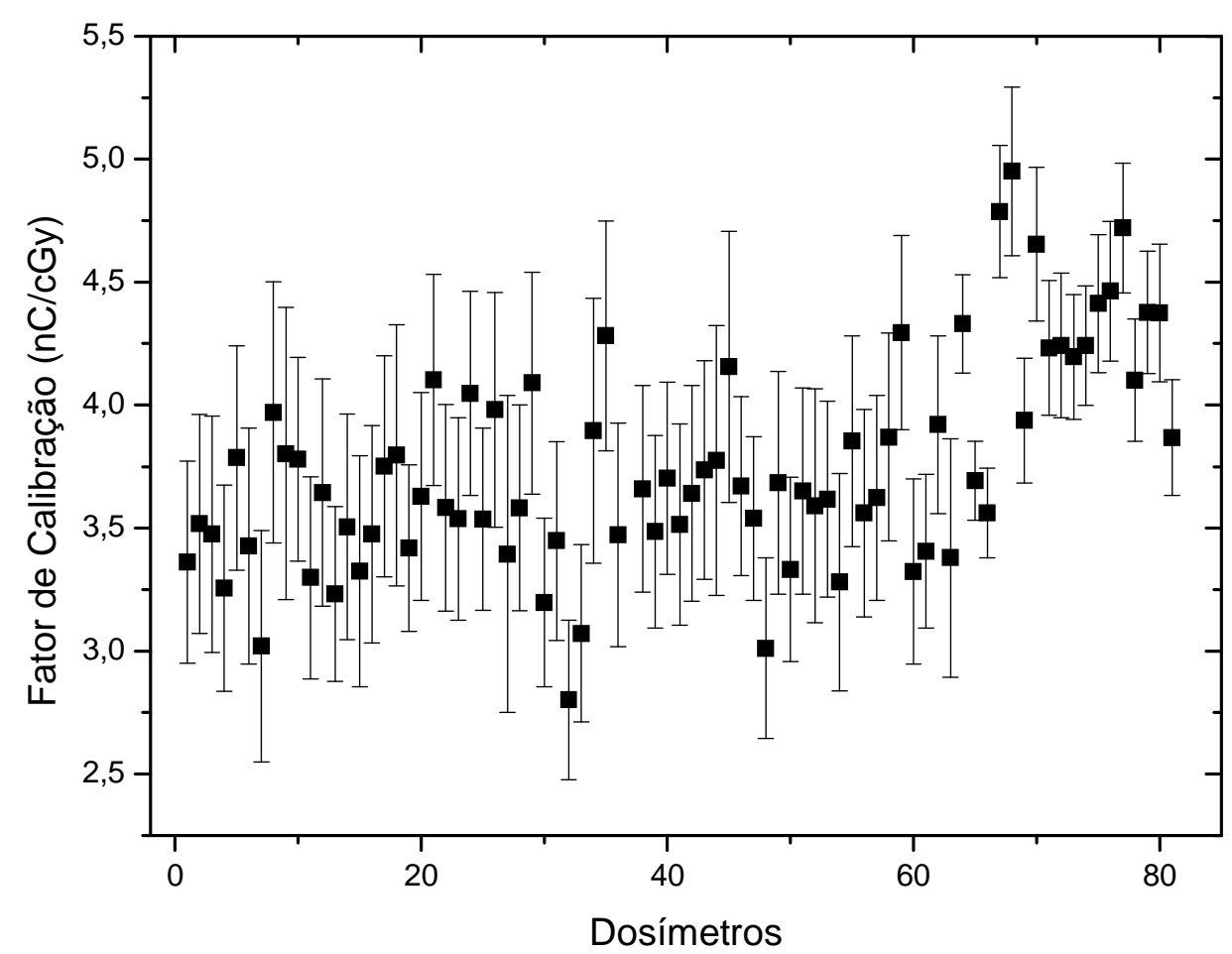

Figura 27 - Fator de calibração $\left(f c a l_{j}\right)$ dos dosímetros avaliados

A média de resposta dos desvios padrões normalizados (coeficiente de variação) dos fatores de calibração aproximou-se de 11,21 \pm 5,47 \%. Para a redução deste valor, medidas e intervalos de dose absorvida adicionais deveriam ser realizados. Contudo, para dar continuidade aos objetivos propostos neste trabalho, optou-se por realizar as determinações experimentais das sementes de iodo-125, pois mais investigações acerca dos fatores de calibração dos dosímetros demandariam um período extenso de mensurações.

\subsection{Medições das sementes de iodo-125}

Os resultados mensurados nas câmaras CRC-15 R, CRC-15 BT, ambas da empresa Capintec e câmara de ionização HDR 1000 com eletrômetro MAX 400, da empresa Standard Imaging, para as quatro sementes são mostradas na TAB. 11. Os valores obtidos são relativos, necessitam de calibração com câmaras primárias ou secundárias rastreáveis metrologicamente para possíveis comparações com os valores fornecidos pelo fabricante das sementes de iodo-125. Porém nota-se, que em cada câmara, os valores médios (obtidos dentre dez mensurações, para cada uma das três 
câmaras) não possuem elevadas dispersões, em torno de um valor médio, constatandose assim a reprodutibilidade, mas não a exatidão, do lote de sementes.

Tabela 11 - Resultados das mensurações de atividade aparente e carga coletada, pelas quatro sementes de iodo-125

\begin{tabular}{|c|c|c|c|}
\hline $\begin{array}{l}\text { Câmaras de } \\
\text { Ionização }\end{array}$ & Sementes & Valor Médio (mCi) & $\begin{array}{l}\text { Coeficiente de } \\
\text { Variação }(\%)\end{array}$ \\
\hline \multirow{5}{*}{ CRC 15-R } & 1 & $5,79 \pm 0,02$ & 0,29 \\
\hline & 2 & $5,76 \pm 0,03$ & 0,47 \\
\hline & 3 & $5,78 \pm 0,04$ & 0,61 \\
\hline & 4 & $5,90 \pm 0,04$ & 0,63 \\
\hline & Sementes & Valor Médio (mCi) & $\begin{array}{l}\text { Coeficiente de } \\
\text { Variação (\%) }\end{array}$ \\
\hline \multirow{5}{*}{ CRC 15-BT } & 1 & $4,95 \pm 0,02$ & 0,40 \\
\hline & 2 & $4,92 \pm 0,03$ & 0,52 \\
\hline & 3 & $4,95 \pm 0,02$ & 0,48 \\
\hline & 4 & $5,04 \pm 0,03$ & 0,65 \\
\hline & Sementes & Valor Médio (nC) & $\begin{array}{l}\text { Coeficiente de } \\
\text { Variação (\%) }\end{array}$ \\
\hline \multirow{4}{*}{ HDR 1000} & 1 & $3,74 \pm 0,02$ & 0,45 \\
\hline & 2 & $3,69 \pm 0,03$ & 0,87 \\
\hline & 3 & $3,77 \pm 0,04$ & 1,07 \\
\hline & 4 & $3,82 \pm 0,04$ & 1,05 \\
\hline
\end{tabular}

Observa-se que qualquer uma das quatro sementes selecionadas poderia ser utilizada nas análises dosimétricas, sem grandes variações em sua atividade aparente. Mas, para padronizar a semente de iodo-125 que será utilizada nas análises dosimétricas, a semente número 1 (TAB. 11) foi selecionada, pois apresentou os menores coeficientes de variação nas três câmaras. A segunda semente de iodo-125 escolhida, como semente substituta, foi a semente número 2 , no entanto, sua utilização não foi necessária neste trabalho.

Apesar dos resultados da TAB. 11, o valor da intensidade Kerma-ar, utilizado neste trabalho, é o valor fornecido pelo fabricante; 7,16 $\pm 0,25 \mathrm{U}(5,64 \pm 0,20 \mathrm{mCi})$, 
considerando com a data de referência o início das mensurações dos parâmetros contidos no formalismo do TG-43 ${ }^{24}$.

\subsection{Constante de taxa de dose $(\Lambda)$}

A TAB. 12 mostra o valor obtido neste trabalho (equação 19), após seis mensurações para o modelo 6711, comparando-as com outros valores descritos na literatura, sendo alguns destes valores encontrados por meio de outros métodos, não exclusivamente pela técnica TL ${ }^{100,104,105,106}$.

Tabela 12 - Valores da constante de taxa de dose deste trabalho e de outras referências

\begin{tabular}{cccc}
\hline Semente de iodo-125 & Referências & Método utilizado & $\Lambda\left(c G y \cdot h^{-1} \cdot U^{-1}\right)$ \\
\hline & Este trabalho & TL & $0,913 \pm 0,076$ \\
& Ref. 25 & MCNP WAFAC & $0,904 \pm 0,021$ \\
Modelo 6711 & Ref. 25 & MCNP Pontual & $0,929 \pm 0,021$ \\
& Ref. 105 & PTRAN (WAFAC) & $0,942 \pm 0,017$ \\
& Ref. 100 & TL & $0,921 \pm 0,055$ \\
Valor consensual (TG-43) & Ref. 61 e 106 & (MC + Exp.) / 2 & $0,965 \pm 0,028$ \\
\hline
\end{tabular}

Observando a TAB. 12, nota-se que o valor encontrado por este trabalho apresenta 5,38 \% de diferença do valor consensual (recomendado pelo protocolo TG-43 para a utilização nos cálculos clínicos de dose - refere-se ao valor médio da constante de taxa de dose mensurada experimentalmente e por simulação Monte Carlo). Porém, comparando o valor obtido com o trabalho que utilizou a técnica $\mathrm{TL}^{100}$, a diferença encontra-se próxima a $0,87 \%$.

Os valores encontrados anteriormente podem ser considerados aceitáveis, dentro da margem de incerteza experimental e das condições experimentais disponíveis e exequíveis para este trabalho, porém o desvio padrão da constante da taxa de dose encontrada neste trabalho é a maior se comparadas com as demais referências. Cautela deve ser tomada quanto à utilização do fator de dependência energética, principalmente proveniente de outras referências, e sobre as correções energéticas sobre o meio utilizado neste trabalho (objeto simulador) em relação à água líquida, ambos os fatores não foram avaliados neste trabalho ${ }^{91}$. 


\subsection{Função de dose radial $(g(r))$}

A FIG. 28 mostra os valores médios das quatro medidas da função de dose radial, em função da distância $r$, realizadas neste trabalho, junto com as comparações dos valores consensuais do TG-43 ${ }^{61}$ e com os valores calculados utilizando uma função polinomial de quinta ordem (equação 8).

Os valores dos coeficientes da função polinomial, utilizados para gerar na FIG. 28 são ${ }^{107}: a_{0}=1,0078 \mathrm{~cm} ; a_{1}=0,1370 \mathrm{~cm}^{-1} ; a_{2}=-0,1843 \mathrm{~cm}^{-2} ; a_{3}=0,0445 \mathrm{~cm}^{-3} ; a_{4}=-$ $0,0046 \mathrm{~cm}^{-4}$ e $a_{5}=0,0002 \mathrm{~cm}^{-5}$. O comprimento ativo da semente, utilizada nas três séries de valores, foi equivalente a $3,0 \mathrm{~mm}$.

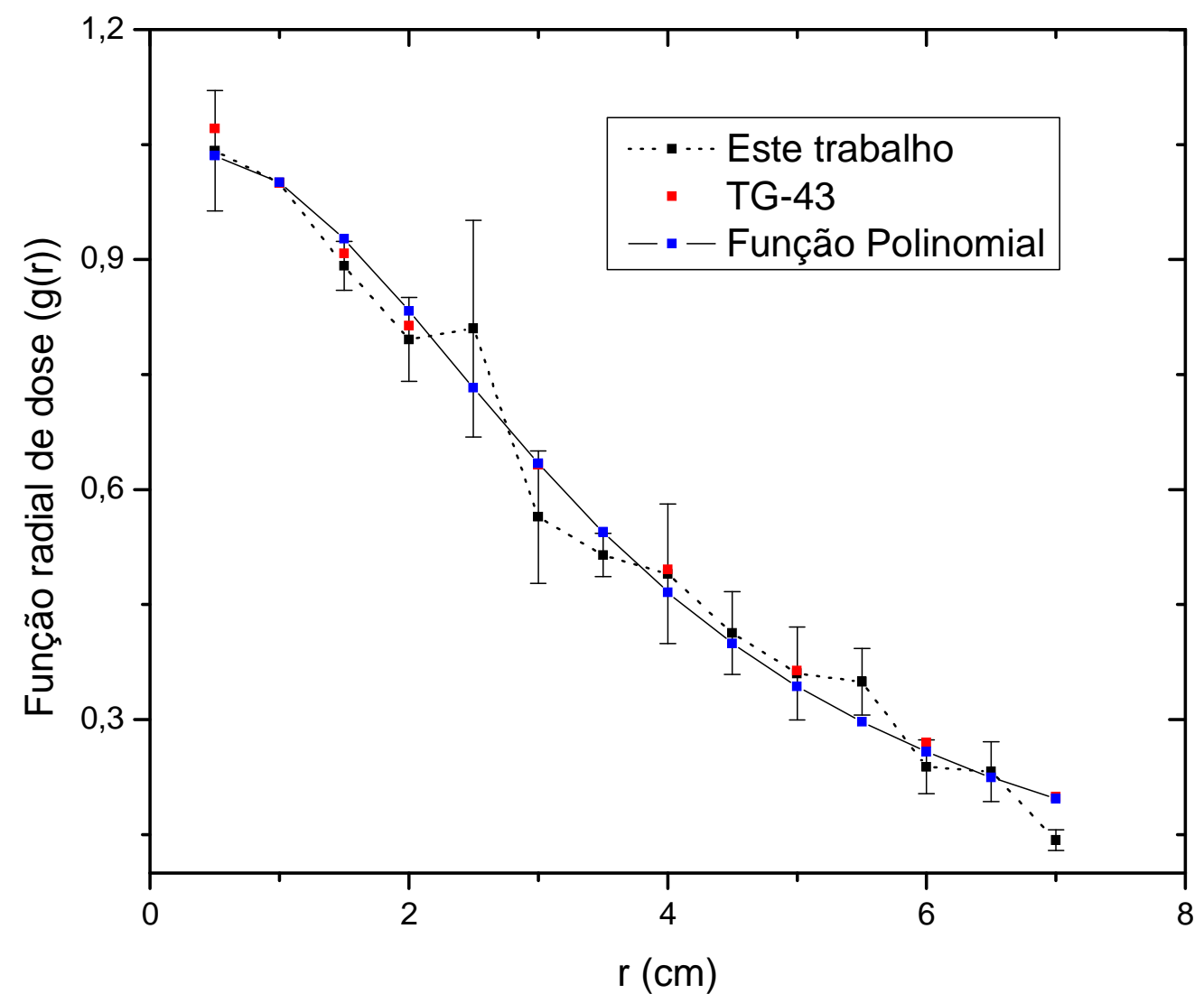

Figura 28 - Valores médios das funções de dose radial, comparando com os valores do TG-43 e com a função polinomial de quinta ordem

Por meio da FIG. 28, nota-se que os valores da função radial mensurados neste trabalho são próximos aos valores consensuais do TG-43 e do polinômio de quinta ordem. Estes valores (TG-43 e função polinomial) foram selecionados, neste trabalho, por questões comparativas, porém há outros trabalhos mais recentes que sugerem outros valores experimentais e teóricos para a função de dose radial ${ }^{100,108}$. 


\subsection{Função de anisotropia $(F(r, \theta))$}

Os valores experimentais das funções de anisotropia são apresentados nas TAB. 13 e TAB. 14, para as distâncias de 0,5 até $4 \mathrm{~cm}$ e 5 até $10 \mathrm{~cm}$, respectivamente. Ratifica-se que estes valores são as médias das posições replementares dos dosímetros, mensurados ao redor de todo o plano transverso da semente, ou seja, em 360 graus.

Os valores das funções de anisotropia entre os ângulos polares de 140 a 180 graus, para a distância de $10 \mathrm{~cm}$ não foram apresentados, pois as respostas neste intervalo foram próximas aos níveis mínimos de detecção da leitora TL.

Tabela 13 - Valores das funções de anisotropia para as distâncias de 0,5 até $4 \mathrm{~cm}$

\begin{tabular}{|c|c|c|c|c|c|}
\hline \multirow{2}{*}{$\begin{array}{c}\text { Ângulo Polar } \\
\theta \text { (graus) }\end{array}$} & \multicolumn{5}{|c|}{$\mathrm{r}(\mathrm{cm})$} \\
\hline & 0,5 & 1 & 2 & 3 & 4 \\
\hline 0 & 0,292 & 0,260 & 0,405 & 0,447 & 0,584 \\
\hline 10 & - & 0,414 & 0,540 & 0,569 & 0,596 \\
\hline 20 & - & 0,609 & 0,698 & 0,757 & 0,733 \\
\hline 30 & 0,97 & 0,778 & 0,834 & 0,841 & 0,853 \\
\hline 40 & - & 0,841 & 0,902 & 0,907 & 0,913 \\
\hline 50 & - & 0,970 & 0,944 & 0,951 & 0,959 \\
\hline 60 & 1,045 & 0,940 & 0,987 & 0,941 & 1,013 \\
\hline 70 & - & 0,942 & 0,997 & 1,001 & 0,963 \\
\hline 80 & - & 0,992 & 0,994 & 1,025 & 1,013 \\
\hline 90 & 1,000 & 1,000 & 1,000 & 1,000 & 1,000 \\
\hline 100 & - & 1,044 & 1,034 & 1,088 & 1,071 \\
\hline 110 & - & 1,056 & 1,054 & 0,952 & 1,069 \\
\hline 120 & 1,004 & 1,000 & 0,997 & 0,975 & 0,979 \\
\hline 130 & - & 1,031 & 0,904 & 1,094 & 1,083 \\
\hline 140 & - & 0,826 & 0,730 & 1,245 & 0,902 \\
\hline 150 & 0,703 & 0,775 & 0,684 & 1,169 & 0,856 \\
\hline 160 & - & 0,768 & 0,607 & 1,011 & 0,983 \\
\hline 170 & - & 0,538 & 0,463 & 0,807 & 0,752 \\
\hline 180 & 0,237 & 0,396 & 0,564 & 0,650 & 0,566 \\
\hline
\end{tabular}


Tabela 14 - Valores das funções de anisotropia para as distâncias de 5 até $10 \mathrm{~cm}$

\begin{tabular}{|c|c|c|c|c|c|}
\hline \multirow{2}{*}{$\begin{array}{c}\text { Ângulo Polar } \\
\theta \text { (graus) }\end{array}$} & \multicolumn{5}{|c|}{$\mathrm{r}(\mathrm{cm})$} \\
\hline & 5 & 6 & 7 & 8 & 10 \\
\hline 0 & 0,564 & 0,732 & 0,580 & 0,307 & 0,884 \\
\hline 10 & 0,643 & 0,700 & 0,655 & 0,234 & 0,603 \\
\hline 20 & 0,810 & 0,833 & 0,829 & 0,474 & 0,788 \\
\hline 30 & 0,869 & 0,879 & 0,920 & 0,447 & 1,179 \\
\hline 40 & 0,936 & 0,910 & 0,959 & 0,792 & 1,174 \\
\hline 50 & 0,977 & 0,977 & 1,065 & 0,534 & 1,084 \\
\hline 60 & 1,015 & 0,908 & 0,953 & 0,971 & 0,990 \\
\hline 70 & 1,016 & 0,917 & 1,048 & 0,569 & 1,083 \\
\hline 80 & 1,013 & 1,004 & 1,116 & 0,692 & 1,146 \\
\hline 90 & 1,000 & 1,000 & 1,000 & 1,000 & 1,000 \\
\hline 100 & 1,135 & 1,121 & 1,537 & 0,929 & 0,985 \\
\hline 110 & 1,005 & 0,906 & 1,074 & 0,546 & 1,043 \\
\hline 120 & 1,199 & 0,920 & 0,991 & 0,632 & 0,989 \\
\hline 130 & 0,867 & 1,087 & 0,998 & 0,488 & 0,879 \\
\hline 140 & 1,039 & 1,217 & 1,195 & 0,609 & - \\
\hline 150 & 0,910 & 1,092 & 1,101 & 0,704 & - \\
\hline 160 & 0,963 & 1,007 & 1,282 & 0,747 & - \\
\hline 170 & 0,919 & 0,803 & 0,957 & 0,349 & - \\
\hline 180 & 0,769 & 0,636 & 1,038 & 0,077 & - \\
\hline
\end{tabular}

Os valores experimentais das funções de anisotropia, contidos nas TAB. 14 e TAB. 15, são comparados com os valores fornecidos pelo TG-43 por meio das FIG. 29, FIG. 30, FIG. 31, FIG. 32 e FIG. 33. As distâncias comparadas variam de 1 a 5 cm, com ângulos polares de 0 até 90 graus. As demais distâncias e ângulos polares não foram comparados, pois o TG-43 possui os valores da função de anisotropia até $5 \mathrm{~cm}$ e 80 graus ${ }^{61}$. As funções de anisotropia obtidas neste trabalho encontram-se em boa concordância com os valores fornecidos pelo TG-43, para a faixa de comparação, a diferença média encontrada, entre os valores obtidos neste trabalho com o TG-43 é aproximadamente $3,1 \%$. Porém, dificuldades experimentais foram encontradas para a obtenção da função de anisotropia em distâncias superiores a $6 \mathrm{~cm}$. Estas dificuldades 
são decorrentes da baixa resposta coletada pelos dosímetros TL, apesar de um elevado tempo de exposição.

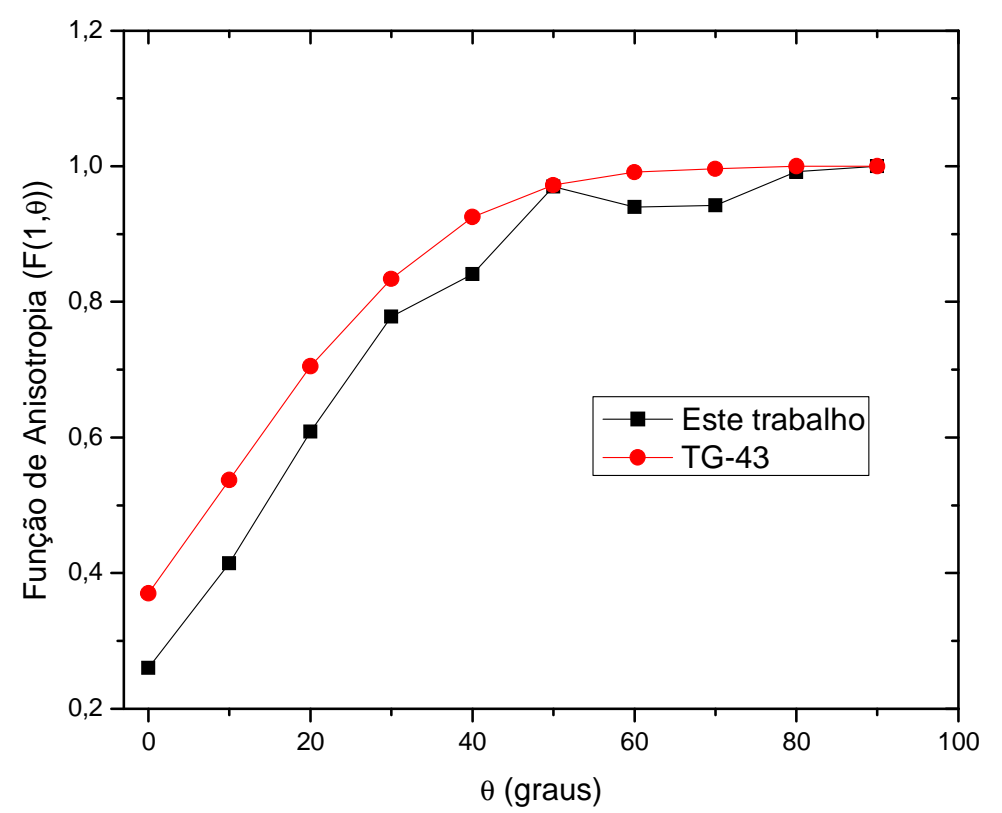

Figura 29 - Comparação dos valores das funções de anisotropia para distância de $1 \mathrm{~cm}$

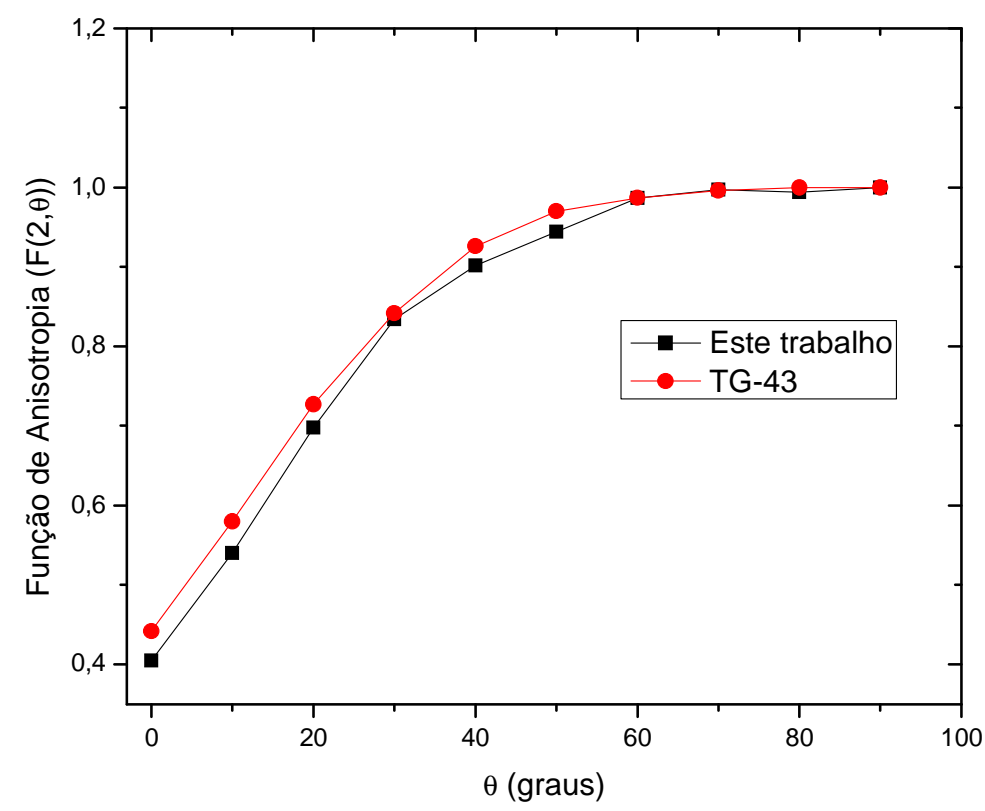

Figura 30 - Comparação dos valores das funções de anisotropia para distância de $2 \mathrm{~cm}$ 


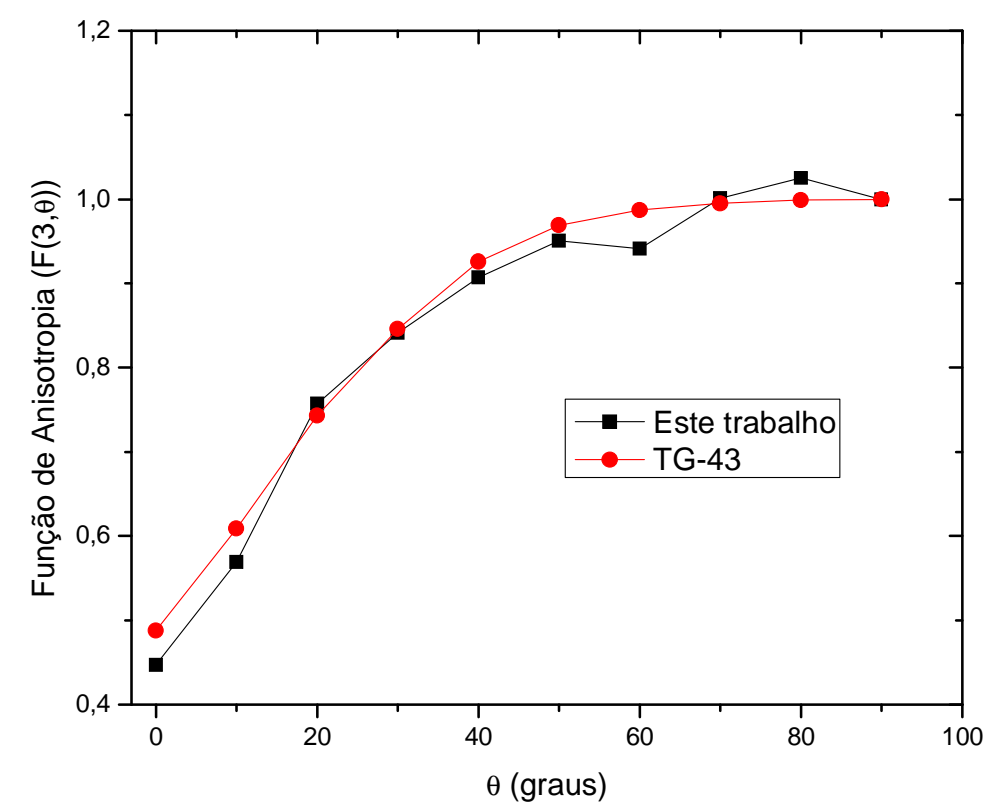

Figura 31 - Comparação dos valores das funções de anisotropia para distância de $3 \mathrm{~cm}$

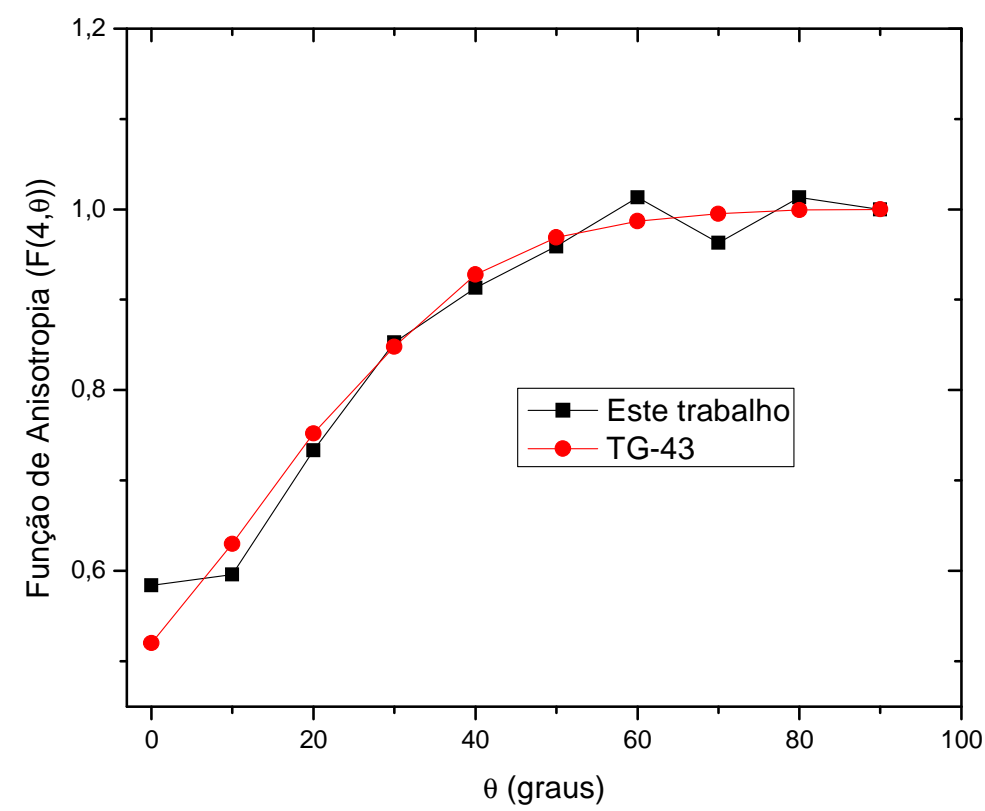

Figura 32 - Comparação dos valores das funções de anisotropia para distância de $4 \mathrm{~cm}$ 


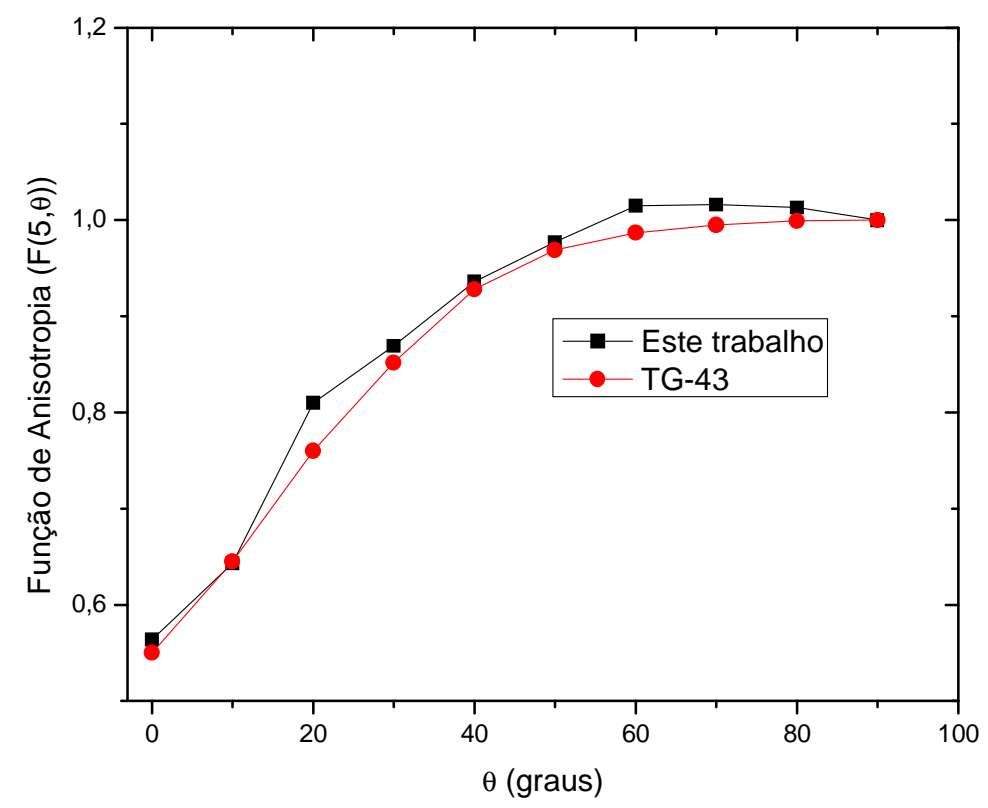

Figura 33 - Comparação dos valores das funções de anisotropia para distância de $5 \mathrm{~cm}$

\subsection{Avaliação das Incertezas}

As verificações das fontes de incerteza contida nos parâmetros dosimétricos são de fundamental importância para a consciente reprodução e comparação dos dados gerados nas investigações ou no controle de qualidade, visando a implementação clínicas. Em janeiro de 2011, a AAPM e o Groupe Européen de CuriethérapieEuropean Society for Therapeutic Radiology and Oncology (GEC-ESTRO) publicou o TG-103 ${ }^{109}$, que aborda os principais fatores das fontes de incerteza envolvidas em avaliações dosimétricas.

Neste trabalho, somente a constante de taxa de dose, funções radiais de dose e as funções de anisotropia tiveram suas incertezas avaliadas, assumindo que não há nenhuma correlação direta entre as fontes de incertezas. As demais fontes de incerteza envolvidas durante todo o processo de análise dosimétrica foram consideradas “estáveis", por exemplo, ${ }^{20}$ :

- Temperatura, pressão e umidade do ambiente na sala onde localiza-se a leitora TL;

- Estabilização da rede elétrica;

- Variação do fluxo de gás nitrogênio;

- Variação do aquecimento do forno durante o tratamento térmico;

- Limite de detecção da leitora. 
A consideração desta estabilidade deve-se ao fato que as mensurações das variações dos parâmetros acima citados são complexas e não apresentaram durante os ensaios efetuados, variações substanciais. Porém, se estas fontes de incertezas apresentarem boas variações elas devem ser avaliadas com atenção ${ }^{110}$.

\subsubsection{Incerteza na determinação da constante de taxa de dose}

As incertezas avaliadas nesta etapa concentram-se principalmente na reprodutibilidade dos dosímetros utilizados e nas incertezas de posicionamento do dosímetros nos objetos simuladores. As incertezas dos fatores de correção, para o cálculo da constante de taxa de dose, foram avaliadas por outros grupos de pesquisa, porém este trabalho utilizou-se destes valores para as estimativas das incertezas neste parâmetro.

A TAB. 15 mostra as principais componentes de incerteza da constante de taxa de dose. A incerteza combinada total é obtida utilizando cada valor do componente de incerteza. A reprodutibilidade dos dosímetros baseia-se nas incertezas obtidas no método de seleção com o irradiador de Cobalto-60 e o posicionamento do TLD considera as incertezas contidas nos orifícios do objeto simulador ${ }^{20}$.

Tabela 15 - Incertezas envolvidas e incerteza combinada total para a determinação experimental da constante de taxa de dose

\begin{tabular}{|c|c|c|}
\hline Componentes & Tipo A (\%) & Tipo B (\%) \\
\hline Reprodutibilidade dos dosímetros ${ }^{105}$ & 4,2 & - \\
\hline Calibração dos TLD ${ }^{105}$ & - & 1,8 \\
\hline Fator de Correção do meio (Água e Solid Water ${ }^{\mathrm{TM}}$ ) 105 & - & 0,7 \\
\hline Posicionamento TLD e semente de iodo- 125 & - & 2,0 \\
\hline Fator de Correção dependência energética ${ }^{105,106}$ & - & 5,0 \\
\hline Intensidade Kerma-ar $\left(S_{k}\right)-$ NIST ${ }^{105}$ & 1,0 & - \\
\hline Incerteza combinada total $(\mathrm{k}=1)$ & \multicolumn{2}{|c|}{$6,2 \%$} \\
\hline
\end{tabular}

\subsubsection{Incerteza na determinação da função de dose radial}

Para as funções radiais de dose, as incertezas são principalmente influenciadas pelas incertezas das taxas de dose dos dosímetros e também pelo posicionamento dos dosímetros e da semente de iodo-125 ${ }^{98,109}$. Experimentalmente, observam-se um 
aumento nas incertezas para as distâncias inferiores a $0,5 \mathrm{~cm}$ e maiores a $5 \mathrm{~cm}{ }^{61,109}$. Estima-se, que a incerteza combinada total para a função de dose radial, neste trabalho, encontra-se próxima a 4,6 \%.

\subsubsection{Incerteza na determinação da função de anisotropia}

Similar a função de dose radial, as incertezas nas funções de anisotropia são principalmente influenciadas pela taxa de dose dos dosímetros, posicionamento dos dosímetros e da semente de iodo-125 ${ }^{98,109}$. As incertezas da função de anisotropia são maiores para regiões próximas ao eixo transversal da semente de iodo-125, onde devido aos componentes internos da semente acarretam em grandes variações de dose ${ }^{109}$. Neste trabalho, a incerteza combinada total para a função de anisotropia é próxima a $5 \%$. 


\section{CONCLUSÕES}

Foram definidos os requisitos básicos, para a criação de um laboratório dosimétrico para as pesquisas dosimétricas e o controle de qualidade das fontes de braquiterapia.

A seleção dos dosímetros por meio da massa individual resultou na segregação de quatro dosímetros, dentro do lote com 204 dosímetros. Os dosímetros segregados apresentaram valores muito distantes da média gerada pelo lote. O valor médio de massa dos dosímetros selecionados correspondeu a 2,71 $\pm 0,11 \mathrm{mg}$.

Com as irradiações do irradiador de Cobalto-60 e utilizando o método do desvio padrões percentuais (DPP), obteve-se 81 dosímetros para as análises dosimétricas, a partir de um lote com 200 dosímetros. Todos os dosímetros selecionados ficaram com até $5,25 \%$ de desvio padrão em quatro mensurações, mostrando-se reprodutíveis para a determinação dos fatores de calibração individual dos dosímetros.

Nove séries de irradiações foram realizadas para a geração dos fatores individuais de calibração dos dosímetros com o auxílio de um sistema de planejamento para calcular os níveis de dose absoluta nos dosímetros analisados. Os resultados finais dos fatores de calibração foram próximos a 11,21 \pm 5,47 \%, para os coeficientes de variação, considerando as três faixas de dose absorvida.

Os resultados de homogeneidade da atividade aparente relativa das sementes de iodo-125 foram plenamente satisfatórios para todas as sementes de iodo-125 disponíveis. A semente de iodo-125 utilizada para as análises dosimétricas possui um coeficiente de variação médio igual a $0,38 \%$, sendo a mais reprodutível, se comparada com as demais sementes disponíveis.

A constante de taxa de dose encontrada foi igual a $0,913 \pm 0,076 c G y \cdot h^{-1} \cdot U^{-1}$. Comparando-a com o valor consensual, sugerido pelo protocolo TG-43, encontra-se uma diferença de 5,38\%. Se comparada com a mesma técnica de obtenção (TL) de outros autores, esta diferença reduz-se para $0,87 \%$.

As funções de dose radiais obtidas neste trabalho renderam valores próximos àqueles sugeridos pelo TG-43 e através de uma função polinomial de quinta ordem. Esta proximidade poderá diferir deste trabalho, se outras referências fossem utilizadas.

As funções de anisotropia geradas neste trabalho produziram bons resultados, quando comparado com os valores do TG-43. As dificuldades experimentais para as medidas que foram realizadas a distâncias superiores a $6 \mathrm{~cm}$. Acima desta distância 
tornam-se muito difíceis de serem mensuradas, pois os valores obtidos tornam-se bastante imprecisos já que a razão sinal/ruído está muito próxima, ou seja, os valores estão na mesma ordem de grandeza do limite de detecção da leitora TL.

Em suma, concluí-se que o laboratório possui as condições para a realização das investigações dosimétricas em fontes de braquiterapia com baixa taxa de dose, especificadamente, para as sementes de iodo-125 que serão produzidas pelo IPENCNEN/SP. Os resultados apresentados mostraram boa concordância, se comparados com valores da literatura. Esses resultados atestam que os procedimentos dosimétricos utilizados (irradiação, leitura e tratamento térmico do dosímetros) estão aptos para a caracterização dosimétrica e controle de qualidade, das sementes de iodo-125 que serão produzidas pelo IPEN-CNEN/SP. 


\section{ETAPAS FUTURAS}

Alguns fatos revelados e apresentados por este trabalho mostram a necessidade de estudos e pesquisas complementares. Estes fatos não fizeram parte do escopo principal deste trabalho, não sendo assim estudados e pesquisados, porém são sugeridos para futuras pesquisas.

A utilização de simulações computacionais, como as simulações utilizando o método Monte Carlo, faz-se importante para avaliar outras características das sementes de iodo-125, principalmente para situações que não são triviais de serem realizadas experimentalmente, tais como para a determinação dos diversos fatores de correção utilizados neste trabalho. Estas simulações também são úteis para as comparações com os valores experimentais e com os demais modelos de fontes para braquiterapia existentes.

Mais investigações devem ser realizadas para a obtenção dos fatores de calibração dos dosímetros, estes fatores são de grande importância para os procedimentos dosimétricos pois são os responsáveis em converter as respostas dos dosímetros TL em doses absorvidas absolutas e as elevadas incertezas nestes fatores podem comprometer todo o processo dosimétrico.

Este trabalho utilizou somente o processo TL para as analises dosimétricas das sementes de iodo-125. Porém, além da dosimetria por termoluminescência, mais pesquisas utilizando outros processos dosimétricos experimentais deverão ser realizados e comparados entre si, como por exemplo, processos utilizando dosimetria por luminescência opticamente estimulada, filmes radiocrômicos e câmaras de ionização.

Analíses estatísticas mais elaboradas e completas são necessárias para o estudo das incertezas envolvidas em todo o processo de dosimetria, principalmente aquelas associadas a aquisição de dados da resposta TL. 


\section{APÊNDICE}

A tabela a seguir, apresenta os valores da função de geometria, utilizando as equações 5 e 6 .

\begin{tabular}{|c|c|c|c|c|c|}
\hline \multirow[b]{2}{*}{$\boldsymbol{\theta}$ (graus) } & \multicolumn{5}{|c|}{$\mathbf{r}(\mathbf{c m})$} \\
\hline & 0,5 & 1,0 & 2,0 & 3,0 & 4,0 \\
\hline 0 & 0,88409 & 0,97027 & 0,99252 & 0,99667 & 0,99813 \\
\hline 10 & 0,88794 & 0,97118 & 0,99274 & 0,99677 & 0,99818 \\
\hline 20 & 0,89887 & 0,97382 & 0,99340 & 0,99706 & 0,99835 \\
\hline 30 & 0,91523 & 0,97783 & 0,99440 & 0,99750 & 0,99860 \\
\hline 40 & 0,93470 & 0,98272 & 0,99562 & 0,99805 & 0,99890 \\
\hline 50 & 0,95474 & 0,98789 & 0,99692 & 0,99863 & 0,99923 \\
\hline 60 & 0,97300 & 0,99270 & 0,99814 & 0,99917 & 0,99953 \\
\hline 70 & 0,98750 & 0,99659 & 0,99913 & 0,99961 & 0,99978 \\
\hline 80 & 0,99680 & 0,99912 & 0,99978 & 0,99990 & 0,99994 \\
\hline 90 & 1,00000 & 1,00000 & 1,00000 & 1,00000 & 1,00000 \\
\hline 100 & 0,99680 & 0,99912 & 0,99978 & 0,99990 & 0,99994 \\
\hline 110 & 0,98750 & 0,99659 & 0,99913 & 0,99961 & 0,99978 \\
\hline 120 & 0,97300 & 0,99270 & 0,99814 & 0,99917 & 0,99953 \\
\hline 130 & 0,95474 & 0,98789 & 0,99692 & 0,99863 & 0,99923 \\
\hline 140 & 0,93470 & 0,98272 & 0,99562 & 0,99805 & 0,99890 \\
\hline 150 & 0,91523 & 0,97783 & 0,99440 & 0,99750 & 0,99860 \\
\hline 160 & 0,89887 & 0,97382 & 0,99340 & 0,99706 & 0,99835 \\
\hline 170 & 0,88794 & 0,97118 & 0,99274 & 0,99677 & 0,99818 \\
\hline \multirow[t]{2}{*}{180} & 0,88409 & 0,97027 & 0,99252 & 0,99667 & 0,99813 \\
\hline & \multicolumn{5}{|c|}{$\mathbf{r}(\mathbf{c m})$} \\
\hline$\theta$ (graus) & 5,0 & 6,0 & 7,0 & 8,0 & 10,0 \\
\hline 0 & 0,99880 & 0,99917 & 0,99939 & 0,99953 & 0,99970 \\
\hline 10 & 0,99884 & 0,99919 & 0,99941 & 0,99955 & 0,99971 \\
\hline 20 & 0,99894 & 0,99926 & 0,99946 & 0,99959 & 0,99974 \\
\hline 30 & 0,99910 & 0,99938 & 0,99954 & 0,99965 & 0,99978 \\
\hline 40 & 0,99930 & 0,99951 & 0,99964 & 0,99973 & 0,99982 \\
\hline 50 & 0,99950 & 0,99966 & 0,99975 & 0,99981 & 0,99988 \\
\hline 60 & 0,99970 & 0,99979 & 0,99985 & 0,99988 & 0,99993 \\
\hline 70 & 0,99986 & 0,99990 & 0,99993 & 0,99995 & 0,99996 \\
\hline 80 & 0,99996 & 0,99997 & 0,99998 & 0,99999 & 0,99999 \\
\hline 90 & 1,00000 & 1,00000 & 1,00000 & 1,00000 & 1,00000 \\
\hline 100 & 0,99996 & 0,99997 & 0,99998 & 0,99999 & 0,99999 \\
\hline 110 & 0,99986 & 0,99990 & 0,99993 & 0,99995 & 0,99996 \\
\hline 120 & 0,99970 & 0,99979 & 0,99985 & 0,99988 & 0,99993 \\
\hline 130 & 0,99950 & 0,99966 & 0,99975 & 0,99981 & 0,99988 \\
\hline 140 & 0,99930 & 0,99951 & 0,99964 & 0,99973 & 0,99982 \\
\hline 150 & 0,99910 & 0,99938 & 0,99954 & 0,99965 & 0,99978 \\
\hline 160 & 0,99894 & 0,99926 & 0,99946 & 0,99959 & 0,99974 \\
\hline 170 & 0,99884 & 0,99919 & 0,99941 & 0,99955 & 0,99971 \\
\hline 180 & 0,99880 & 0,99917 & 0,99939 & 0,99953 & 0,99970 \\
\hline
\end{tabular}




\section{REFERÊNCIAS BIBLIOGRÁFICAS}

\footnotetext{
${ }^{1}$ BEYZADEOGLU, M.; OZYIGIT, G.; EBRULI, C. Basic radiation oncology. New York: Springer, 2010.

${ }^{2}$ WORLD HEALTH ORGANIZATION - CANCER. Disponível em: <http://www.who.int/cancer/en/>,
} acesso em 28/09/2010.

3 BRASIL. MINISTÉRIO DA SAÚDE. INSTITUTO NACIONAL DE CÂNCER. Estimativa da incidência de câncer no Brasil 2010. Rio de Janeiro: 2010.

${ }^{4}$ VAN DYK, J. (Ed.). The modern technology of radiation oncology - A compendium for medical physicists and radiation oncologists. Madison: Medical Physics Publishing, 1999.

${ }^{5}$ HALPERIN, E. C.; PEREZ, C. A.; BRADY, L.W. (Ed.). Perez and Brady's Principles and Practice of Radiation Oncology. 5. ed. Baltimore: Lippincott Williams \& Wilkins, 2008.

${ }^{6}$ PODGORSAK, E. B. (Ed.). Radiation oncology physics: A handbook for teachers and students. Vienna: International Atomic Energy Agency (IAEA), 2005.

${ }^{7}$ CHEN, Z.; D'ERRICO, F.; NATH, R. Principles and requirements of external beam dosimetry. Radiat. Meas. 42: S2-S21, 2007.

${ }^{8}$ KHAN, F. M. The physics of radiation therapy. 3. ed. Philadelphia: Lippincott Williams \&Wilkins, 2003.

${ }^{9}$ WILLIAMSON, J. F.; THOMADSEN, B. R.; NATH, R. (Ed.). Brachytherapy physics - AAPM summer school 1994. Madison: Medical Physics Publishing, 1995.

${ }^{10}$ INTERNATIONAL ATOMIC ENERGY AGENCY. IAEA-TECDOC-1274 - Calibration of photon and beta ray sources used in brachytherapy. Viena: International Atomic Energy Agency (IAEA), 2002.

11 GHASSOUN, J.; MOSTACCI D.; MOLINARI, V.; JEHOUANI, A. Detailed dose distribution prediction of Cf-252 brachytherapy source with boron loading dose enhancement. Appl. Radiat. Isot. 68(2): 265-270, 2010.

12 RIVARD, M.; DAVIS, S. D.; DEWERD, L. A.; RUSCH, T. W.; AXEROLD, S. Calculated and measured brachytherapy dosimetry parameters in water for the Xoft Axxent X-Ray Source: An electronic brachytherapy source. Med. Phys. 33(11): 4020-4032, 2006.

13 RONG, Y.; WELSH, J. S. Surface applicator calibration and commissioning of an electronic brachytherapy system for nonmelanoma skin cancer treatment. Med. Phys. 37(10):5509-5517, 2010.

${ }^{14}$ HOLT, R. W.; THOMADSEN, B. R. Miniature X-ray tubes will ultimately displace Ir-192 as the radiation sources of choice for high dose rate brachytherapy. Med. Phys. 35(3): 815-817, 2008.

${ }^{15}$ LAWRENCE, D.; SONDHAUS, C.; FEDER, B.; SCALLON, J. Soft x-ray "seeds” for cancer therapy. Radiology. 86(143), 1966.

${ }^{16}$ HILARIS, B. S.; HENSCHKE, U. K.; HOLT, J. G. Clinical experience with long half-life and lowenergy encapsulated radioactive sources in cancer radiation therapy. Radiology 91: 1163-1167, 1968.

${ }^{17}$ WILLIAMSON, J. F. Brachytherapy technology and physics practice since 1950: A half-century of progress. Phys. Med. Biol. 51: R303-R325, 2006.

${ }^{18}$ MUGHABGHAB, S. F.; DIVADEENAM, M.; HOLDEN, N. E. Neutron Cross Sections - Volume 1 - Neutron Resonance Parameters and Thermal Cross Sections - Part A: Z = 1 - 60, Academic Press, New York, 1981. 
${ }^{19}$ REUS, U.; WESTMEIER, W. Atomic Data and Nuclear Data Tables. 29: 193-406, 1983.

${ }^{20}$ ZEITUNI, C. A. Dosimetria de fontes de iodo-125 aplicadas em braquiterapia. Tese de doutorado. IPEN/CNEN-SP, 2008.

21 Legrand, J.; PEROlat, J.; LAGOUTINE, F.; GALliC, Y. Table de radionucléides. Commissariat à l'Energie Atomique Bureau National de Métrologie. França, 1975.

${ }^{22}$ KATAKURA, J. Nuclear Data Sheets. 86: 955, 1999. Disponível em <<http://www.nndc.bnl.gov/ nudat2 /decaysearchdirect.jsp?nuc=125I\&unc=nds $>>$ Acesso em: 05/10/2010.

${ }^{23}$ USHER-MOGA, J.; BEACH, S. M.; DEWERD, L. A. Spectroscopic output of ${ }^{125}$ I and ${ }^{103}$ Pd low dose rate brachytherapy sources. Med. Phys. 36(1): 270-278, 2008.

24 ONCURA ONCOSEED ${ }^{\mathrm{TM}}$ IMC6711 - Instructions for the use of Iodine-125 Seeds for Medical Brachytherapy Treatments. Arlington Heights, Illinois, 2005.

${ }^{25}$ RIVARD, M. J. Monte Carlo radiation dose simulations and dosimetric comparison of the model 6711 and $9011{ }^{125}$ I brachytherapy sources. Med. Phys. 36(2): 486-491, 2009.

${ }^{26}$ PATEL, N. S.; CHIU-TSAO, S. T.; WILLIAMSON, J. F.; FAN, P.; DUCKWORTH, T.; SHASHA, D.; HARRISON, L. B. Thermoluminescent dosimetry of the Symmetra ${ }^{\text {TM }}{ }^{125}$ I model I25.S06 interstitial brachytherapy seed. Med. Phys. 28(8): 1761-1769, 2001.

${ }^{27}$ MEIGOONI, A. S.; YOE-SEIN, M. M.; AL-OTOOM, A. Y.; SOWARDS, K. T. Determination of the dosimetric characteristics of InterSource ${ }^{125}$ iodine brachytherapy source. Appl. Radiat. Isot. 56:589-599, 2002.

28 ZUOFENG, L. Monte Carlo calculations of dosimetry parameters of the Urocor Prostaseed ${ }^{125}$ I source. Med. Phys. 29(6): 1029-1034, 2002.

${ }^{29}$ CHEN, Z. J.; NATH, R. A systematic evaluation of the dose-rate constant determined by photon spectrometry for 21 different models of low-energy photon-emitting brachytherapy sources. Phys. Med. Biol. 55: 6089-6104, 2010.

${ }^{30}$ ROSTELATO, M. E. C. M. Estudo e Desenvolvimento de uma Nova Metodologia para Confecção de Sementes de Iodo-125 para Aplicação em Braquiterapia. Tese de doutorado. IPEN-CNEN/SP, 2005.

${ }^{31}$ FEHER, A. Desenvolvimento de procedimento utilizando processo de soldagem plasma para confecção de sementes de ${ }^{125}$ I. Dissertação de mestrado. IPEN-CNEN/SP, 2006.

${ }^{32}$ MOURA, J. A. Estudo e desenvolvimento de metodologia para controle de qualidade em processo de produção de fontes seladas de Iodo-125 para aplicação em braquiterapia. Dissertação de mestrado. IPEN-CNEN/SP, 2009.

33 International Standard Organization (ISO). Radiation protection Sealed radioactive sources General requirements and classification. USA; 1995. (ISO-2919).

${ }^{34}$ BAMPOE, J.; BERNSTEIN, M. Advances in radiotherapy of brain tumors: radiobiology versus reality. Journal of Clinical Neuroscience. 5(1): 5-14, 1998.

${ }^{35}$ GUTIN P.; PHILLIPS T.; HOSOBUCHI Y.; WARA W., MACKAY A.; WEAVER KA.; LAMB S.; HURST S. Permanent and removable implants for the brachytherapy of brain tumors. Int. J. Radiat. Oncol. Biol. Phys. 7(10): 1371-1381, 1981.

${ }^{36}$ ZHOU, F.; YAN, J.; HUANG, L.; LIU C.; ZHANG, X.; ZHOU, W.; YAN, Y. Iodine-125 interstitial brachytherapy for experimental liver cancer. Journal of Medical Colleges of PLA. 22(2): 87-91, 2007. 
${ }^{37}$ SHIPLEY, W. U.; NARDI, G. L.; COHEN, A. M.; LING, C. C. 125I Implant as boost therapy in patient irradiated for localized pancreatic carcinoma: a comparative study to surgical resection. Cancer. 45: 709, 1980.

38 SEALY R.; BURET E.; CLEMINSHAW H.; STANNARD C.; HERING E.; SHACKLETON D.; KORRUBEL J.; LE ROUX P.; SEVEL D.; VAN OLDENBORGH M.; VAN SELM J. Progress in the use of iodine therapy for tumours of the eye. Br. J. Radiol. 53(635): 1052-1060, 1980.

${ }^{39}$ PACKER S.; ROTMAN M. Radiotherapy of choroidal melanoma with iodine 125. Int. Ophthalmol. Clin. 20(2):135-142, 1980.

${ }^{40}$ SHIPLEY, W.; KOPLESON, G.; NOVACK, D.; LING, C.; DRETLER, S.; PROUT, G. Properative irradiation, lymphadenectomy, and ${ }^{125} \mathrm{I}$ implant for selected patients with localized prostatic carcinoma: a correlation of implant dosimetry with clinical results. J. Urol. 24: 639, 1981.

41 WHITMORE W.; HILARIS B.; GRABSTOLD H. Retropubic implantation of iodine-125 in the treatment of prostatic cancer. J. Urol. 108:918-920, 1972.

${ }^{42}$ PORTER A.; FORMAN J. Prostate brachytherapy - An overview. Cancer. 71(3): 953-958, 1993.

${ }^{43}$ GRIMM P.; BLASKO J.; RAGDE H.; SYLVESTER J.; CLARKE D. Does brachytherapy have a role in the treatment of prostate cancer? Hematol. Oncol. Clin. North. Am. 10(3): 653-673, 1996.

${ }^{44}$ LANGLEY S.; LAING R. Iodine seed prostate brachytherapy: an alternative first-line choice for early prostate cancer. Prostate Cancer Prostatic Dis. 7(3): 201-207, 2004.

${ }^{45}$ HEYSEK R. Modern brachytherapy for treatment of prostate cancer. Cancer Control. 14(3): 238-243, 2007.

${ }^{46}$ VAN DE GRAFF, K. Human anatomy. 6 ed. New York: McGraw-Hill Company, 2001.

47 SROUGI, M. A próstata como ela é. Folha de São Paulo, São Paulo, 03 de novembro de 2002. Caderno Cotidiano, p. 8.

${ }^{48}$ National Cancer Institute - Comprenhensive Cancer Information. Disponível em < http://cancerinfo.trikobe.org/for_patient/pdq/summary/EN/CDR0000062965.html>, acesso: 11/10/2010.

${ }^{49}$ BRASIL. MINISTÉRIO DA SAÚDE. INSTITUTO NACIONAL DE CÂNCER. Programa nacional do controle de câncer da próstata: documento de consenso. Pág: 13-15 Rio de Janeiro: 2002.

50 BLASKO, J. C.; GRIMM, P. D.; RAGDE, H. Brachytherapy and organ preservation in the management of carcinoma of the prostate. Semin. Rad. Oncol. 3(4): 240-249, 1993.

${ }^{51}$ POLLACK, A.; ZAGARS, G. K. ; ROSEN, I. I. Prostate cancer treatment with radiotherapy: maturing methods that minimize morbidity. Semin. Oncol. M. D. Anderson Cancer Center, 26(2): 150$161,1999$.

52 SAITO, S.; NAGATA, H.; KOSUGI, M.; TOYA, K.; YOROZU, A. Brachytherapy with permanent seed implantation. Int. J. Clin. Oncol. 12: 395-407, 2007.

${ }^{53}$ GRIMM, P.; SYLVESTER, J. Advances in Brachytherapy. Reviews in Urology. 6(4): S37-S48, 2004.

${ }^{54}$ BUTLER, W.; DORSEY, A.; NELSON, K.; MERRICK, G. Quality assurance calibration of ${ }^{125}$ I rapid strand in a sterile environment. Int. J. Radiation Oncology Biol. Phys. 41(1): 217-222, 1998.

${ }^{55}$ ONCURA RAPIDSTRAND ${ }^{\mathrm{TM}}$ - Instructions for the use of RAPID Strand for Interstitial Brachytherapy Treatments. Arlington Heights, Illinois, 2009. 
56 BATTERMANN, J. I-125 implantation for localized prostate cancer: The Utrecht university experience. Radiotherapy and Oncology. 57: 269-272, 2000.

${ }^{57}$ HOLM, H.; JUUL, N.; PEDERSEN J.; et al. Transperineal iodine-125 seed implantation in prostatic cancer guided by transrectal ultrasonography J. Urol. 130: 273-286, 1983.

${ }^{58}$ RASHID, H.; BJARNGAR, B. E.; CHIN, L. M.; RICE, R. K. Dosimetry of ${ }^{125}$ I in a los-density material using scaling. Med. Phys. 20: 765-768, 1993.

59 THOMADSEN, B.; WILlIAMSON, J.; RIVARD, M.; MEIGOONI, A. Anniversary Paper: Past and current issues, and trends in brachytherapy physics. Med. Phys. 35(10): 4708-4723, 2008.

${ }^{60}$ NATH, R.; ANDERSON, L.; LUXTON, G.; WEAVER, K.; WILLIAMSON, J.; MEIGOONI, A. Dosimetry of interstitial brachytherapy sources: Recommendations of the AAPM Radiation Therapy Committee Task Group No. 43. Med. Phys. 22(2): 209-234, 1995.

${ }^{61}$ RIVARD, M. J.; COURSEY, B. M.; DEWERD, L. A.; HANSON, W. F.; HUQ, M. S.; IBBOTT, G. S.; MITCH, M. G.; NATH, R.; WILLIAMSON, J. F. Update of AAPM Task Group No. 43 Report: A revised AAPM protocol for brachytherapy dose calculations. Med. Phys. 31(3): 633-674, 2004.

${ }^{62}$ RIVARD, M.; BUTLER, W.; DEWERD, L.; HUQ, M.; IBBOTT, G.; MEIGOONI, A.; MELHUS, C.; MITCH, M.; NATH, R.; WILLIAMSON, J. Supplement to the 2004 update of the AAPM Task Group No. 43 Report. Med. Phys. 34(6): 2187-2205, 2007.

${ }^{63}$ LOFTUS, T. P. Exposure standardization of iodine-125 seeds used for brachytherapy. J. Res. Natl. Bur. Stand. 89: 295-303, 1984.

${ }^{64}$ LOEVINGER, R. Wide-angle free-air chamber for calibration of low energy brachytherapy sources. Med. Phys. 20: 907, 1993.

${ }^{65}$ SELTZER, S. M.; LAMPERTI, P. J.; LOEVINGER, R.; MITCH, M. G.; WEAVER, J. T.; COURSEY, B. M. New national air-kerma-strength standards for ${ }^{125} \mathrm{I}$ and ${ }^{103} \mathrm{Pd}$ brachytherapy sources. J. Res. Natl. Inst. Stand. Technol. 108(5): 337-358, 2003.

${ }^{66}$ NATH, R.; YUE, N. Dosimetric characterization of an encapsulated interstitial brachytherapy source of

${ }^{125}$ I on a tungsten substrate. Brachytherapy. 1: 102-109, 2002.

${ }^{67}$ MCKEEVER, S. W. S. Thermoluminescence of solids. Cambridge: Oklahoma: Cambridge University Press, 1985.

${ }^{68}$ HOROWITZ, Y. S. (ed.) Thermoluminescence and thermoluminescence dosimetry. Vol. 1- 3, Boca Raton: CRC Press, 1983.

${ }^{69}$ MCKEEVER, S. W. S.; MOSCOVITCH, M.; TOWNSEND, P. D. Thermoluminescence dosimetry materials: Properties and uses. Ashford: Nuclear Technology Publishing, 1995.

${ }^{70}$ YUKIHARA, E. G.; FREITAS, M. B. Dosimetria TL/OSL - ABFM 2010. São Paulo, 2009.

${ }^{71}$ DANIELS, F.; BOYD, C. A.; SAUNDERS, D. F. Thermoluminescence as a research tool. Science. 117: 343-349, 1953.

72 CHEN, R.; MCKEEVER, S. W. S. Theory of thermoluminescence and related phenomena. Singapore: World Scientific, 1997.

${ }^{73}$ BOS, A. J. J. High sensitivity thermoluminescence dosimetry. Nucl. Instr. And Meth. In Phys. Res. B 184: 3-28, 2001.

74 ZIMMERMAN, D. W.; RHYNER, C. R.; CAMERON, J. R. Thermal annealing effects on the thermoluminescence of LiF. Health Physics 12: 525-531, 1965. 
${ }^{75}$ FURETTA, C. Handbook of Thermoluminescence. Singapore: World Scientific, 2003.

${ }^{76}$ HOROWITZ, Y. S. The annealing characteristics of LiF:Mg,Ti. Radiat. Prot. Dosim. 30(4): 219-230, 1990.

77 GAMBOA-DEBUEN, I.; BUENFIL, A. E.; RUIZ, C. G.; VILlAfUERTE, M. R.; FLORES, A.; BRANDAN, M. E. Thermoluminescent response and relative efficiency of TLD-100 exposed to lowenergy x-rays. Phys. Med. Biol. 43: 2073-2083, 1998.

78 KRON, T.; MOBIT, P.; MUNIZ, J.; PRADHAN, A.; TOIVONEN, M.; WALIGORSKI, M. A checklist for reporting of thermoluminescence dosimetry (TLD) measurements. Phys. Med. Biol. 44: L15-L17, 1999.

${ }^{79}$ EVANS, R. D. The atomic Nucleus. New Delhi: Tata McGraw-Hill, 1958.

80 International Organization for Standardization - American Society for Testing and Materials (ISO/ASTM). Standard Practice for Use of Thermoluminescence-Dosimetry (TLD) Systems for Radiation Processing (ISO/ASTM- 51956). USA; 2002.

81 ATTIX, F. H. Introduction to radiological physics and radiation dosimetry. New York: WileyInterscience, 1986.

${ }^{82}$ GHIASSI-NEJAD, M.; JAFARIZADEH, M.; AHMADIAN-POUR, M. R.; GHAHRAMANI, A. R. Dosimetric characteristics of ${ }^{192}$ Ir sources used in interstitial brachytherapy. Appl. Radiat. Isot. 55: 189$195,2001$.

${ }^{83}$ MEIGOONI, A. S.; SOWARDS, K.; SOLDANO, M. Dosimetric characteristics of the InterSource ${ }^{103}$ palladium brachytherapy source. Med. Phys. 27(5): 1093-1100, 2000.

${ }^{84}$ CHIU-TSAO, S.; DUCKWORTH, T. L.; HSIUNG, C.; LI, Z.; WILLIAMSON, J.; PATEL, N. S.; HARRISON, L. B. Thermoluminescent dosimetry of the SourceTech Medical model STM1251 ${ }^{125}$ I seed. Med. Phys. 30(7): 1732-1735, 2003.

85 ABBOUD, F.; HOLLOWS, M.; SCALLIET, P.; VYNCKIER, S. Experimental and theoretical dosimetry of a new polymer encapsulated iodine-125 source - SmartSeed: Dosimetric impact of fluorescence x rays. Med. Phys. 37(5): 2054-2062, 2010.

${ }^{86}$ IAEA TRS-398. Absorbed Dose Determination in External Beam Radiotherapy: An International Code of Practice for Dosimetry based on Standards of Absorbed Dose to Water. Vienna, International Atomic Energy Agency; vs: 11; 2004.

87 International Commission on Radiation Units and Measurements. Tissue substitutes in radiation dosimetry and measurement. Maryland, ICRU Report No. 44, 1989.

${ }^{88}$ HILL, R.; KUNIC, Z,; BALDOCK, C. The water equivalence of solid phantoms for low energy phton beams. Med. Phys. 37(8): 4355-4363, 2010.

89 International Commission on Radiation Units and Measurements. Electron beams with energies between 1 and $50 \mathrm{MeV}$. Maryland, ICRU Report No. 35, 1984.

90 TELLO, V. M.; TAILOR, R. C.; HANSON, W. F. How water equivalent are water-equivalent solid materials for output calibration of photon and electron beams?. Med. Phys. 22(7): 1177-1189, 1995.

91 WILLIAMSON, J. F.; RIVARD, M. R. TLD and Monte Carlo techniques for reference-quality brachytherapy dosimetry. In: AAPM Summer Scholl, July, 23, 2009.

92 Thermo Electron Corporation. Model 3500 Manual TLD Reader with WinREMS ${ }^{\mathrm{TM}}$ Operator's Manual. Ohio, August 2005. 
93 Thermo Electron Corporation. Harshaw Standard TTP Recommendations Technical Notice. Ohio, December 2002.

${ }^{94}$ Exacta Indústria Ltda - Laboratório de Metrologia - Laudo técnico para sensor de temperatura. São Paulo: 2010.

95 HERMANN, K.; GEWORSKI, L.; MUTH, M.; HARDER, D. Polyethylene-based water-equivalent phantom material for X-ray dosimetry at tube voltages from 10 to $100 \mathrm{kV}$. Phys. Med. Biol. 30: 1195$1200,1985$.

${ }^{96}$ LUXTON, G. Comparison of radiation dosimetry in water and in solid phantom materials for I-125 and Pd-103 brachytherapy sources: EGS4 Monte Carlo study. Med. Phys. 21(5): 631-641, 1994.

${ }^{97}$ FURETTA, C.; WENG, P. Operational thermoluminescence dosimetry. Singapore: World Scientific, 1998.

${ }^{98}$ SILVA, M. A. Caracterização dosimétrica das fontes de braquiterapia na forma de fios de Irídio192 de baixa taxa de dose, produzidos pelo laboratório de fontes de braquiterapia CTR/IPEN/CNEN-SP. Dissertação de mestrado. IPEN/CNEN-SP, 2003.

99 IAEA TECDOC-1583. Commissioning of Radiotherapy Treatment Planning Systems: Testing for Typical External Beam Treatment Techniques - Report of the Coordinated Research Project (CRP) on Development of Procedures for Quality Assurance of Dosimetry Calculations in Radiotherapy. Vienna, International Atomic Energy Agency; 2004.

${ }^{100}$ KENNEDY, R.; DAVIS, S.; MICKA, J.; DEWERD, L. Experimental and Monte Carlo determination of the TG-43 dosimetric parameters for the model 9011 THINSeed ${ }^{\mathrm{TM}}$ brachytherapy source. Med. Phys. 37(4): 1681-1688, 2010.

101 ZEITUNI, C. A.; MOURA, E. S.; ROSTElATO, M. E. C. M.; MANZOLI, J. E.; MOURA, J. A.; FEHER, A.; JUNIOR, D. K. Statistical differences and systematic effect on measurement procedure in thermoluminescent dosimetry of the iodine-125 brachytherapy seeds. In: International Nuclear Atlantic Conference - INAC 2009, 2009, Rio de Janeiro. Proceedings... 2009.

102 ROMANYUKHA, A.; KING, D.; BENEVIDES, L. A. Effect of background radiation on the lower limit of detection for extended dosemeter issue periods. Radiat. Prot. Dosim. 131(2): 180-187, 2008.

103 Thermo-Scientific. TLD-100 Thermoluminescent Dosimetry Material - Specifications. Ohio: January 2009.

104 TAYLOR, R. E. P.; ROGERS, D. W. O. An EGSnrc Monte Carlo-calculated database of TG-43 parameters. Med. Phys. 35(9): 4228-4241, 2008.

105 DOLAN, J.; LI, Z; WILLIAMSON, J. F. Monte Carlo and experimental dosimetry of an ${ }^{125}$ I brachytherapy seed. Med. Phys. 33(12): 4675-4684, 2006.

${ }^{106}$ MITCH, M. G.; DEWERD, L. A.; MINNITI, R.; WILLIAMSON, J. F. Treatment of uncertainties in radiation dosimetry. In: AAPM Summer Scholl, July, 23, 2009.

${ }^{107}$ NATH, R.; MEIGOONI, A. S.; MELI, J. A. Dosimetry on transverse axes of ${ }^{125}$ I and ${ }^{192}$ Ir interstitial brachytherapy sources. Med. Phys. 17(6): 1032-1040, 1990.

108 TAYLOR, R. E. P.; ROGERS, D. W. O. More accurate fitting of $125 \mathrm{I}$ and 103 Pd radial dose functions. Med. Phys. 35(9): 4242-4250, 2008.

${ }^{109}$ DEWERD, L. A.; IBBOTT, G. S.; MEIGOONI, A. S.; MITCH, M. G.; RIVARD, M. J.; STUMP, K. E.; THOMADSEN, B. R.; VENSELAAR, J. L. M. A dosimetric uncertainty analysis for photon-emitting 
brachytherapy sources: Report of AAPM Task Group No. 138 and GEC-ESTRO. Med. Phys. 38(2): 782801, 2011.

110 CAMPOS, V. P. Desenvolvimento e avaliação de um novo porta detector/filtro para monitoramento termoluminescente com $\mathrm{CaSO}_{4}$ :Dy/PTTE. Dissertação de Mestrado. IPEN/CNEN-SP, 2005. 